NBSIR 85-3258

\title{
Summaries of Center for Fire Research Grants and In-House Programs - 1985
}

Sonya M. Cherry

U.S. DEPARTMENT OF COMMERCE

National Bureau of Standards

National Engineering Laboratory

Center for Fire Research

Gaithersburg, MD 20899

November 1985

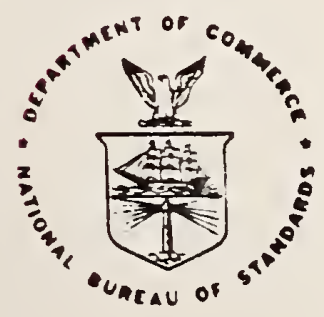

U.S. DEPARTMENT OF COMMERCE

NATIONAL BUREAU OF STANDARDS

$Q C$

100

.456

$85-3258$

1985 



\title{
SUMMARIES OF CENTER FOR FIRE RESEARCH GRANTS AND IN-HOUSE PROGRAMS - 1985
}

Sonya M. Cherry

\author{
U.S. DEPARTMENT OF COMMERCE \\ National Bureau of Standards \\ National Engineering Laboratory \\ Center for Fire Research \\ Gaithersburg, MD 20899
}

November 1985

U.S. DEPARTMENT OF COMMERCE, Malcolm Baldrige, Secretary NATIONAL BUREAU OF STANDARDS. Ernest Ambler, Director 



\section{CENTER FOR FIRE RESEARCH PROGRAMS}

Ad Hoc Working Group of Mathematical Fire Modeling . . . . . . . . . . . . . . 2

Compartment Fire Modeling Research . . . . . . . . . . . . . . . . . . . 3

Exploratory Fire Research. . . . . . . . . . . . . . . . . . . 8

Fire Growth and Extinction . . . . . . . . . . . . . . . . . . . . 15

Fire Performance and Validation. . . . . . . . . . . . . . . . . . 22

Fire Research Information Services . . . . . . . . . . . . . . . 26

Fire Simulation. . . . . . . . . . . . . . . . . . . . . 27

Flammability and Toxicity Measurement. . . . . . . . . . . . . . . . . . 31

Hazard Analysis. . . . . . . . . . . . . . . . . . . . . . 36

\section{GRANTS}

Brown University

A Study of the Effects of Oxygen, Transport and Temperature History

on the Chemistry of PMRA and Cellulose Pyrolysis. . . . . . . . . . . . . 40

Brown University

Soot Dynamics in Flames . . . . . . . . . . . . . . . . . 42

Brown University

Study of Effects of Material Properties on Flaming Combustion of

Charring Fuels. . . . . . . . . . . . . . . . . . . . . 46

California Institute of Technology

Experimental Study of Environment and Heat Transfer in a Room Fire. . . 50

Case Western Reserve University

Experimental and Analytical Study of Fire Sprinkler Scaling Laws. . • . 54

Case Western Reserve University

Flame Spread Limits . . . . . . . . . . . . . . . . . . . 61 
Clemson University

Ternary Reactions Among Polymer Substrate-Organohalogen-Antimony

Oxides in the Condensed Phase Under Pyrolytic, Oxidative and

Flaming Conditions. . . . . . . . . . . . . . . . . . . .

Factory Mutual Research Corp.

Calculated Interaction of Water Droplet Sprays with Fire Plumes

in Compartments . . . . . . . . . . . . . . . . . . . . . .

Factory Mutual Research Corp.

Development of a Model to Provide Comprehensive Fire Property

Data. . . . . . . . . . . . . . . . . . . . . . . .

Factory Mutual Research Corp.

Effects of Water Discharge Rate and Drop Size on Spray Cooling

in Residential Fires. . . . . . . . . . . . . . . . . . . . . .

Factory Mutual Research Corp.

Experimental Fire and Smoke Verification Data for Multiroom

and Corridor Conditions . . . . . . . . . . . . . . . . . .

Factory Mutual Research Corp.

Prediction of Fire Dynamics . . . . . . . . . . . . . . . .

The Pennsylvania State University

A Model for Vertical Wall Fire in Stratified Atmosphere . . . . . . .

The Pennsylvania State University

An Investigation of Turbulent Fires on Vertical and Inclined Walls. .

Princeton University

Flow Field Effects on the Sooting Structure of Diffusion Flames . .

Rutgers, The State University of New Jersey

Negatively Buoyant and Penetrative Flows Generated in Enclosure

Fires . . . . . . . . . . . . . . . . .

Southwest Research Institute

Analysis of Hazards to Life Safety in Fires: A Comprehensive Multi-

Dimensional Research Program. . . . . . . . . . . . . . . . .

Stanford University

The Behavior of Furniture Frames During Fire. . . . . . . . . .

University of California, Berkeley

Fire Modeling . . . . . . . . . . . . . . . . . . . 
Fire Propagation in Concurrent Flows. . . . . . . . . . . . . . . . .

University of California, Berkeley

Flame Radiation . . . . . . . . . . . . . . . . . . . . . .

University of Dayton Research Institute

Mathematical Modeling of Furniture Fires. . . . . . . . . . . . . .

University of Maryland

Transient Heat Transfer in Ceiling Jets . . . . . . . . . . . . . . .

University of Mississippi Medical Center

Study of Some Aspects of the Toxicology of the Inhalation of Carbon

Monoxide and Cyanide in Fire Victims. . . . . . . . . . . . . . .

University of Pittsburgh

Toxicity of Plastic Combustion Products . . . . . . . . . . . .

University of Virginia

Methods for Enhancement and Evaluation of Fire Risk Assessments . . . 


\title{
Summaries of Center for Fire Research Grants and In-House Programs - 1985
}

\begin{abstract}
This report was prepared for distribution at the First International Symposium on Fire Safety Science; October 7-11, 1985. It contains extended abstracts of grants for fire research sponsored by the Center for Fire Research, National Bureau of Standards, as well as descriptions of the internal programs of the Center for Fire Research.

Key words: Cellulose; charring; combustion; fire models; flame spread; ignition; polymers; smoke; soot; toxicity.
\end{abstract}


AD HOC WORKING GROUP OF MATHEMATICAL FIRE MODELING

CENTER FOR FIRE RESEARCH

FY 85

\section{Professional Personnel}

Robert S. Levine, Chairman of Steering Committee

John A. Rockett, Chairman of Computer Committee

James G. Quintiere, Chairman of Models Subcommittee

NOTE: The Modeling Committee is chaired by Professor Howard Emmons, formerly of Harvard University, the Subprogram Committee by John de Ris of Factory Mutual, and the User's Needs Committee by Irwin Benjamin of Benjamin-Clarke.

A number of CFR personnel are members of the technical comnittees.

\section{Program Objectives}

The objectives of this committee are to facilitate the development and use of mathematical models of fire and to coordinate and facilitate research needed to improve the models. The Steering Committee includes members from other government agencies who have influence on their agencies " research and development in this field. The coordination, of course, is voluntary.

Project Areas

Each applicable area is included in another program abstract. The major portion of the CFR effort is in the Fire Modeling Program.

Associated Grants

Several grants are listed elsewhere.

Activity

During FY-85, the Working Group held a plenary meeting on the "Current Status and Plans for the Models," and a workshop on "Non-Steady Burning Rates of Solid Fuels Including the Effect of Char." Minutes of each meeting were prepared and distributed to the participants. 


\section{COMPARTMENT FIRE MODELING RESEARCH \\ FIRE SAFETY TECHNOLOGY DIVISION \\ FY 85}

\section{Professional Personnel}

Leonard Y. Cooper, Head

John A. Rockett, Senior Research Scientist

Henri E. Mitler, Physicist

David W. Stroup, Fire Protection Engineer

Anne Woodhouse, Guest Worker (University of Maryland)

\section{Program Objectives}

(1) Develop, maintain, improve and provide assistance in the use of benchmark Compartment Fire Model computer codes.

(2) Develop and maintain a library of submodel algorithms for general use in compartment fire models.

(3) Formulate, develop, and establish the validity of new and improved analytic/computational compartment-fire-phenomena submodel algorithms for use in compartment fire simulations.

Scope

The work focuses on the development of benchmark computer codes(s) which would be useful in simulating the phenomena which occur in compartment fire scenarios. The term "benchmark computer code" is intended to connote a welldocumented computer code which: a) is based on physics and numerics of proven reliability; b) is numerically robust; and c) is user-friendly in the sense that it can be used with relative ease by researchers and professional fire safety practitioners, and that it can be transferred to and used with computer hardward facilities readily available to the fire science/technology community.

While the benchmark computer code(s) would be up-to-date in the sense of including algorithms which describe the details of fire phenomena currently under investigation in the Fire Research Community, they would not be responsive to forecasts of future research thrusts. In terms of the complexity of compartment configurations, the capability of the new generation of benchmark code(s) would be limited to the simulation of fire-generated environments only in those compartment spaces which affect actual fire development, e.g., in rooms of fire involvement and "freely connected" adjacent spaces. In terms of the level of "user-friendliness", the code(s) would be useful to researchers and practitioners with relatively high levels of commitment and technical skill.

\section{Projects and Products}

\section{Compartment Fire Models}

The Benchmark Compartment Fire Model (BCFM). With a variety of objectives in mind, many different compartment fire model computer codes have been developed within the fire safety/research community. Yet, no one of these can be described as being a "benchmark" model in the sense that it is reliable enough 
To be accepted as a standard of reference for the performance of designoriented fire models. It is the major objective of the Compartment Fire Modeling Research (CFMR) Group to develop such a BCFM computer code. During the last year a program for the development of the BCFM was established, and the program was initiated.

Single-Room Fire Simulations. The Harvard single-room fire model has been operational at NBS for some years. It has been used both for demonstration calculations and as a test bed for new modeling concepts. The "offical" Harvard 5, model has been enriched successfully. The results of this have led to two new and different versions of the model; namely, NBS/Harvard 5.2 and 5.3. The first stage effort in the above-mentioned BCFM development program is to consolidate the advances of these Harvard-based codes. This will involve the testing of BCFM ideas, and it will lead to a BCFM prototype oneroom compartment fire model by 1986.

NBS/Harvard 5.2 has been applied in the simulation of full-scale fire tests carried out at NBS for the U.S. Park Service. In this study, physically reasonable input parameters resulted in a good simulation of the experimental data. In another special study for the U.S. Park Service a simple method for designing smoke control systems in atrium-like configurations was developed.

Under support of the Nuclear Regulatory Commission (NRC) NBS/Harvard 5.3 is being generalized to include the effect of burning in the vitiated air of the upper layer. Also supported by the NRC is a comparison of the capabilities of several different compartment fire models.

NBS/Harvard 5.3 was used to simulate the fire environments generated during tests in the full-scale, ventilated, fire test facility of the Lawrence Livermore National Laboratory.

Additional progress was made in making the ASET (Available Safe Egress Time) computer program more user-friendly. This work is now continuing as a joint activity with the Fire Simulation Laboratory Group of CFR.

In a special study for the FAA a model of the external fuel-spill fire-generated environment in aircraft cabins was developed and used to establish an analytic methodology for simulating the thermal response of cabin ceiling materials. The analysis was developed in conjunction with experimental data available from FAA fire tests on a full-scale, wide-body, aircraft fuselage.

Multi-Room Fire Simulation. The Harvard 6 code was brought to NBS in 1983. It was made operational on the CFR computer, made to conform strictly to the ANSII FORTRAN 77 standard, and a series of minor errors were corrected. Several enrichments have been added to the code. As a part of this effort, an extensive debugging capability was also added. A separate plot package, orginally developed for NBS/Harvard 5.2, has been adapted. Comparisons are now being made between simulations of the resulting code and data from a series of full-scale multi-room tests which were carried out at NBS in 1980.

Under support from the Navy, a study is being carried out to identify means of using deterministic compartment fire modeling to improve the risk analysis of the Navy's Fire Damage Simulation Model. 
Cooper, L.Y., Rockett, J.A., Mitler, H.E. and Stroup, D.W., "A Program for the Development of a Benchmark Compartment Fire Model Computer Code", to appear as NBSIR.

Cooper, L.Y., "The Need and Availability of Test Methods for Measuring the Leakage Characteristics of Door Assemblies", NBSIR 84-2876, 1984 Symp. on Applications for Fire Science to Fire Engineering, to appear in ASTM STP 882.

Cooper, L.Y., Nelson, H.E., and Thorne, S., "National Park Service Full-Scale Burns: Analysis and Insights Gained", a video tape report to the U.S. National Park Service (1984).

Cooper, L.Y., and Stroup, D.W., "ASET: A Computer Program for Calculating Available Safe Egress Time", 1984 SFPE Symp. on Computer Applications in Fire Protection: Analysis, Modeling and Design, Fire Safety Journal, 9, 29 (1985).

Cooper, L.Y., and Nelson, H.E., "Implementing Life Safety Through Designed Safe Egress", to appear in Chapter on Fire in Monograph on Planning and Design of Tall Buildings, Council on Tall Buildings and Urban Habitat.

Cooper, L.Y., "The Thermal Response of Aircraft Cabin Ceiling Materials During a Post-Crash, External Fuel-Spill, Fire Scenario", 23rd AIAA Aerospace Sciences Meeting (1985), to appear in Proc. of lst Inter. Symp. of Fire Safety Science.

Cooper, L.Y., "An Interim Buoyancy Smoke Control Approach (for Atrium-like Arrangements", Appendix B of NBSIR 84-2896: Fire Safety Evaluation System for National Park Service Accommodations (1984).

Rockett, J.A., "Park Service Room Fire Test Simulations, Using the Harvard Level 5.2 Computer Fire Model", Fire Science and Technology, 4, 135 (1984).

Baum, H., and Rockett, J.A., "Analysis of Forced Ventilation in Container Ship Holds", Journal of Fluid Mechanics 142, pp. 309-342 (1984).

Rockett, J.A., "Data for Room Fire Models", Combustion Science and Technology, 40, 137 (1984).

Rockett, J.A., "Two Approaches to the Analysis of Actual Fires", 1984 SFPE Symposium on Computer Applications in Fire Protection: Analysis, Modeling and Design, Fire Safety Journal, 9, 17 (1985).

Rockett, J.A., and Morita, M., "The NBS/Harvard 6 Multi-Room Fire Simulator", to appear as INBSIR.

Rockett, J.A., Morita, M. and Cooper, L.Y., "Comparisons of NBS/Harvard 6 Simulations and Full-Scale, Multi-room Compartment Fire Test Data", to appear as NBSIR.

Rockett, J.A., "Fire Growth in Combat Ships", to appear as NBSIR.

Mitler, H.E., "The Harvard Fire Model", 1984 SFPE Symposium on Computer Applications in Fire Protection: Analysis, Modeling and Design, Fire Safety Journal, $\underline{9}, 7$ (1985). 
Mitler, H.E., "Comparison of Several Compartment Fire Models", to appear as NBSIR.

Stroup, D.W, "Heat-Transfer-Related Calculations" and "Egress Calculations for the Jefferson National Memorial Historical Site", Appendices A and B, respectively, of NBSIR 84-2897: Jefferson National Memorial Historical Site Analysis of Inpact of Fire Safety Features (1985).

\section{Compartment Fire Model Library of Submodel Algorithms and Associated Computer Subroutines}

This project involves a series of short- and long-term activities. These will include a) merging the physical subroutines of the NBS/Harvard computer codes into a single, portable, subroutine library; b) reviewing the subroutine algorithms of the NBS/Harvard computer codes, and identifying those which are of "benchmark" quality c) developing a format for a Catalogue of Compartment Fire Submodel Algorithms, and a mechanism for publication, distribution and revision of the Catalogue. The Catalogue will be for general use in zone compartment fire models.

Stroup, D.W., "The Establishment of a Catalogue of Compartment Fire Submodel Algorithms and Associated Computer Subroutines", to appear as NBSIR.

3. Compartment-Fire-Generated Flow Dynamics, Flame Spread/Growth and Heat Transfer: Submodel/Algorithm Development and Verification.

A theoretical study of the structure and upward spread rate of wall fires has been undertaken from the point of view that the results be consistent with available experimental data, and useful in an algorithm which is simple enough for use in full compartment fire models.

A reduced-scale, experimental program is being carried out, where the thermal response of different ceiling constructions positioned above fires of different strengths and fire ceiling separations is being measured. This and other experimental programs will complement continuing theoretical activities which are being carried out to formulate, develop and validate algorithms for simulating compartment-fire-generated flow dynamics and heat transfer. A practical application of such activities is the development of algorithms for simulation fire detection system components. One such algorithm has been used to generate a guide on the design of thermal fire detection systems.

NBS/Harvard 5.2 was used to evaluate each of five different plume entrainment submodels when used in single-room fire simulations. A series of simulations were run both for, small fires, for which experimental room gas flow measurements were available, and for larger fires where experimental data is not now available.

The dynamics of forced ventilation in the context of a two-layer compartment fire model has been analyzed, and an algorithm for simulating the phenomenon was developed. This was used to enrich NBS/Harvard 5.3.

A study has been initiated with the objectives of mathmatically modeling the smoldering of cigarettes on furniture, describing the influence of furniture on 
the burning of a cigarette, and predicting whether furniture will ignite for a particular cigarette configuration and furniture composition. This work is supported by the Consumer Product Safety Commission.

Cooper, L.Y., "On the Signficance of a Wall Effect in Enclosures with Growing Fires", Combustion Science and Technology, 40, 19 (1984).

Cooper, L.Y., "A Buoyant Source in the Lower of Two, Homogeneous, Stably Stratified Layers - A Problem of Fire in an Enclosure", to appear in 20th Proceeding of International Symposium on Combusiton (1984).

Cooper, L.Y., "Thermal Response of Unconfined Ceilings Above Growing Fires and the Importance of Convective Heat Transfer", NBSIR 84-2856, 22nd ASME/AIChE National Heat Transfer Conference (1984).

Cooper, L.Y. and Woodhouse, A., "The Buoyant Plume-Driven Adiabetic Ceiling Temperature Revisited", NBSIR 85-3134, 23rd ASME/AIchE National Heat Transfer Conference (1985).

Cooper, L.Y., "Heat Transfer in Compartment Fires Near Regime of Ceiling JetWall Impingement", to be presented at 1985 Fall Meeting of the Eastern Section of the Combustion Institute.

Mitler, H.E., "Zone Modeling of Forced Ventilation Fires", Combustion Science and Technology, 39, 88 (1984).

Rockett, J.A., "A Comparison of Plume Entrainment Models", to appear as NBSIR.

Stroup, D.W., "Development of a Computerized Probe Positioner", to appear as NBS IR.

Stroup, D.W., "Thermal Detector Response", 1985 Annual Meeting of NFPA.

Stroup, D.W., Evans, D.D. and Martin, P., "Evaluating Thermal Fire Detection Systems, to appear as NBS Special Publication.

Evans, D.D. and Stroup, D.W., "Methods of Calculating the Response Time of Heat and Smoke Detectors Installed Below Large Unobstructed Ceilings", NBSIR 85-3167.

Woodhouse, A., Marks, C.H. and Cooper, L.Y., "An Experimental Study of the Transient Thermal Response of Unconfined Ceilings above Fire Plumes", to be presented at the 1985 Fall Meeting of the East Section of the Combustion Institute.

\section{Associated Grants and Contracts}

1. Yogesh Jaluria - Rutgers - The State University of New Jersey, "Negatively-Buoyant and Penetrative Flows Generated in Enclosure Fires."

2. Colin H. Marks - University of Maryland, "Transient Heat Transfer in Ceiling Jets." 


\section{EXPLORATORY FIRE RESEARCH \\ FIRE MEASUREMENT AND RESEARCH DIVISION \\ CENTER FOR FIRE RESEARCH \\ FY 84}

\section{Professiona 1 Personne 1}

Walter M. Shaub, Head

James E. Brown, Research Chemist

Lisha Glinsman, Chemist

Takashi Kashiwagi, Materials Research Engineer

W. Gary Mallard, Research Chemist

William Manders, Post Doc

George W. Mulholland, Research Chemist

Thomas J. Ohlemiller, General Engineer

William J. Parker, Physicist

William M. Pitts, Research Chemist

Kermit C. Smyth, Research Chemist

Philip Taylor, Post Doc

Atsushi Inaba, Guest Worker

Chris Jarvis, Guest Worker

J. Houston Miller, Faculty Research Associate

Roberto Samson, Guest Worker

Elizabeth Finlayson, Guest Worker

Akihiko Ito, Guest Worker

\section{Program Objectives}

(1) Improve the understanding of the chemical and physical processes which underline macroscopic fire phenomena. The research embraces broad areas covering both solid and gas phase processes, with particular attention to polymer degradation, the effect of thermal radiation, and the hot gas chemistry and physics leading to incomplete combustion.

(2) Devise new techniques and methods for studying these phenomena.

(3) Furnish fundamental scientific information to support the other activities within the Center for Fire Research.

\section{Scope}

This work is scientific not empirical. It embraces broad areas underpinning CFR programs with focussed study in the areas of materials degradation, hot gas physics and chemistry, and thermal radiation. Efforts are directed toward improved understanding of the chemical and physical processes which underlie macroscopic fire phenomena and include development of new techniques and methods for studying these processes. 


\section{Polymer Gasification and Ignition}

The prediction of ignition, flame spread, steady burning and flashover requires a knowledge of the rate of gasification of solids. However, in current fire growth modeling, while gas phase processes are reasonably well understood and reasonably accurately modeled except regarding radiation from flames, the role of the condensed phase is often neglected or very crudely modeled due to the lack of understanding of chemical and physical processes which can occur in the condensed phase. The goal of this project is to increase the understanding of condensed phase processes which lead to gasification and ignition through a carefully designed program of theoretical and experimental research.

The mechanisms of thermal degradation of poly(methyl methacrylate) (PMMA) and polystyrene (PS) are being studied by measuring weight loss rates of samples and the molecular weight of rapidly quenched samples thermally degraded in nitrogen or in vacuum at temperatures up to $420^{\circ} \mathrm{C}$. The effects of initial number average degree of polymerization ( $\mathrm{DP}_{\mathrm{o}}$ ), polymerization method (radical vs anionic polymerization), toxicity and unsaturated polymerization ends on the degradation mechanisms are being studied. Results show that the degradation rate of PMMA increases with an increase in initial degree of polymerization of PMMA up to a certain value $\left(\mathrm{DP}_{\mathrm{O}} \sim 5000\right)$ although the overall activation energy of the weight loss does not change significantly. However, PS samples do not show significant effects of $D_{0}$. The effects of differences in polymerization method on degradation rates are significant for PMMA but negligible for PS. This is mainly due to the location of unsaturated double bonds in the vinyl polymerization ends from the radical polymerization method. It appears that "weak links" do not have any significant effects on sample weight loss rates. Preliminary results show that there are slight effects of tacticity on degradation of PMMA. Its stability increases in the order of isotactic, syndrotactic and atactic structures.

Two theoretical models are being developed to calculate changes in weight loss and in the molecular weight distribution of a polymer, including random scission initiation, depropagation and termination reactions in the absence of any transport processes. This calculation simulates the above thermal analysis results on PMMA. One of the two models is based on a discrete approach. In this model, each differential equation is written with respect to an individual degree of polymerization. The model uses about 1000-100,000 ordinary differential equations. The effects of initial degree of polymerization on degradation rates are calculated. The predicted results agree well with the above experimental results. The other model is based on a continuous approach and analytical solutions are being derived with the least amount of numerical calculation. In both models, the validity of the approximation of steady-state radical concentration during degradation (this has been always used without any rigorous justification) is being examined.

Another theoretical model is being developed to describe the in-depth effect of bubbles on the steady-state transport of volatile degradation products to the surface of a polymer subjected to an incident heat flux. In this model, the effect of the bubbles on the surrounding molten polymer is felt through the bubble number distribution function, $\mathrm{n}$, which appears in the equations for 
conservation of mass, momentum, species and energy in the melt. The equation for the evolution of $n$ includes the effects of bubble growth, convection and nucleation. With these equations, formulas for the mass flux of volatiles from the polymer surface and the bubble void fraction are developed, for the special case of constant polymer mass fraction.

"Thermal and Oxidative Degradation of Poly(methyl methacrylate): Molecular Weight" by Kashiwagi, T., Hirata, T., and Brown, J.E., Macromolecules, 18, 131-138 (1985).

"Thermal and Oxidative Degradation of Poly(methyl methacrylate): Weight Loss" by Hirata, T., Kashiwagi, T. and Brown, J.E., Macromolecules, 18, 1410-1418 (1985).

"A Model Describing the Steady-State Pyrolysis of Bubble-Forming Polymers in Response to an Incident Heat Flux", by Wichman, I.S., to appear in Combustion and Flame.

"Differences in PMMA Degradation Characteristics and Their Effects on its Fire Properties" by Kashiwagi, T., Inaba, A. and Brown, J.E., to be presented at the First International Symposium on Fire Safety Science (1985).

\section{Smoldering Combustion of Cellulosics}

The propensity for smoldering exhibited by cellulosic materials continues to be a subject of major concern. Smoldering combustion is driven by exothermic oxygen attack on the surface of organic materials; wood-based materials such as cellulosic insulation are particularly prone to this attack. The process is slow but self-sustaining once initiated. It poses a life threat as a copious source of toxic gases. Also, it provides a relatively easy pathway to flaming combustion that may not be precluded by flame retardants. It is this latter aspect--smoldering as an initiator of flaming-- which has been examined recently for cellulosic insulation materials. Smolder to flaming tests were conducted using unretarded cellulosic insulation material and insulation with either boric acid (a smolder-retardant) or borax (a flame retardant). Both suppress flaming effectively when the smoldering insulation is isolated from other flammable material. Much of their effectiveness is lost when unretarded wood abuts the smoldering insulation since the wood itself ignites.

Smolder spread over solid wood will be examined in a series of experiments now being designed. Initial emphasis will be on the effective equivalence ratio and major gasification products. Pyrolysis of cellulose is a subject of continuing interest. A series of experiments is underway on product analysis from deuterated cellulose that should clarify the relative roles of the amorphous and crystalline regions in early gasification processes.

Physical property data for char forming materials are being carefully developed to support an effort aimed at predicting the heat release rate of wood. A new pyrolyzer has been constructed for this purpose. It is being used to obtain mass generation rate data and heats of combustion of the volatile pyrolysis products from wood components (cellulose, hemicellulose and lignin). Thermal property data for various soft and hardwoods are also being obtained as a function of temperature and fractional mass loss. A model is 
used to predict the heat release rates of woods in a vertical orientation as a function of incident flux and specimen thickness. The predictions of the model will be compared against cone calorimeter results.

"Calculations of the Heat Release Rate by Oxygen Consumption for Various Applications", by Parker, W.J., submitted to Journal of Fire Sciences (1984).

"Forced Smolder Propagation and the Transition to Flaming in Cellulosic Insulation", by Ohlemiller, T., NBSIR, in review.

"Modeling of Smoldering Combustion Propagation" by Ohlemiller, T., NBSIR 84-2895, National Bureau of Standards, Washington, DC, June 1984.

\section{Fundamentals of Wood Gasification and Combustion}

This work is aimed at clarifying and quantifying the physical and chemical processes underlying gasification of wood at fire level heat fluxes and the conditions required to oxidize the resultant gases. Major support comes from the Department of Energy.

An extensive set of one-dimensional radiative heating tests on thermally thick wood samples has been completed; these included the effects of wood type, grain orientation, water content, thickness, flux and ambient oxygen level on gasification rate and product composition. The conditions required to fully oxidize certain of these products are currently being explored in a laminar flow reactor. In the next stage of this work, a predictive model of the gasification process will be developed.

"Products of Wood Gasification" by Ohlemiller, T., Kashiwagi, T. and Werner, K., NBSIR 85-3127 (April 1985).

\section{Soot Formation Chemistry and Physics}

Flame radiation from incandescent soot dominates flame spread and heat transfer in large fires. Escaping particulates hinder vision and impair breathing, as well as being a sensitive signature for fire detection. Despite this importance, there is little understanding at the molecular level of the soot formation process; $i . e .$, how small molecules grow rapidly to become soot particles. We are now in the sixth year of a long-term study of the fundamental chemistry and physics of soot formation, carried out jointly with the NBS Thermal Processes Division in the Center for Chemical Engineering.

A series of optical and mass spectrometric profile measurements have been completed for methane/air diffusion flames on our Wolfhard-Parker burner. We have used fluorescence to monitor $\mathrm{OH}_{2} \mathrm{C}_{2}$, and polycyclic hydrocarbons (three ways), multi-photon ionization to detect methyl radicals and small soot particles and Rayleigh-mie scattering to observe the emergence of large soot particles. In addition, mass spectrometric profiles of $\mathrm{CO}_{2}, \mathrm{H}_{2} \mathrm{O}$, methane, acetylene, butadiene, benzene, toluene, diacetylene, triacetylene, vinyl acetylene, methylacetylene, and allene have been taken. These results clearly delineate the region of soot nucleation: soot particles first appear on the high temperature, radical-rich side of a zone containing numerous pyrolysis products. Velocity measurements using laser Doppler velocimetry and thermo- 
couple temperature profiles have also been obtained. The combined data provide the most detailed description of the chemical structure in a hydrocarbon diffusion flame obtained to date.

In addition to species characterization studies, physical properties of soot are being investigated. The kinetics of cluster aggregation and structure of the resulting clusters have been studied using a "Brownian dynamics" computer simulation of conditions appropriate for soot growth. These simulations are now being extended with the new NBS Cyber 205 to increase the number of particles in an agglomerate from about 200 to 2000 and to include rotational diffusion as well as translational diffusion. An experimental study of soot microstructure is in progress for comparison with the results of the computer simulations. A heated smoke sampling system has been developed for collecting up to three samples of smoke from a modified furniture calorimeter. The sampler will be used to obtain smoke emission data in support of the Defense Nuclear Agency study of the global effects of a major nuclear exchange.

"Intermolecular Potential Calculations for Polycyclic Aromatic Hydrocarbons" by Miller, J.H., Mallard, W.G. and Smyth, K.C., J. Phys. Chem. 88, 4963 (1984).

"Calculations of the Dimerization of Aromatic Hydrocarbons; Implications for Soot Formation" by Miller, J.H., Smyth, K.C. and Mallard, W.G., Twentieth Symposium (International) on Combustion) (in press).

"Global Soot Growth Model" by Mulholland, G.W., accepted for First International Symposium on Fire Safety Science.

"Refractive Index and Evaporation Rate of Individual Smoke Droplets" by Mulholland, G.W., McKenzie, R. and Marx, E., Langmuir, 1, 367 (1985).

"Multiphoton Ionization Detection of Molecules in Flames" by Smyth, K.C., Mallard, W.G. and Miller, J.H., SPIE Symposium on Laser Chemistry and Diagnostics, Vol. 482, 66 (1984).

"Soot Inception in a Methane/Air Diffusion Flame as Characterized by Detailed Species Profiles" by Smyth, K.C., Miller, J.H., Dorfman, R.C., Mallard, W.G. and Santoro, R.J., Comb.\&Flame (in press).

"Detection of the Methyl Radical in a Methane/Air Diffusion Flame by Multiphoton Ionization Spectroscopy" by Smyth, K.C. and Taylor, P.H., Chemical Physics Letters (submitted).

\section{Turbulent Chemically-Reacting Flow}

In a large fire plume, the combustion region is turbulent and is characterized by highly variable (both spatial and temporal) distributions of temperature and species concentration. In such cases the flame properties are dominated by the substantial temperature and species concentration fluctuations. Due to the scarcity of measurements on such systems and the complexity of the phenomena, the understanding of turbulent fire plumes is poor. This project is designed to be a basic experimental study of chemically reacting flow in which the effects of density differences due to composition, temperature, and heat release on turbulent mixing are elucidated. 
The project has required the development of new experimental diagnostic techniques as well as the applications of these techniques to measurement in turbulent flow fields. Up to the present time we have been primarily concerned with the effects of density differences due to composition on the mixing behavior of an axisymmetric jet flowing into a slow coflow of a second gas.

Rayleigh light scattering has been shown to be a particularly powerful technique for monitoring real-time, spatially resolved concentration fluctuations in these flow fields. By combining the light scattering technique with hot-wire anemometry a new diagnostic for simultaneous concentration and velocity measurement has been developed. As a part of this work an extensive experimental study of the responses of hot-wire and film anemometers to flows of different gases was initiated. This study has not only improved our understanding of these velocity measurement devices, but has also yielded a much improved understanding of heat transfer from cylinders.

As part of our diagnostic development a digital line camera has been designed and fabricated at NBS. This camera is designed to be sensitive enough to allow real-time measurements along a line in these turbulent flow fields using Rayleigh light scattering. Preliminary measurements have shown that this goal has been achieved. The use of this camera will allow a much improved characterization and understanding of entrainment and mixing in turbulent flows.

An extensive study of turbulent mixing behavior along the centerline of the axisymmetric jet has been completed. Both flow visualization using shadowgraphy and Rayleigh light scattering point measurements have been used to investigate flows having jet/coflow density ratios covering the range from 0.14 to 37 . The availability of measurements over such a wide range of densities has enabled many density effects to be discerned. A manuscript describing this work is in preparation.

"The Application of Laser-Deduced Rayleigh Light Scattering to the Study of Turbulent Mixing" by Pitts, W.M. and Kashiwagi, T., NBSIR 83-264l and Journal of Fluid Mechanics 141 (1984) 391.

"A New Diagnostic Technique for Simultaneous, Time-Resolved Measurement of Concentration and Velocity in Simple Turbulent Flow Systems" by Pitts, W.M. McCaffrey, B.J. and Kashiwagi, T., Fourth Symposium on Turbulent Shear Flows, Karlsruhe, FDR, Sept. 1983.

"Response Behavior of Hot-Wires and Films to Flows of Different Gases" by Pitts, W.M. and McCaffrey, B.J., in press, and submitted to the International Journal of Heat and Mass Transfer.

"Effect of Density Variations Due to Composition on the Mixing Behavior of Axisymmetric Turbulent Jets" by Pitts, W.M., manuscript in preparation. 


\section{Associated Grants and Contracts}

1. "Thermal and Material Transport and the Solubility of Oxygen and Other Gases in Oxidizing Polymer", Joseph Flynn and Emanuel Horowitz, The Johns Hopkins University.

2. "Ternary Reactions Among Polymer Substrate-Organohalogen-Antimony Oxides in the Condensed Phase Under Pyrolytic, Oxidative and Flaming Conditions", Michael J. Drews and Christine W. Jarvis, Clemson University.

3. "Flow Field Effects on the Sooting Structure of Diffusion Flames", Irvin Glassman, Ian M. Kennedy and Frederick L. Dryer, Princeton University.

4. "A Study of the Effects of Oxygen Transport, and Temperature History on the Chemistry of Polymethyl Methacrylate and Cellulose Pyrolysis", Eric M. Suuberg, Brown University.

5. "Flame Radiation", Chang-Lin Tien, Lawrence Berkeley Laboratory.

6. "Soot Dynamics in Flames", Richard A. Dobbins, Brown University. 


\section{FIRE GROWTH AND EXTINCTION \\ CENTER FOR FIRE RESEARCH \\ FY 85}

Staff

David Evans, Acting Head

James Quintiere, Head

Carol Thompson, Secretary

Howard Baum, Research Physicist

Edward Budnick, Fire Protection Engineer

Dan Corley, Physicist

Margaret Harkleroad, Physicist

Randy Lawson, General Physical Scientist

Bernard McCaffrey, Mechanical Engineer

Ken Steckler, Physicist

Indrek Wichman, Mechanical Engineer

Anil Trehan, Guest Worker, Univ. of MD

Joe Loftus, Research Associate, Benjamin-Clarke Associates

William Rinkinen, Engineering Technician

Alex Flores-Calderes, Coop Student

Larry Buffington, Fire Protection Engineering Student

James Morehart, Mechanical Engineering Student

Hiroshi Koseki, Guest Worker, FRI (Japan)

Matti Kokkala, Guest Worker, (Finland)

David Rasbash, Guest Worker, (Univ. of Edinburgh)

Koso Saito, IPA (Princeton)

Program Objectives

Through research we aim to develop predictive methods to describe the processes of growth and extinction related to natural fire phenomena and fire safety systems.

\section{Scope}

The work addresses the processes of fire growth and decay associated with fires within structures and with free burning fires. It examines the overall dynamics of fire growth and its suppression in order to identify and understand the significant underlying processes; ignition, flame spread, burning rate, extinction, and the related transport processes. It utilizes mathematical techniques, experimental studies and correlations, and similitude methods to develop accurate predictions for realistic configurations and materials. As appropriate, it formulates and demonstrates its predictive methods for specific applications.

Introduction

In FY 85, there were several additions to the professional and support staff. Edward Budnick joined the group to begin studies of the global aspects of fire suppression in enclosures. Indrek Wichman bolstered the groups staff in studies of flame spread phenomena. Three new students, Anil Trehan, Larry Buffington and James Morehart started experimenta? studies within the group as a beginning to their training in fire research. Several guest 
workers from other fire research institutions brought different viewpoints and skills to the group. Of particular note was the presence of David Rasbash from the University of Edinburgh to work and lecture in the area of fire suppression. Two new areas of experimentation were begun. Fire suppression experiments were begun by quantifying enclosure fire effects during active fire suppression with water sprays in a series of large scale room burnextinguishment tests. Enclosure smoke flow was modeled in experiments using dyed salt and fresh water. Experiments were performed to map the entire salt water flow through a $17 \mathrm{ft}$. model of a navy ship.

\section{Project Areas}

\section{Turbulent and Reacting Flows}

This study combines the use of theoretical, computational and experimental methods to resolve phenomena associated with turbulent reacting flows in an internally consistent manner. Specifically, in the analysis of urban conflagrations, individual plume structures are characterized by modeling and laboratory scale experiments, multiple plumes by theoretical analysis, and development of the large convection column by computational methods.

Methods to predict ongoing vortex mixing calculations were extended to allow for analysis of finite size "blobs" of material imbedded in a reactant. These calculations quantify the deformation of initially circular blobs of material in the turbulent reacting flow.

Calculations of the entire flow pattern about a single fire plume that is consistent with laboratory measured correlations for fire plumes were completed. These calculations will be used to calculate enclosure fire phenomena such as plume flow near a wall and in a corner, as well as large scale fire phenomena associated with flow around multiple plumes in the open.

\section{Publications}

McCaffrey, B.J., Fire Plume Dynamics-A Review. Conference on Large-Scale Fire Phenomenology; 1984 September 10-13; National Bureau of Standards, Gaithers burg, MD.

Baum, H.R. and Rehm, R.G., Calculations of Three Dimensional Buoyant Plumes in Enclosures. SIAM Journal of Scientific and Statistical Computing; 1984 December; 5(4): 958-977.

Rehm, R.G., and Baum, H.R., Numerical Computation of 3-Dimensional Fire Induced Flows and Smoke Coagulation, Lecture Notes in Physics, Ninth Int. Conf. on Numerical Methods in Fluid Dynamics, Vol. 218, Soubbaramayer and Boujot (Editors), Springer Ver-lag, Berlin, pp. 453-458, 1985.

Rehm, R.G., Baum, H.R., Barnett, P.D., and Corley, D., Finite Difference Calculations of Buoyant Convection in an Enclosure: Verification of Non-linear Algorithm. Applied Numerical Mathematics (to appear 1985).

Baum, H.R., and Rehm, R.G., Time-Dependent Simulation of Combustion-Driven Flows, Invited Paper, Eastern States Section Combustion Institute Fall Technical Meeting. Clearwater Beach, Florida, December 3-5, 1984. 
Laboratory experiments were used to quantify the major aspects of material burning characteristics under conditions of altered ambient temperature, oxygen concentration, and external radiation common to enclosure fire environments. Measurements of PMMA wall slab pyrolysis rate under various model enclosure ventilation conditions were used to provide quantitative predictive methods for use in enclosure fire models. Preliminary analysis shows that the mass loss rate of burning PMMA ( $\left.\dot{m}^{\prime \prime}\right)$ wall slabs in enclosures can be predicted using the sum of two terms one for the upper layer conditions $(i=$ upper) and the other for lower layer conditions ( $i=$ lower).

Each has the form:

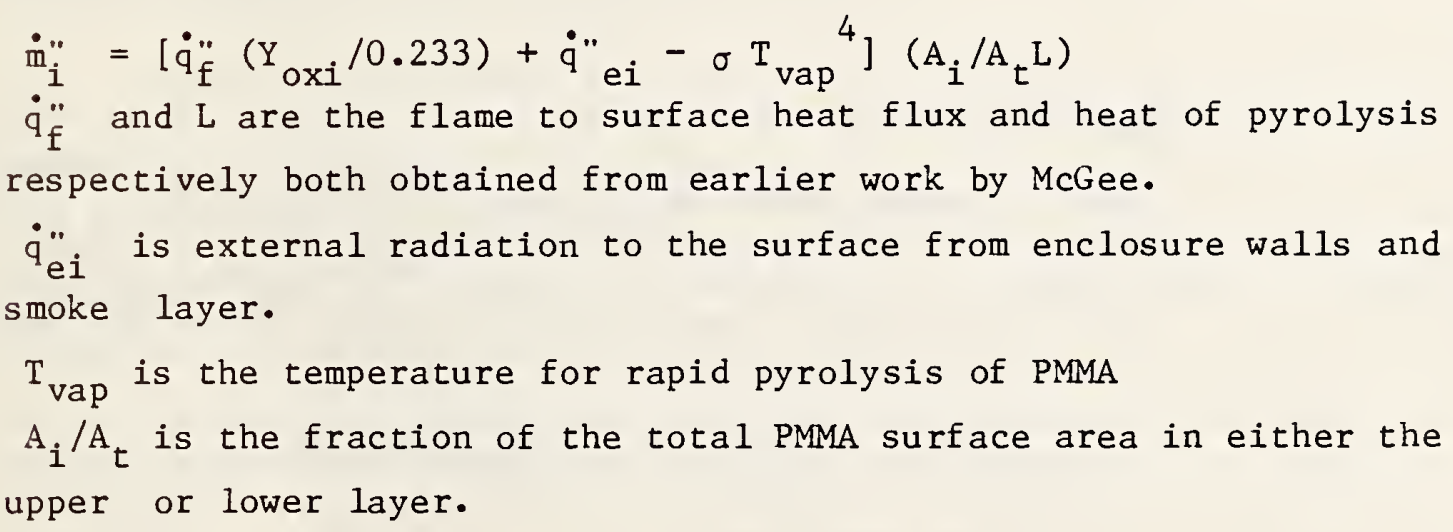

Large scale experiments were conducted on board the U.S. Coast Guard ship to quantify energy release rate, smoke production, and smoke flow from fires involving cables. Smoke flow through the compartmented structure of a ship has been measured simulating the fire using buoyant flow modeling with dyed saltwater injected into freshwater. Quantification is based on dimensional analysis that matches distances and times in the saltwater flow model to distances and times measured for smoke movement in actual fire tests with the two parameters

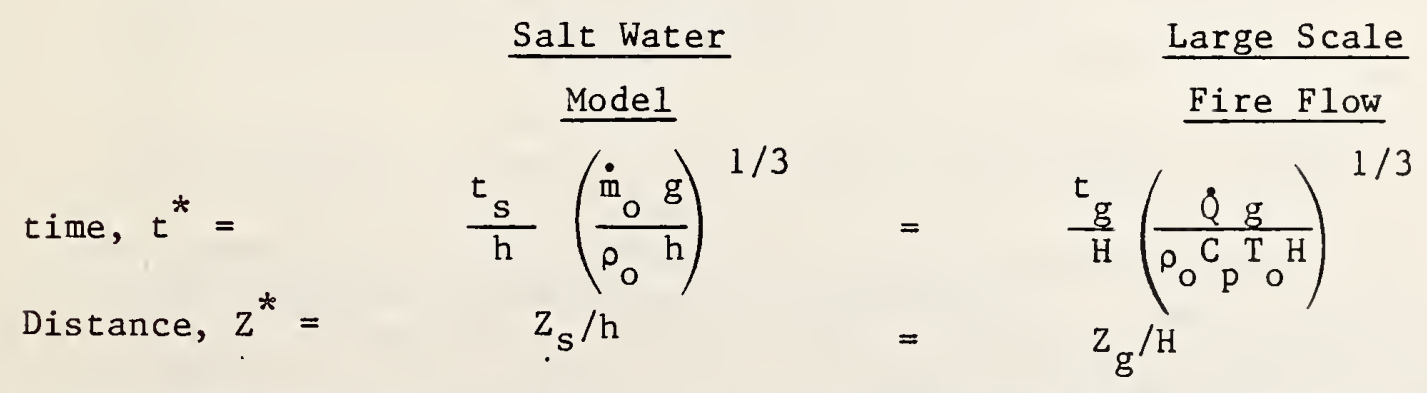

Notice that one salt water experiments, quantifies conditions for all heat release rate fires in the large scale for identically scaled geometries. 
Quintiere, J. Perspective on Compartment Fire Growth. Combustion Science and Technology; 1984; 39(1-6): 11-54.

Quintiere, J., Baum, H, and Lawson, R. Fire Growth in Combat Ships, NBSIR 853159 , June 1985.

Quintiere, J., Steckler, K. and Corley, D. Assessment of Fire Induced Flows in Compartments. Fire Science and Technology; 1984; 4 (1): 1-14.

Steckler, K. Smoke Flow and Energy Release Rate in Full Scale Navy Cable Fire Tests (NBSIR in preparation).

Steckler, K. and Baum, H. Saltwater Modeling of Fire Induced Flows in Multicompartment Structures (report in preparation).

\section{Ignition and Flame Spread}

From data taken with a radiant panel apparatus, observations of ignition and lateral flame spread on a vertically oriented material have led to a practical procedure for determining general property data. Relying on a known relationship for the surface heat loss and heat transfer theories for ignition and flame spread, the following effective properties can be determined.

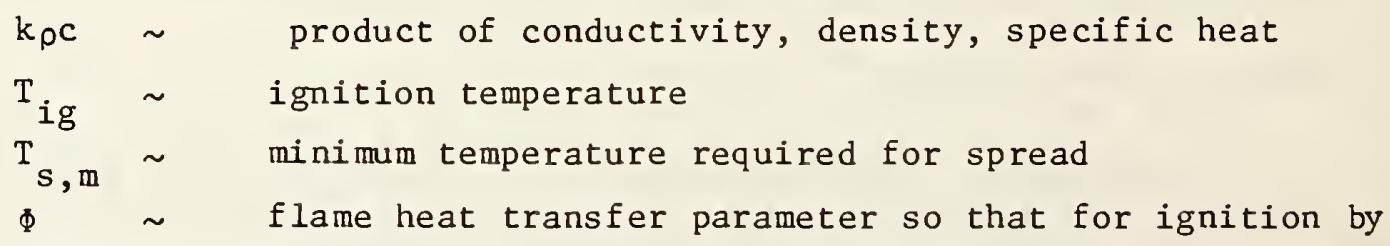
thermal radiation $\left(\dot{q}_{\mathrm{e}}\right)$ ) under natural convection cooling, the time to ignite is

$$
t \sim\left(k_{\rho} c\right)\left[\left(T_{i g}-T_{i}\right) / \dot{q}_{e} e^{2}\right.
$$

and for opposed flow spread velocity under natural convection

$$
V=\frac{\Phi}{k_{\rho c}\left(T_{i g}-T_{s}\right)^{2}}, T_{s} \geq T_{s, m}
$$

for a specified surface temperature $\mathrm{T}_{S}$. Over forty materials have been successfully analyzed. In particular, aircraft panels have been tested to establish a basis for predicting post-crash aircraft fires. The flame spread measurement concept has been taken from the laboratory and standardized in a commercially available apparatus. This new apparatus is being considered for standardization by the International Maritime Organization.

Progress to develop a counterpart procedure for upward flame spread has also been made. The basic premise here is that the spread velocity can be derived from an expression of the form: 


$$
v=\frac{\dot{q}^{2} \delta_{f}}{k_{\rho c}\left(T_{i g}-T_{s}\right)^{2}}
$$

where $\dot{q}^{\prime \prime}$ is the flame heat flux and $\delta_{f}$ is the flame extinction length beyond the pyrolysis zone. In general the numerator parameters are not constant: both vary with position and time. From static experiments on a vertical heat transfer surface (2.5m) wall slabs and line burner sources (Y. Hasemi) have yielded total heat flux distributions which can be roughly correlated for all cases into a function only of position normalized with the flame length measured from the base of the test sample. Although radiation and convection have not been separated, the total maximum heat flux is generally found to be between 2 to $3 \mathrm{~W} / \mathrm{cm}^{2}$ in the flame zone and in accordance with the data of Ahmad and Faeth overal1. Current measurements are attempting to determine the radiative and convective components.

Dynamic experiments of upward flame spread on wood samples have been conducted by $K$. Saito and analyzed by Wichman for PMMA and wood samples. The effects of sample width, height and the ignition energy supplied by a line burner source were studied. Surface temperature measurements, along with a parallel radiative piloted ignition study, have been used to define an ignition temperature to define the pyrolysis front and its speed. Although bubbles are observed in the PMMA near $290^{\circ} \mathrm{C}$, ignition appears to occur near $360^{\circ} \mathrm{C}$.

Work was also begun to model flame spread and burning of oil spills on water. This work is directed at eventual prediction of oil consumption by burning under natural environmental conditions including wind, waves, and ice formations. A complete review of available research was performed and the framework for the modeling was established.

\section{Publications}

Quintiere, J.G. and Harkleroad, M. Wall Flames and Implications for Wall Flames and Implications for Upward Flame Spread. AIAA 23rd Aerospace Sciences Meeting, January 14-17, 1985/Reno, Nevada. AIAA-85-0456.

Wichman, I.S. Model Describing the Influences of Finite-Rate Gas-Phase Chemistry on Rates of Flame Spread Over Solid Combustibles. Combustion Science and Technology; 1984; 40(5-6): 233-255.

NBSIR 85-3130 Wichman, I.S. A Mode1 Describing the Steady-State Pyrolysis of Bubble-Forming Polymers, in Response to an Incident Heat Flux. May 1985.

Quintiere, J. Some Aspects Influencing Fire Spread Over Room Linings and in the ASTM Tunnel Test Fire and Materials.

Quintiere, J. and Harkleroad, M. New Concept for Measuring Flame Spread Properties, NBSIR 84-2943, November 1984.

Quintiere, J., Babrauskas, V., Cooper, L., Harkleroad, M., Steckler, K. The role of Aircraft Panel Materials in Cabin Fires and Their Properties, FAd Report in preparation. 
Harkleroad, M., and Quintiere, J., Ignition and Flame Spread Measurements of Aircraft Paneling Materials. FAA Report in preparation.

\section{Fire Suppression}

Work continued to understand the extinction dynamics associated with water spray suppression of lifted methane jet flames characteristic of gas-well blowout fires. The stability of free jet flames above gas outlets of various diameters was studied at a scale greater than any previous work. Measurements show substantial deviations from literature correlations developed from smaller scale experiments.

Water spray extinguishment of enclosure fires was studied with a first series of measurements during active suppression of multi-crib fires. These tests showed dramatic effects of drop size and flow rate changes. Drop size measurements were made in-house on new automated analysis equipment that utilizes shadowgraphic techniques. Less detailed measurements were made on commerical fire fighting equipment from manufacturers in Japan, Germany, Sweden, and the United States to help support a test program initiated by local fire departments.

To begin the construction of a thermal model for spray suppression of solid fuel fires, heat transfer and evaporation measurements were completed for water droplets falling on a heated surface. Infrared thermography was studied as a means to quantify surface temperature distributions around evaporating droplets. Eventually, these measurements will be used to check computed transient temperature profiles using models of the cooling process.

In analysis of fire protection systems, tables for a new handbook for calculating expected response times for thermally activated systems was produced. This work uses the latest available experimental correlation and extends previous work into the space directly above the fire.

\section{Publications}

Evans, D.D. and Pfenning, D. Water Sprays Suppress Gas-Well Blowout Fires, Oil and Gas Journal, Vol. 83, No. 17, April 29, 1985, pp. 80-86.

McCaffrey, B.J. Momentum Diffusion Flame Characteristics and the Effects of Water Spray, NBSIR in preparation.

McCaffrey, B.J. Jet Diffusion Flame Suppression Using Water Sprays - An Interim Report. Combustion Science and Technology; 1984; 40 (1-4): 107-136.

Milke, J., Evans, D.D., and Hayes, Jr., W.D. Water Spray Suppression of Fully-Developed Wood Crib Fires in Compartments, NBS Report of Test, FR 3956, January, 1985.

Hayes, Jr., W.D. Literature Survey on Drop Size Data, Measuring Equipment and Discussion of the Significance of Drop Size in Fire Extinguishment, NBSIR 853100 , January, 1985.

Budnick, E.K. Estimating Effectiveness of State-of-the-Art Detectors and Automatic Sprinklers on Life Safety in Residential Occupancies. Fire Technology; 1984 August; 20(3): 5-22. 
Evans, D.D. Calculating Sprinkler Actuation Time in Compartments. Fire Safety Journal, Vol. 9, 147-155, 1985.

Evans, D.D. and Stroup, D.W. Methods to Calculate the Response Time of Heat and Smoke Detectors Installed Below Large Unobstructed Ceilings, NBSIR 853167, February, 1985.

Stroup, D.W., Evans, D.D., Martin, P. Evaluating Thermal Fire Detection Systems, NBS Special Publication in preparation. 
FIRE PERFORMANCE AND VALIDATION

FIRE MEASUREMENT AND RESEARCH DIVISION

CENTER FOR FIRE RESEARCH

FY 85

\section{Professional Personnel}

Sanford Davis, Head

Emil Braun, Physicist

J. Newton Breese, Computer Programmer

Billy T. Lee, Fire Prevention Engineer

Richard D. Peacock, Chemical Engineer

J. Samuel Steel, Physicist

Huang Dingyi, Guest Worker (Shanghai Fire Research Institute)

J. P. (Rick) Jarvis, Guest Worker (Clemson University)

\section{Objectives}

The objectives are to develop the generic methodology for assessing the accuracy and limitations of fire models and measurement methods and to design and conduct tests to evaluate the fire performance of components, systems, and structures.

\section{Scope}

This work includes two important efforts: first, the conduct of unique, highly instrumented experiments to establish fire behavior on a realistic scale in order to contribute to model development and, second, the evaluation and validation of fire models by providing a mathematical tool for comparing experimental data with model outputs utilizing expertise in facility fire test experimental design, instrumentation, and data processing and analysis.

\section{$\underline{\text { Projects }}$}

\section{Validation of Fire Models}

The objective of this project is to develop the methodology for the evaluation and validation of fire models; it focuses on the development of mathematical and computational techniques for fulfilling this objective. With the large amount of data collected during the room/corridor tests including multiple tests run to develop statistical information on test reproducibility, the presentation of the data in a standardized graphical form is extremely important in the interpretation of the results.

Two software tools are in different stages of development to address this need. SPEEDY, a general purpose collection of FORTRAN routines to perform standard and specialized fire related calculations has been under 
development for several years. Another program, RAPID, is being developed as an interactive graphics facility to assist in the analysis of the large volume of fire data. One of the key issues to be determined in the validation process is the form the final assessment the validity of a model will take. While a single number may be a desirable result, a more realistic goal is to provide assessments of individual parameters.

Davies, A.D., Applied Model Validation, Nat. Bur. Stands. NBSIR 85-3154, May 1985.

Peacock, R.D., Davis, S., and Lee, B.T., Experimental Data for Model Validation, Nat. Bur. Stands., NBSIR in preparation.

\section{Smoke Transport Model Development}

The objective of this project is to provide support for continued development of the toxic hazard model by implementation of full-scale tests designed to measure transport of smoke and toxic gases, supporting efforts to model vertical smoke movement and to validate the horizontal transport model. With the completion of the townhouse, it is now practical to carry out full-scale experiments to measure smoke transport vertically, both up and down. Three series of experiments are being performed using a square wave output from a natural gas diffusion burner: open shaft, vent only, and vent with staircase. In addition to the burner experiments in the townhouse, furniture burns will be performed in the room/corridor facility; both the burn room and the target room have been instrumented for gas analysis and for animal exposure experiments.

\section{Upgrade of Large-Scale Testing Facilities}

The two story fire test facility (townhouse) in the large-scale fire research laboratory has been constructed and instrumented for measurement of temperature, smoke, gas concentrations, and pressure on each of two levels connected by an inside stairway. The windows on the second story open into an exhaust system which has the capability of measuring rate of heat release from any fire in the townhouse.

The NBS furniture calorimeter has been upgraded further during the past year. A larger hood, instrumented for smoke and soot sampling, has been installed and a new weighing platform was acquired. In addition to providing a means for obtaining data for free-burning fires (upholstered furniture, mattresses, trash, etc.), the new system will enable the study of small-scale fires for the nuclear winter project.

A new computer based data acquisition system has been installed in the full scale fire test facilities that has dramatically increased our data collection capabilities. The core of the new system is comprised of two Hewlett-Packard desk top computers that control all data collection and provide for graphics output on a large screen color monitor on the test floor. Related computer equipment includes a hard disk system for each computer, a printer connected to the two computers, a nine track tape drive for data storage, and an RS-232 interface for each computer connected to 
the NBSNET to transmit data directly to larger computers at NBS. Currently, two data collection stations (a 100 channel system and a 200 channel system) are available for test instrumentation on the test floor in Building 205.

4. Flame Spread on Walls

The objective of this project is to examine flame spread on selected wall materials in full-size room fires to provide a data base for the development and refinement of analytical models. This work complements small-scale work on flame spread (upward, downward, and lateral) both before and after flashover. A full-size room has been constructed on a weighing platform to monitor mass loss of the wall materials during the burning process. The experimental study is designed to analyze flame spread along a combustible wall surface using a controlled ignition source along the floor, in the corner, or at the wall/ceiling interface. The heat release and mass loss of the specimen can be monitored to determine the combustion efficiency of the burning material as the fire develops.

Lee, B.T., Effect of Wall and Room Surfaces on the Rates of Heat, Smoke, and Carbon Monoxide Production in a Park Lodging Bedroom Fire, Nat. Bur. Stands., NBSIR 85-2998, February 1985.

Lee, B.T., Evaluation and Refinement of Test Methods Used for Measuring Fire Hazards of Shipboard Hull Insulations and Mattress Insert Foams, Nat. Bur. Stands., NBSIR 85-3148, May 1985.

Lee, B.T., Standard Room Fire Test Development at the National Bureau of Standards, Amer. Soc. for Testing and Mat'1s., STP 882, Philadelphia, PA.

Lee, B.T., Quarter-Scale Room Fire Tests of Interior Finishes, Submitted to Fire and Materials.

\section{Fire Safety Aspects of Solid Fuels}

The objective of this continuing project is to study the hazards associated with the installation, operation, and maintenance of solid fuel burning appliances used for space heating in single family dwellings and in similar small scale applications. The overall research program included the evaluation of a number of different protection systems designed to shield combustible wall and ceiling surfaces from the effects of radiant energy from hot stove and chimney connector surfaces and has resulted in a predictive model for heat transfer from solid fuel appliances. Another aspect of the program included the evaluation of a number of different types of thimbles or wall pass-through systems which will, in effect, help maintain the surface temperature of combustibles in the walls within code acceptable temperature rise limitations throughout the exposure.

Two parallel studies, both funded by CPSC, will continue into next year. One effort will study the effects on safety of the use of new high efficiency combustion devices becoming available in the wood heating industry. The primary concerns are the buildup of creosote in chimneys 
(to be determined quantitatively with a specially built chimney) and the thermal load lmposed on the surroundings by the devices. The other effort will evaluate the safety of the installation of the fireplace inserts in a code acceptable fireplace, a study which complements earlier grant research funded through CFR by DOE which studied fireplace inserts in a minimum code specified fireplace.

Loftus, J.J., and Peacock, R.D., Evaluation of Thimble-Chimney Connector (Wall Pass-Through) Systems for Solid Fuel burning Appliances, Nat. Bur. Stands., NBSIR 84-2969, November 1984.

Loftus, J.J., and Peacock, R.D., Clearances and Methods of Protection for Wall and Celling Surfaces Exposed to Radiant Heating Appliances, Nat. Bur. Stands., NBS Technical Note 1205, December 1984.

Peacock, R.D., and Dipert, R.A., STOVE: A Predictive Model for Heat Transfer from Solid Fuel Appliances, Nat. Bur. Stands., NBSIR in preparation.

Peacock, R.D., Chimney Fires: Intensity and Duration, Submitted to Fire Technology.

\section{Miscellaneous}

Last year, it was reported that we carried out a testing program for the Veterans Administration to evaluate their building concept for hospital construction. The final report has been published.

Lawson, J.R., Fire Performance of Interstitial Space Construction System, Nat. Bur. Stands., NBSIR 85-3158, May 1985.

A short-term project was carried out for the Nuclear Regulatory Commission to provide a mechanism for estimating the impact of miscellaneous fires in nuclear power plants.

Lee, B.T., Heat Release Characteristics of Some Combustible Fuel Sources in Nuclear Power Plants, Nat. Bur. Stands., NBSIR 85-3195, July 1985. 
FIRE RESEARCH INFORMATION SERVICES

CENTER FOR FIRE RESEARCH

FY 85

\section{Project Leader}

Nora H. Jason

\section{Program Objective}

The Fire Research Information Services (FRIS) is an on-going project within the Center for Fire Research (CFR), National Bureau of Standards. It was started in 1971 and incorporated several personal collections at the National Bureau of Standards, as well as the Federal Fire Council collection. Over the years, it has grown and now contains approximately 30,000 reports, documents and books. (On an average, 1500 items are added to the collection each year.) It reflects the programmatic needs of the Center for Fire Research, as well as developing a national and international fire research collection for use by NBS staff, researchers, fire departments, fire science students and the fire community at large.

One of the major obstacles in fire research has been accessing fire research information. Although the FRIS collection is one of the most complete, it only has been a manual system and, therefore, not readily accessible to the fire research community. The first step has been initiated toward filling this gap. FRIS has begun to automate its collection and the on-line bibliographic database is called FIREDOC. This is a new project and once the pilot implementation phase of the database is tested, and the feedback from the users in the fire research community has been assessed, all current bibliographic records and then retrospective records will be incorporated into FIREDOC.

An extensive document distribution program is carried on, both on a regular basis and on a demand basis. The publication and distribution of grantee reports (in the NBS Government Contract Report series) to selected subject interest groups is part of this program. All NBS report series are listed in the automated bibliographic data base and available through the Government Printing Office of the National Technical Information Services.

The journal collection contains approximately 100 titles. The focus is on the research activities of the CFR, as well as fire-related research needs. The titles are quite unique to FRIS.

For interested people who cannot come to the FRIS, an extensive interlibrary loan program is carried out with participating libraries throughout the United States. FRIS is located at the National Bureau of Standards, Building 224, Room A-252. The telephone number if (301)921-3249. 


\section{Professional Personnel}

Harold E. Nelson, Head

Daniel Gross, Research Engineer

Richard L. Smith, Knowledge Engineer

W. Douglas Walton, Fire Protection Engineer

Pam Ward, Computer Specialist

\section{Program Objectives}

To provide for the expedient transfer of scientifically based technology to the professional applications community and provide a point of interface between the computer based activity of the Center for Fire Research and others doing similar or complimentary work.

\section{Scope}

The work addresses development of engineering systems for design application, and the development of expert systems, the collection of the supporting data and programs, and the operation of a working and training laboratory dedicated to computer modeling and other fire safety computations.

\section{Projects}

1. Engineering Method Development. The purpose of this project is to assemble, adjust, coordinate existing data, models, physics, and other needed elements to develop engineering methods useable by fire protection engineers and others involved in building design. The object is a progressive evolution of a fire protection engineering technology based on scientific investigation and technical experiments undertaken by NBS and others in the fire research community. The overall approach is to develop validated engineering methods for appraising fire safety in buildings or design and the impact of specific fire criteria proposals. The program is designed to produce a progressively expanding set of capabilities with useful methods becoming available in the near future. The program has a three level approach. Some work is already underway in levels one and two. The levels are as follows:

Level One: Assessment of life safety within a reasonably large space which includes the area of fire origin (eg: auditoriums, hospital wards, offices, laboratories, machine shops, and similar spaces.)

Level Two: Assessment of life safety and the mitigation of damaging fire effects in a facility involved in a series of connected rooms and spaces on a single floor (eg: hospital nursing unit, and similar divided spaces.) 
Level Three: Assessment of life safety, mission continuity, and property value risk covering multistory conditions.

Currently the majority of this effort is supported by funds from the Air Force. The development of an algorithm covering through level two is targeted for the current year and an initial system providing support to Air Force designers is targeted for completion the following year and proofing in the third year.

2. Fire Simulation Laboratory. For more than a decade researchers have been developing computer programs to predict or model the growth of fire and its effects in buildings. Although the variety of fire scenarios which can be addressed with these computer programs is limited at present, there is a growing interest in the fire protection community in adapting these computer programs for specific needs.

This interest, and the need for efficient transfer of recently developed technology in computerized fire simulation, has prompted the Center for Fire Research (CFR) to establish a Fire Simulation Laboratory (FSL). This laboratory is a place where individuals from the private sector, Federal, state and local government agencies, academic institutions and others can utilize computer programs, state of the art graphics, video and reference materials, and associated data bases to:

(1) further develop computer fire modeling programs and integrate them with data.

(2) demonstrate the capability of computer fire models to address fire questions and issues.

(3) provide training in the use and application of fire simulation techniques, and

(4) 'provide answers to fire problems.

The laboratory will be used: by fire researchers to augment their experimental programs; by fire protection engineers to assist in the design of building fire protection systems; by architects to develop building layouts that simplify fire safe design; by fire and building code officials to help in evaluating fire safety and determining code equivalency; by material manufacturers to explore the significance of the fire properties of materials; by the fire service to explore fire fighting tactics and preplans and as a training aid; by fire investigators to reconstruct fire scenarios and by fire educators to develop course material.

The laboratory currently contains 4 personal computer work stations, two high resolution graphics work stations, a special minicomputer for symbol manipulation programs, a digitizing table for entering building design data, a plotter and a printer. The work stations are connected to the CFR minicomputer and the planned computerized data base in the Fire Research Information Service. A future connection will be made to the new NBS main frame computers. 
Computer programs being made available for use and development in the laboratory address room fire growth, fire and smoke transport through buildings, building structural fire protection, escape and rescue, and sprinkler response. Special graphic disolay programs are also available. A preliminary data base for use with some of the programs is being assembled.

To introduce potential users to fire simulation and prediction techniques and to the laboratory a series of workshops will be held at the laboratory. The workshops will be tailored to specific user groups and will include "hands on" use of selected computer programs. The first trial workshop is scheduled for late October.

3. Data Sources for Predictive Modeling. The object of this project is to recommend sources of data on materials, products and processes for use in predictive modeling of fire growth and smoke transport.

This project is reviewing the types of inputs specified in current predictive models of fire growth and smoke transport and identify (a) published sources for basic property and engineering data, and (b) available and preferred test methods which measure specified responses to heat and flame. A principal output will be a data catalog of the thermophysical properties of materials and of selected fire responses of combustible contents.

4. Expert Systems. This new project has as its objective to develop a computer program which will make an expert estimate of the fire safety of a building based on CFR's deterministic physical models, technical data, and expert judgment. It will have the capability to explain any conclusions it makes. In addition, it should be readily useable by CFR's clients.

The approach being used is to write a computer program using a LISP machine and state-of-the-art expert system development software tools. The approach is to base an expert system on a methodology similar to the one used in the report "Credible Engineering Methodologies" by H.E. Nelson. The particular expert systems developed will be determined by selecting appropriate subjects for the construction of expert systems and are important to the fire community. Our initial expert is $\mathrm{H}$. Nelson.

During the first year of this project, considerable time and effort were spent on the selection and ordering of the LISP computer and state-of-theart expert system development software tools. In addition, a demonstration expert system (ASKBUDJR) was developed on a personal computer. It was written in a subset of command LISP. While it does not have all the features of a real expert system, it has some of them such as a forward chaining procedure and a frame data base representation. More importantly, the development of ASKBUDJR lead to considerable insight on the possible knowledge representation for the larger, more sophisticated system.

\section{Publications}

Gross, D., "Data Sources for Parameters Used in Predictive Modeling of Fire Growth and Smoke Spread", NBSIR 85-3223. 
Nelson, H.E., Jefferson National Memorial Historical Site Analysis of Impact of Fire Safety Features, National Bureau of Standards, NBSIR-84-2897, Gaithersburg, MD, March 1985.

Nelson, H.E. and Shibe, A.J., The Development of A Fire Evaluation System for Detention and Correctional Occupancies, National Bureau of Standards, NBSIR-84-2976, Gaithersburg, MD, December 1984.

Walton, W.D., The User's View of Computer Hardware and Software, SFPE Bulletin 84 (4), 1-4, October 1984.

Walton, W.D. and Twilley, W.H., Heat Release and Mass Loss Rate Measurements for Selected Materials, National Bureau of Standards, NBSIR 84-2960, Gaithersburg, MD, December 1984.

Walton, W.D., ASET-B A Room Fire Program for Personal Computers, National Bureau of Standards, NBSIR 85-3114, Gaithersburg, MD, April 1985.

Walton, W.D., The User's View of Computer Hardware and Software, Fire Safety Journal, 9(1\&2), 3-6, May/July 1985. 


\section{FLAMMABILITY AND TOXICITY MEASUREMENT \\ CENTER FOR FIRE RESEARCH \\ FY85}

\section{$\underline{\text { Professional Personnel }}$}

Vytenis Babrauskas, Head

John F. Krasny, Textile Technologist

Barbara C. Levin, Toxicologist

Maya Paabo, Research Chemist

Joan Rotoloni, Textile Technologist

Trudi Holt, Guest Worker, University of Pittsburgh

Joshua L. Gurman, Research Associate (AISI)

Joseph V. Rutkowski, Postdoctoral Associate

\section{Program Objectives}

To develop measurement methods and the underlying principles for characterizing the combustibility of furnishings and building materials and the impact of the combustion products on living organisms.

\section{Scope}

Typical efforts of this group include:

- assessing the appropriate applications of the NBS toxicity screening test method

a determining the extent to which a limited number of gases determine the lethality of combustion products

- developing a rationale and the methodology for predicting soot and specific gas production in full-scale fires from bench-scale methods

口 exploring possible alternatives to animal testing for measuring the impact of combustion products on people

a generating a valid, detailed model for the burning of upholstered furniture

- producing a data base for the burning parameters of various furnishings for use in fire hazard models

a developing an appropriate measurement methodology for the propensity of cigarettes to ignite soft furnishings

a reinforcing the relationship of combustion in the cone calorimeter to large scale burning and aiding the promulgation of the cone calorimeter for engineering and code applications

\section{Background}

This group was formed in April 1985 by combining the group previously studying burning rate properties and furniture flammability, and the group studying fire toxicity and bioassay methods. By doing so, the Center is placing greater emphasis on the integration of engineering and biologic measures, with the goal of providing a unified basis for describing the fire properties of materials. 


\section{Projects}

1. Heat release rate and related properties of materials

The focus in this area is measurement of materials properties in the cone calorimeter. This instrument was initially developed for heat release rate studies. Over the last two years the capability was added to do both smoke obscuration and soot mass characterizations. In addition, data are regularly taken on ignitability, mass loss rate, and the production of a number of gas species. A task group in ASTM subcommittee E5.21 has been working on developing an ASTM standard based on the cone calorimeter. As a parallel effort, in the international community, ISO TC92 SC1 WG5 (the ISO working group on heat release rate) has made a decision to develop the cone calorimeter into an ISO standard. Work has been started on correlations of smoke production, as measured in the cone calorimeter, and in full scale. Initial results on upholstered furniture are very encouraging in this area.

Babrauskas, V., Bench-scale Methods for Prediction of Full-scale Fire Behavior of Furnishings and Wall Linings, Technical Report 84-10, Society of Fire Protection Engineers (1984).

\section{Upholstered furniture flammability}

A concerted effort in the area of furniture flammability has been going on at the Center for ten years. Due to this intense activity, what was a decade ago an area with little systematic or quantitative knowledge has become tractable for routine fire engineering purposes. Much of this experimental and analytical work at NBS, in addition to the quantitative work reported in the literature has been distilled into an applications-oriented monograph, issued this Fall. Work is also continuing in a number of areas: mattress heat release rate full-scale/bench-scale correlations, post-flashover studies, comparability of ignitability measures in the cone calorimeter and in open flame ignition tests, and furniture frame effect studies.

Krasny, J.F., and Babrauskas, V., Burning Behavior of Upholstered Furniture Mockups, I. of Fire Sciences. 2, 205-235 (1984).

Babrauskas, V., Pillow Burning Rates, Fire Safety J. ㅇ, 199-200 (1984/85).

\section{Cigarette ignition study}

Over a third of residential fire casualties are caused by cigarettes dropped inadvertantly on upholstered furniture and mattresses. To reduce this toll, Congress passed the "Cigarette Safety Bill" in October 1984. Its objective is to study the feasibility of producing commercially acceptable cigarettes with a significantly lower propensity to ignite soft furnishing substrates than the majority of present brands. The Flammability and Toxicity Measurement group is charged with preparing a report on the state of the art in understanding cigarette ignition of soft furnishings, as well as with carrying out an extensive experimental program. Initially, a number of commercial cigarette brands will be ranked by placing them on upholstered substrates varying in 
cigarette ignition resistance, and noting ignition or non-ignition, as well as time-weight loss curve characteristics. The common characteristics of the cigarettes with a relatively low ignition propensity will be established, and will form the basis for designing experimental cigarettes with those characteristics varied systematically. Evaluation of the experimental cigarettes should bring further insight into the mechanism of cigarette ignition. Simultaneously, other programs at CFR are performing experiments to establish thermal conditions around burning cigarettes, their energy transfer to substrates, and the ensuing ignition process. Attempts will be made to model this process mathematically, with a view towards identifying means to interfere with substrate ignition by cigarettes.

\section{Toxicity Measurement Method Development}

The Center for Fire Research has developed a test method to assess the acute inhalation toxicity of combustion products from materials thermally decomposed under specific laboratory conditions. Although this test screens materials under presumed worst case (but still realistic) flaming and non-flaming conditions, it does not subject materials to all fire conditions. Other limitations noted in the report on the test method (NBSIR 82-2532) included the amount of material which can be tested, the lack of mass monitoring, the restriction to small samples in one fixed orientation, and the lack of knowledge of oxygen conditions at the specimen.

These limitations have been examined and addressed in the past year. The capacity of the quartz beaker that is now routinely used is $1000 \mathrm{~m}$ l and it does allow at least 8 grams of flexible polyurethane foam to be tested. This amount of foam is equivalent to a concentration of $40 \mathrm{mg} / \mathrm{l}$, which is higher than concentrations of toxicological concern. The furnace has also been modified such that continuous mass loss will be possible during material decomposition. We now have the capability to provide aeration to the combustion site and to monitor the oxygen concentration in the cup furnace. While there are still problems in the examination of assemblages of non-uniform structure in the cup furnace, a recent study has shown that such testing is possible.

In addition, a new combustion system, which is a modification of the cone calorimeter developed by the Center for Fire Research to measure the rate of heat release, has been designed. This new radiant energy system will permit the evaluation of materials under a variety of combustion conditions and measure the effects of these conditions on toxicity. This cone radiant furnace is now built and connected with an animal exposure chamber. Individual and composite materials may be tested in both vertical and horizontal orientations. In addition, the new system is designed to provide continuous mass loss measurements and to allow square wave exposures of the animals.

Levin, B. C., Paabo, M., Fultz, M. L., Bailey, C., Conditions conducive to the generation of hydrogen cyanide from flexible polyurethane foam. Proceedings of 7 th UJNR conference, October 1983, NBS, published March 1985.

Levin, B. C., The National Bureau of Standards Toxicity Test Method, Fire Technology. 21, 134-145 (1985). 
Levin, B. C., The National Bureau of Standards Toxicity Test Method. Proceedings of the Spring Conference of the Fire Retardant Chemicals Association, November 1984.

\section{Toxicological Effects of Pure Gases and Mixtures of Gases}

The focus on pure gas studies during the past year has been largely on hydrogen cyanide. Experimental studies were necessary since there have been limited studies examining the effects of short term acute inhalation exposures. In our work, Fischer 344 male rats received square wave exposure to preset atmospheric concentrations of HCN mixed with air such that oxygen deprivation did not contribute to the toxicity. The NBS smoke toxicity exposure chamber was used for these tests, modified so as to allow delivery and measurement of gaseous materials. LC $_{50}$ values (the concentration of HCN necessary to kill $50 \%$ of the animals during the exposure and a 24 hour post-exposure period) were determined for exposure times ranging from 1 to 60 minutes and found to be 3010 ppm for 1 minute, $1570 \mathrm{ppm}$ for 2 minutes, $570 \mathrm{ppm}$ for 5 minutes, $290 \mathrm{ppm}$ for 10 minutes, $170 \mathrm{ppm}$ for 20 minutes, $110 \mathrm{ppm}$ for 30 minutes and $86 \mathrm{ppm}$ for 60 minutes.

The toxicity of fire gases also needs to be studied to determine whether the toxic effects of a material's combustion products can be explained by the interactions of the major fire gases or if minor, more obscure gases need to be considered. $\mathrm{LC}_{50}$ values for $\mathrm{Fischer} 344$ rats have been determined for carbon monoxide (CO) in air for 10, 20, 30, and 60 minute exposures using the NBS Toxicity Test Method. Similar $\mathrm{LC}_{50}$ values have been calculated for hydrogen cyanide ( $\mathrm{HCN}$ ) in air. Combination experiments of $\mathrm{CO}$ and $\mathrm{HCN}$ indicated that they act in an additive manner. Non-lethal concentrations (1-5\%) of carbon dioxide $\left(\mathrm{CO}_{2}\right)$ in combination with sublethal concentrations of CO caused death of the rats. Decrease of the oxygen $\left(\mathrm{O}_{2}\right)$ concentrations in the presence of various combinations of the major toxic fire gases increased the toxicity even further. Examination of the combustion products from some materials tested at their $\mathrm{LC}_{50}$ values indicated that the observed toxicity could be explained by the interaction of the main toxic fire gases. These results on the toxicological effects of multiple fire gases are being used in the development of a computer model for predicting the toxic hazard that people will experience under various fire scenarios.

Levin, B. C., Paabo, M., Bailey, C., Harris, S. E., and Gurman, J. L., Toxicological effects of the interactions of fire gases and their use in a toxic hazard assessment computer model. The Toxicologist. 5, 127 (1985).

Levin, B. C., Procell, L., Gurman, J. L., Paabo, M., Baier, L., Braun, E. and Newball, H. H., Physiological response of rats to acute inhalation exposures of hydrogen cyanide. Proceedings of the Fifth Annual Chemical Defense Bioscience Review, sponsored by the U. S. Army Medical Research Institute of Chemical Defense, Johns Hopkins Applied Physics Laboratory, Columbia, MD, May 29-31 1985. 
6. A Review of the Literature on the Gaseous Products and Toxicity Generated from the Pyrolysis and Combustion of Seven Plastics

A survey and a detailed review of the literature on the thermal decomposition products and inhalation toxicity of seven plastics commonly found in residential homes are being done under the sponsorship of the Consumer Product Safety Commission (CPSC). The materials being examined are poly(vinyl chloride), polystyrene, nylon, polyethylene, ABS, polyester, and rigid polyurethane.

Braun, E., and Levin, B. C., Polyesters: A review of the literature on products of combustion and toxicity, NBSIR 85-3139, June 1985.

\section{Associated Grants}

1. Argonne National Laboratory, Joseph R. Stetter - Feasibility of Field Detection and Analysis of the Toxic Products of Combustion.

2. Brown University, Merwin Sibulkin - Study of Effects of Material Properties on Flaming Combustion of Charring Fuels.

3. Factory Mutual, Archibald Tewarson - Development of a Model to Provide Comprehensive Fire Property Data.

4. The Johns Hopkins University School of Hygiene and Public Health, Zoltan Annau - Simulation of Escape from Toxic Gases Using an Animal Model.

5. Southwest Research Institute, Gordon Hartzell - Analysis of Hazards to Life Safety in Fires.

6. University of Dayton Research Institute, Mark Dietenberger - Mathematical Modeling of Furniture Fires.

7. University of Mississippi, Arthur S. Hume - Study of Some Aspects of the Toxicology of the Inhalation of Carbon Monoxide and Cyanide in Fire Victims.

8. University of Pittsburgh, Yves Alarie - Toxicity of Plastic Combustion Products. 


\section{HAZARD ANALYSIS \\ FIRES SAFETY TECHNOLOGY DIVISION \\ FY 85}

\section{Professional Personnel}

Richard W. Bukowski, Head

Daniel M. Alvord, Computer Specialist

Bernard M. Levin, Research Psychologist

Walter W. Jones, General Physical Scientist

A. Jeffrey Shibe, Research Fire Protection Engineer

S. Wayne Stiefel, Operations Research Analyst

John H. Klote, Mechanical Engineer

Keith Wayland, Visiting Professor (Univ. of Puerto Rico)

\section{Program Objectives}

To develop predictive, analytical methods which enable the quantitative assessment of hazard and risk from fires.

\section{Scope}

The predictive methods being developed are based on numerical modeling but, also include hand calculation methods for estimating hazards and production of design curves/tables for use by architects and engineers. To ensure use, necessary data must be readily available and data input and presentation must be in terms readily understandable by the average professional. Thus, the projects include a strong emphasis on state-of-the-art computer graphics and computer aided design techniques.

\section{Projects}

\section{Toxic Hazard Assessment Models}

The objective of this project is to develop quantitative methods to predict the development of occupant hazard in building fires. This involves the synthesis of many of the activities in the center such as modeling, toxicity, test methods and data production, suppression, and evacuation/human behavior into a coordinated approach which can be used for practical problem solving. Considerable progress has been made in identifying the key elements and structure of such a procedure and developing the necessary capabilities of each. An example is the initial work conducted this year on the development of a hybrid transport model which combines zone modeling in the region near the fire where buoyancy dominates and network modeling in the remainder of the building where flows are the result of HVAC, stack effect and wind forces. Such a hybrid model provides the level of detail necessary for hazard determinations while providing efficiencies in computer facilities needed for analysis of large, complex structures.

In addition to enhancements in the technical base, progress has been made in the useability of the models. A simplified user guide for FAST (V17) has been prepared and a "pilot" data base report containing resource information 
on required input data for many common materials has been compiled. Work on an interactive input program has been initiated and the output graphics has been extended to three dimensional representations of the structure.

Bukowski, R.W. and Jones, W.W., "The Development of a Method for Assessing Toxic Hazard", Fire Journal, Vol. 79, No. 2, 24-26, 28-29, 82, March 1985.

Bukowski, R.W., "Evaluation of Furniture Fire Hazard Using a Hazard Assessment Computer Model", to be published in Fire and Materials.

Bukowski, R.W., "The Application of Models to the Assessment of Fire Hazard from Consumer Products, NBSIR 85-3219, NBS Gaithersburg, MD 20899, August 1985.

Bukowski, R.W., "Toxic Hazard Evaluation of Plenum Cables, Fire Technology, Vol. 21, No. 4, November 1985.

\section{Building Smoke Transport Model}

This work consists of development of a hybrid (zone/network) computer model to simulate smoke movement throughout large buildings including simulation of the effects of HVAC systems, smoke control systems, inside to outside pressure difference, wind and smoke buoyancy. This model is to simulate the movement of near ambient temperature ("cold") smoke based on the perfect mixing assumption. The movement of buoyant ("hot") smoke in the vacinity of the fire and in transitions between cold and hot is to be simulated by the well known zone approach. In the initial phases of the project a survey of users of fire and smoke computer programs will be conducted to determine the strengths and weaknesses of different models and the potential applications for the hybrid model.

In recent years, the possibility of using elevators as a means of fire escape has received considerable attention from the fire protection community. This project is a joint. effort between NBS and the National Research Council of Canada to investigate the feasibility of elevator smoke control systems.

A study has been conducted which evaluated several possible elevator smoke control systems by means of the NBS computer program ASCOS. The potential problem due to pressures produced by moving elevator cabs was identified. An analysis of this elevator "piston effect" was developed and tests were conducted in the United States and Canada which verify that theory.

Full scale fire tests of elevator smoke control are planned for the near future at the NRCC test tower near Ottawa.

Klote, J.H. and Tamura, G., "Smoke Control and Fire Evacuation by Elevators", submitted to ASHRAE Transactions for publication.

\section{Evacuation Modeling}

Over the past year the work in this area has concentrated on two areas: improvments to the Escape and Rescue Model and initial work on a model for human behavior. 
The Escape and Rescue Model was originally developed in support of the Fire Safety Evaluation System for Board and Care Facilities. It consists of a network (node and $a r c$ ) model which simulates occupant evacuation from large, multi-story buildings and includes (as the title states) both escape by able persons and the need for personal alerting or rescue of persons not capable of self-evacuation. Primary improvements accomplished this year include conversion of the computer code to FORTRAN 77 (to provide portability to many computers) and the capability to run the code interactively. An option to print a very detailed trace of the evacuation process has also been added.

The human behavior model is an attempt to include within the evacuation process, commonly reported actions of people in fire situations. An example of such actions is the tendency of males to investigate rather than escape when presented with an ambiguous fire cue (e.g. smell smoke as opposed to seeing something burning). The behaviors included are largely based on the observations of Keating in his interviews of fire survivors. While presently written in BASIC as a stand-alone program, the intent is to include this within the overall evacuation model.

Alvord, D.M., "Status Report on the Escape and Rescue Model and the Fire Emergency Evacuation Simulation for Multifamily Buildings", NBSGCR-85-496, NBS, June 1985.

\section{Smoke Transport Modeling}

Modeling the growth and spread of fire and the movement of smoke and toxic gases is the primary objective of this project. The work is based on a theory which considers the "far field" of a fire and thus we look primarily at spread and flows which are near a fire, although outside of the compartment of origin. The goal is two-fold. The first part is to provide a connection between models which consider the "near" field or room of origin and those which look at the "far" field effects and are known as network models. These latter are primarily smoke control and HVAC models. Also of interest are the evacuation models which will need this type of information in order to provide true personnel simulations. The second goal is connecting laboratory scale experiments with full scale tests, the goal being to provide an estimate of what will happen in a fire based on experiments which can be conducted in laboratory sized equipment. If successful, this application of the model will allow a great economy of scale as we will be able to reduce the amount of full scale testing that needs to be performed on materials and structural configurations used in buildings and ships.

Vertification of these models and extensions to them are an ongoing process. Currently there are several full scale (single floor and multifloor) experiments ongoing at NBS and elsewhere which provide verification of the model(s). In addition, as each piece of the model is validated, new work can commence. Examples are addition of self-consistent buring objects (pool fires and furniture) and addition of HVAC and smoke control.

Much of the effort has gone into developing numerical software which is both fast and reliable, and basic tools which will allow us to provide better algorithms. In the future we will concentrate more on physical aspects of this problem and look at additional ways of understanding it. 
Jones, W.W., "A Multicompartment Model for the Spread of Fire, Smoke and Toxic Gases", Fire Safety Journal 9,55 (1985).

Jones, W.W. and Bodart, X., "Buoyancy Driven Flow as the Forcing Function of Smoke Transport Models", to be published as an NBSIR (1985).

\section{Computer Graphics}

The purpose of this task is to support the modeling effort by providing output which is readily useable. A secondary purpose is use of graphics in providing in-situ visualization of experimental data to aid in understanding what processes occur as a fire grows and spreads, both in laboratory as well as full scale tests. We are working with state-of-the-art equipment and software, much of the latter being developed in-house. A primary goal is to be able to show smoke spread through a building in real time in a three-dimensional animation sequence.

Jones, W.W. and Fadell, A.B., "A Device Independent Graphics Kernal, NBSIR (in review).

\section{Associated Grants and Contracts}

1. Edward Zukoski - Cal Tech, "Experimental Study of Environment and Heat Transfer in a Room Fire."

2. Edward Wahl - Federal Emergency Management Agency (FEMA), "Major Fire Investigations."

3. Carl M. Harris - University of Virginia, "Methods for Enhancement and Evaluation of Fire Risk Assessments." 


\section{CENTER FOR FIRE RESEARCH \\ NATIONAL BUREAU OF STANDARDS \\ FY 1985}

Institution: Division of Engineering, Brown University

Grant No: $\quad 60$ NANB4D0036

Grant Title: A Study of the Effects of Oxygen, Transport and Temperature History on the Chemistry of PMMA and Cellulose Pyrolysis

Principle Investigator: Eric Suuberg

Division of Engineering

Brown University

Providence, RI 02912

(401) $863-1420$

Other Professional Personnel: T. Kelly (Graduate Student)

W. Lilly (Research Engineer)

NBS Scientific officer: Dr. Takashi Kashiwagi

Technical Abstract:

The goal of this project is an elucidation of the effect of several key variables on the chemistry of pyrolysis of polymethyl methacrylate (PMMA) and cellulose. These variables include the heating rate of the sample, the partial pressure of oxygen at the surface of the sample, and those sample characteristics that affect the transport of pyrolysis products out of the sample. Detailed product analysis of both vapor and condensed phase products of pyrolysis will be used to infer under what conditions already established or suggested chemical mechanisms may or may not be applied to fire modeling situations. In the case of PMMA, vapor products mainly consist of monomer. The condensed phase products are characterized by gel permentation chromatography (GPC), providing information concerning the degree of polymerization as a function of cited variables. The analysis of vapor and liquid products of cellulose pyrolysis is somewhat more complex. Particular attention will be given to characterization of what are commonly called "tar" products, since these are the products that represent the most combustible vapor products. GPC will be used to characterize these materials, providing information about molecular weight distributions and hence, vapor pressures of the products.

This project is presently at the midpoint of its first year. Efforts to date have been devoted mainly to preparing necessary equipment and analytical procedures. The initial focus of the work is PMMA pyrolysis. Later stages of the project, involving cellulose pyrolysis, will be coordinated with another NBS sponsored project at Brown, concerned with rates and heats of retarded and unretarded cellulose pyrolysis. Particular attention will also be given to oxidative low heating rate pyrolysis of cellulose. 
The work on PMMA pyrolysis has involved examining thin (solution cast) films of Plexiglas $G$ heated at rates of $5 \mathrm{~K} / \mathrm{min}$ up to temperatures of approximately $625 \mathrm{~K}$. This combination of conditions has been chosen for the initial phases of this project to provide comparison with recent work at the Bureau. The work at the Bureau has shown that oxygen transport into films of $200 \mu \mathrm{m}$ thickness is not rate limiting, but that monomer transport outward may be rate controlling with such thickness. This is consistent with earlier reports that suggested the possibility of mass transfer resistance in $50 \mu \mathrm{m}$ thick films. Our preliminary results confirm that there is significant impediment to escape of de-polymerization fragments (mainly monomer) in films of approximately $50 \mu \mathrm{m}$ thickness. Even in such thin films, bubbles are seen to nucleate during pyrolysis.

The above results naturally imply that the apparent rate of vaporization of the polymer will be strongly influenced by the rate at which monomer can diffuse through the polymer, and by the fluid properties of the degrading polymer melt (as affects bubble motion). To address these issues, measurements of monomer diffusion coefficients in the polymer are to be performed. Also, the validity of assuming a classical ceiling temperature (471K) in modeling PMMA pyrolysis will be examined by use of special monomer impregnated samples (by monitoring their molecular weight distributions as a function of temperature history). These data are essential to construction of an appropriate combined chemical reaction-mass transfer limited model of pyrolysis that accounts for a variety of important physical phenomena, that simple chemical kinetic models cannot predict.

The influence of oxygen on the pyrolysis of PMMA has been shown to be somewhat dependent on the nature of the starting material. This study will also examine the influence of low concentrations of oxygen on the pyrolysis of PMMA samples of various initial characteristics.

The extent to which the suggested chemical and transport mechanisms are sensitive to heating rate will also be addressed. The question is whether the kinetics of vapor release and the molecular weight distributions of depolymerization fragments deduced at one heating rate may be confidently extrapolated to another. An apparatus has been constructed which permits us to examine the range of heating rates from a few degrees per minute to thousands of degrees per second, allowing examination of any possible heating rate conditions of interest in fire situations.

Reports and Papers:

None as of this writing. 
CENTER FOR FIRE RESEARCH

NATIONAL BUREAU OF STANDARDS

FY 1985

Institution: Division of Engineering, Brown University, Providence, R.I. Grant No.: NB83NADA4025

Grant Title: Soot Dynamics in Flames

Principal Investigator: Professor R. A. Dobbins

Division of Engineering

Brown University

Providence, R.I. 02912

Telephone: (401) 8631422

Other Professional Personnel: Mr. Constantine Megaridis (Ph.D. Student)

NBS Scientific Officer: Dr. George Mulholland

Technical Abstract:

We seek a deeper understanding of the aerosol dynamic processes which control the behavior of the soot aerosol present within flames as well as in the smoke which they release. To this end we have developed soot sampling methods to provide a high degree of spatial resolution which are based on the thermophoretic effect. The soot particles are captured both on grids and on bulk specimen carriers, serving as thermophoretic probes, for examination by transmission (TEM) and scanning (SEM) electron microscopy, respectively. In particular we examine the regions of the laminar ethene diffusion flame where the processes of coagulation act in concert with particle formation, surface growth, oxidation or release from the flame. Morphological features which are readily determined are spherule size and state of agglomeration. Image observations are compared with predictions of solutions to the aerosol dynamic equation that include terms which describe the above processes. The method yields information to supplement the optical observations which provide excellent data on soot volume fraction but which provide no information on soot morphology. Early observations show quantitative behavior of soot spherule size as a result of surface growth and oxidation.

I. THEORETICAL STUDIES OF THE AEROSOL DYNAMIC EQUATION APPLIED TO SOOT IN FLAMES

The aerosol dynamic equation has been modified by the inclusion of a particle source term and a particle surface growth term. This integrodifferential equation is approximately solved by two techniques. The first method is an integral solution which is rapid and which is well adapted to accept experimental observations. In the integral solution the particle size distribution function is assumed to be $\log$ normal and its predictions are compared with those of a second approximate solution using the MAEROS code of Gelbard (Ref. 1). These two methods of solution provide a theoretical framework to interpret the experimental results. 
Detailed calculations to simulate the development of the soot aerosol will be made when further data becomes available. However, interesting trends are revealed by the integral solutions and provide important insight into the effect of the flame processes on the soot aerosol size distribution.

(1) In the lowest portion of the flame where particle production is strong, there exists a quasi-equilibrium between the production and the coagulation terms. The second moment of the size distribution function which determines its width, under quasi-equilibrium conditions grows through the cooperation of the formation and coagulation terms. Thus a broad size distribution is almost instantaneously formed in the lowest region of the flame where particle formation is strong.

(2) The presence of free molecular surface growth implies that the rate of increase of particle radius is independent of particle size. Significant growth under these conditions means that the size distribution is made more narrow. Conversely it appears that the impact of surface oxidation attack is to broaden the size distribution as the mean size is decreased. The size of the primary particles or spherules is an excellent measure of the surface growth and surface oxidative attack. The EM observations provide a high quality determination of spherule size.

An improved bimodal integral solution is being developed to improve the representation of the integral solution in the region of the flame where the particle formation is strongest.

\section{EXPERIMENTAL STUDIES OF THE SOOT AEROSOL BY ELECTRON MICROSCOPY}

On experimental aspects there has been progress toward understanding the capabilities and limitations of the thermophoretic probe method. Although the method of thermophoretic sampling has been used by others (Ref. 2, 3, 4) the details relating to spatial and temporal resolution have been overlooked in the past. The availability of the bulk specimen carrier with the Philips 420 STEM provides an excellent probe device. The carrier is a strip of metal of dimensions $3.5 \times 11.0 \times 0.1 \mathrm{~mm}$. We have found that the deposition of $200 \mathrm{~A}$ thick layers of chromium and gold inhibits the formation of alloy or oxide droplets on the surface when the probe is subjected to flame temperatures. A positioning device has been constructed which allows a soot sample to be collected over variable exposure times. The device consists of a chuck, which is energized by an electromagnet and retracted by a spring force and is capable of supporting the probe which is either the conventional EM grid, a fine mesh of $3 \mathrm{~mm}$ diameter, or the bulk specimen carrier. The probe is introduced with its flat surface parallel to the streamlines in order to minimize the interference with the flame flow field. Transit time of the probe into and out of the flame has been measured to be $60 \mathrm{~ms}$. Position control and repeatability in the flame coordinate system based on the burner mouth is achieved by means of a cathetometer. Vertical position ( $z$ ) repeatability of the leading edge of the probe is estimated to be about $\pm 0.2 \mathrm{~mm}$ or better. Radial position $(r)$ is estimated to be repeatable to $\pm 0.2 \mathrm{~mm}$. Figure 1 shows a sketch of the flame, the thermophoretic probe, and the flame coordinate system. 
Soot deposition rates are dominated by particle thermophoresis (soot particle drift down the temperature gradient). Observed soot deposition mass fluxes are several orders of magnitude greater than those that would be expected on the basis of only Brownian diffusion (Ref. 6). The grid probe has a small thermal inertial but gives a higher image resolution since it permits TEM observations. The bulk specimen carrier has a much larger thermal inertia, permits a lower residence times, and can give excellent spatial resolution.

Preliminary observations have been made for low and intermediate heights of the flame $(z=5,10,20,30,40 \mathrm{~mm})$ and provide an idea about the tendencies of the variables:

1. $z=5 \mathrm{~mm}$ (intense nucleation region)

No obvious variation of spherule size with $r$ is apparent. The degree of agglomeration increases substantially as we move toward $r$ where soot volume fraction is a maximum. It is also important to state ${ }^{c}$ that no soot was observed at $r<r_{c}$ near the axis of the flame. This is not true at any other height.

2. $z=10 \mathrm{~mm}$

A small but perceptible variation of spherule size increasing as $r\left(>r_{c}\right)$ $\rightarrow r_{c}$ and the degree of agglomeration increases substantially.

3. $z=20 \mathrm{~mm}$

A substantial increase of spherule size and degree of agglomeration is noted as $r\left(r_{c}\right) \rightarrow r_{c}$. Maximum spherule size is about 30 to $40 \mathrm{~nm}$.

4. $z=30$ and $40 \mathrm{~mm}$

Similar to results at $z=20 \mathrm{~mm}$ but with spherule size increasing moderately with height at all values of $r$.

The spherule size increases by 10 fold as $z$ increases from about $5 \mathrm{~mm}$ to 50 $\mathrm{mm}$. The SEM measurements, which afford high spatial definition, generally compare well with TEM measurements, which have higher image quality but poorer spatial resolution. Preliminary surveys by TEM show smaller spherules high in the flame where oxidation is present. Future work will emphasize the interactive use of both SEM and TEM methods of morphological analysis. 


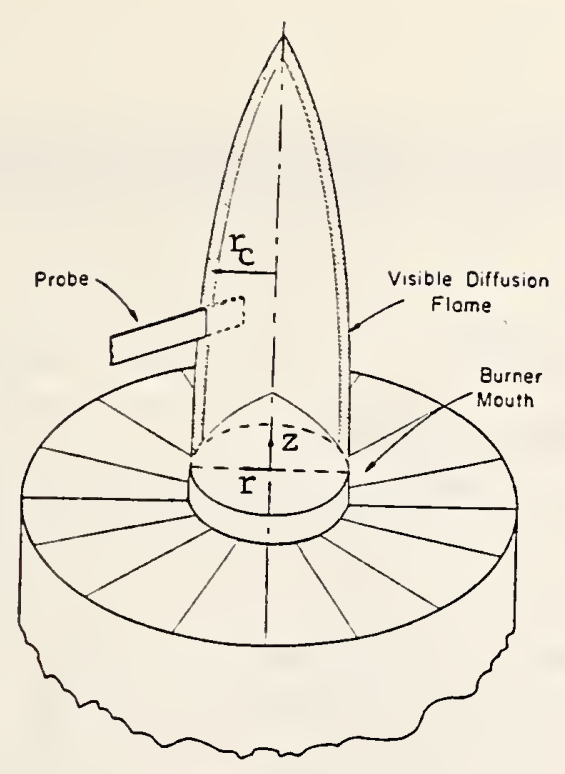

Figure 1.

\section{REFERENCES}

1. Gelbard, F., "MAEROS", Computer Program and Algorithm Review, Aerosol Science and Technology, $\underline{3}, 117-118$ (1984).

2. Tesner, P. A. et al., "Kinetics of Dispersed Carbon Formation", Combustion and Flame, 17, 253-260 (1970).

3. Jagoda, I. J. et al., "An Experimental Investigation into Soot Formation and Distribution in Polymer Diffusion Flames", Combustion and Flame, $\underline{37}$, 261-274 (1980).

4. Skolnik, E. G. and McHale, E. T., "Sampling of Soot in Diffusion Flames", Combustion and Flame, 37, 327-330 (1980).

5. Santoro, R. J., Semerjian, H. G., and Dobbins, R. A., "Soot Particle Measurements in Diffusion Flames", Combustion and Flame, 51, 203-218 (1983).

6. Rosner, D., personal communication, forthcoming article. 


\section{CENTER FOR FIRE RESEARCH NATIONAL BUREAU OF STANDARDS \\ FY 85}

Institution: Brown University

Grant No.: NBS Grant NB83NADA4017

Grant Title: Study of Effects of Material Properties on Flaming Combustion of Charring Fuels

Principal Investigator: Professor M. Sibulkin

Division of Engineering

Brown University

Providence, RI 02912

Telephone: (401)863-2867

Other Professional Personnel: S. S. Tewari, Postdoctoral Fellow

Y. Chen, Graduate Research Assistant

K. Siskind, Undergraduate Research Assistant

NBS Scientific Officer: Dr. V. Babrauskas

Technical Abstract:

The objective of the present research program is to determine the effects of changes in material properties on the burning rates and extinction limits of solid fuels. In particular, we are currently looking at the effects of solid phase fire retardants on the burning of cellulose. We wish to measure the changes in material properties caused by these retardants, and to use this information to determine how these retardants act to suppress fires. This information will help in the design of materials with improved fire safety characteristics.

The first phase of this investigation studied the flaming combusiton of pure and fire retarded cellulose samples, and the results are summarized in last years annual report. This year our emphasis has been on analytical and experimental studies on the heat of gasification of char forming materials.

A general analysis of pyrolysis of charring materials was completed and numerical calculations have been made for cellulose. The aims of the analysis were to develop a mathematical model for the pyrolysis of charring materials (i) to determine the relationship of the heat of gasification $h_{g}$ to the heat of pyrolysis $h_{p}$, where

$$
\mathrm{h}_{\mathrm{g}} \equiv \dot{\mathrm{q}}^{\prime \prime}(\mathrm{in}) / \dot{\mathrm{m}}^{\prime \prime}(\mathrm{out}) \text { and } \mathrm{h}_{\mathrm{p}}=\mathrm{h}_{\mathrm{w}} \text { (gas + char) }-\mathrm{h}_{\mathrm{c}}(\text { solid), }
$$

and (ii) to determine the sensitivity of the results to changes in the (assumed) properties of the material. For thermally thick vaporizing materials (such as PMMA), analyses shows that $h_{g}=h_{p}$ and that the pyrolysis rate is independent of time. However, for charring materials (such as cellulose), the process is time dependent and it was found that there is no simple relationship between $h_{g}$ and $h_{p}$. The effects of a number of parameters on the heat of gasification of cellulose were investigated by means of numerical analysis. The computer program used was developed at the 
Factory Mutual Rescarch Corp. for onedimensional pyrolysis using a global chemical reaction. Propcrty values for cellulose and its char have been estimated from a survey of the literature. An external heat flux level was chosen based on our previous expcrimental results on the burning of cellulose. We looked at the effects of variations in those material properties which are poorly known such as the char density and thermal conductivity, the heat of reaction, and the kinetic rate of raction. The calculated results show that the heat loss from the surface due to radiation is very important and can reach 80 percent of the external heat flux. For a $2 \mathrm{~cm}$ slab of cellulose we found that after a short induction period $(-20 \mathrm{~s})$ the value of $h_{g}$ was about twice the value of $h_{p}$ and subsequently decreased to values less than $h_{p}$ at $t-200 \mathrm{~s}$ (Fig. 1). This change in $h_{g}$ with time which is primarily due to the finite thickness of the material has to be considered in studies of the burning of charring materials which are not thermally thick. The properties varied in the sensitivity study were: the char conductivity product $\rho_{C}{ }^{k} C$ (by a factor of 4); the reaction rate parameter $A$ (by a factor of 100 ); and the heat of reaction $h_{r}$ (by a factor of 4). It was found that the surface temperature was not a sensitive function of thesc property changes. As a result, $h_{p}$ is not sensitive to changes in ${ }^{\rho} \mathrm{C}^{k} \mathrm{C}$ or $A$ (but changes in step with $h_{r}$ ). The value of $h_{g}$ was found to be moderately sensitive to these property changes. Increases in ${ }^{\rho} \mathrm{C}^{\mathrm{k}} \mathrm{C}$ caused $\mathrm{h}_{\mathrm{g}}$ to decrease; increases in $\mathrm{A}$ also caused $\mathrm{h}_{\mathrm{g}}$ to decrease by a small amount. Changes in $\mathrm{h}_{\mathrm{r}}$ caused corresponding changes in $h_{g}$. Calculations were also made for different incident flux levels. As expected, the rate of pyrolysis was found to increase with increasing incident flux; but, contrary to expectation, the values of $h_{g}$ after an initial transient are nearly independent of incident flux level (Fig. 2).

Talks based upon this work were given at the 1984 Technical Meeting of the Eastern States Section/The Combustion Institute and at the CFR Workshop on "Non-Stcady Burning Rates of Solid Fuels Including the Effects of Char." A paper based on this work has been accepted for the "First International Symposium on Fire Safety Science."

Construction of the apparatus for the measurement of the heat of gasification has been completed. The heart of the apparatus is an electronic balance with a specially designed sample holder mounted within an extensively modified glass draft-shield chamber. A 2-stage gas supply system has been developed to

first scavenge air from the chamber and replace it by an inert gas (nitrogen), and then to supply a reduced flow of inert gas to remove the products of pyrolysis. The sample is heated by a radiant lamp assembly which has been designed to give a uniform surface heat flux with an intensity which simulates the energy flux to the sample surface during burning. The surface temperature during pyrolysis is measured using an infrared pyrometer with a $2.1 \mu \mathrm{m}$ detector which can "see" through the chamber window. The pyrometer is installed with a rotating mount to facilitate its calibration against a black-body furnace. Considerable effort during this period had to be devoted to overcoming experimental difficulties. Two problems led to additions to the apparatus. Under long term heating $(10 \mathrm{~min})$ the pyrex absorber plate overheated and cracked. It was replaced by a quartz piate, and an air cooling system was added to minimize emission of radiant energy from the absorber plate (which would have affected the infrared temperature measurement). The expcriment had been designed with a vertical (rather than a horizontal) pyrolysis surface to minimize the optical depth of the smoke layer normal to the surface. However, trial runs showed considerable recirculation of smoke within the chamber. This problem was finally solved by using an auxiliary housing at the rear of the apparatus to inject additional scavenging gas into the weighing chamber. 
A computer program for the acquisition of data and its subsequent analysis has been developed. In order to obtain useful values of the mass loss rate $\mathrm{dm} / \mathrm{dt}$, it was found to be necessary to smooth the digitized mass readings $m(t)$. This has becn done by generating a running least squares fit to $\mathrm{m}(\mathrm{t})$ and calculating $\mathrm{dm} / \mathrm{dt}$ from the curve fit. A similar curve fit was needed to obtain smoothed values of the surface temperature $T(t)$ since the analog output of the I.R. pyrometer fluctuates slightly.

At this time we have just obtained our first results for a set of cellulose samples retarded with 0 to 3 percent sodium hydroxide, and pyrolyzed at an incident flux level of $40 \mathrm{~kW} / \mathrm{m}^{2}$. These initial data on the effects of retardant addition gave the trends shown on Figs. 3 and 4 after $100 \mathrm{~s}$ of heating. The pyrolysis rate $\mathrm{m}^{\prime}$, which is also the rate of production of volatiles, is found to increase with retardant concentration $Y_{R}$. This increase occurs even though the conversion of cellulose to char also increases with retardant concentration. The results for the heat of gasification $h_{g}$ (calculated from the definition given above) show a decrease of $h_{g}$ with increasing retardant concentration. Since diffusion flame theory shows that $\mathrm{a}^{\mathrm{g}}$ decrease in $\mathrm{h}_{\mathrm{g}}$ promotes burning, we must look for other mechanisms to explain how sodium hydroxide inhibits fires.

\section{COMPLETED PUBLICATIONS}

"Mcasurement of Flaming Combustion of Pure and Fire Retarded Cellulose" M. Sibulkin and S. S. Tewari, Combustion and Flame $\underline{59}, 31$ (1985).

"Heat of Gasification for Pyrolysis of Charring Materials," M. Sibulkin (accepted for presentation at First International Symposium on Fire Safety, Oct. 1985).

"An Experimental Study of the Burning of Pure and Fire Retarded Cellulose," S. S. Tcwari, Ph.D. Thesis, Brown University, 1984 and NBS-GCR-85-485 (1985).

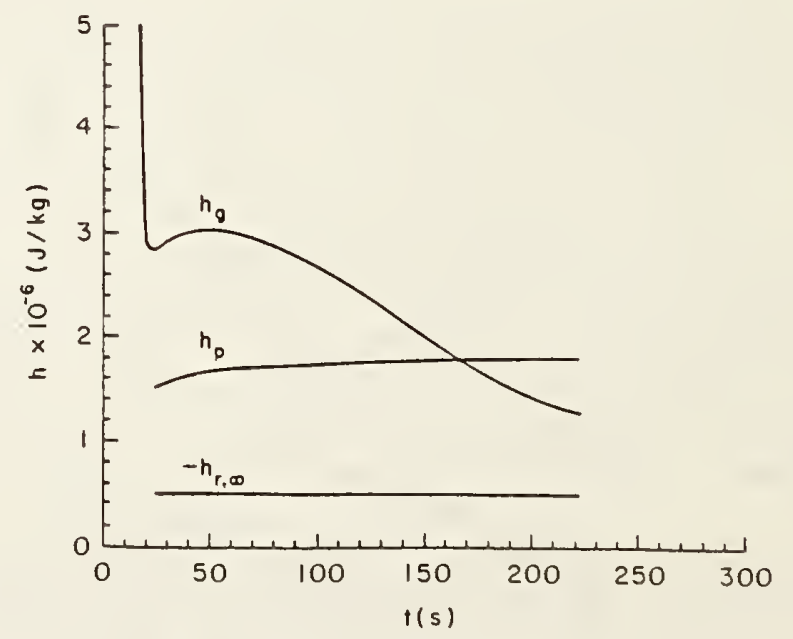

Fig. 1. Comparison of heats of reaction, pyrolysis and gasification. 


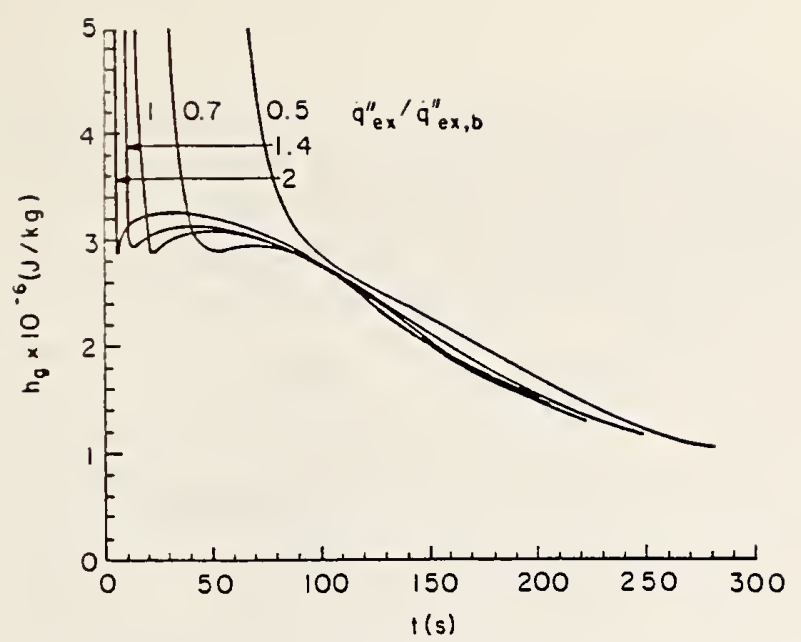

Fig. 2. Effect of incident heat flux on heat of gasification.

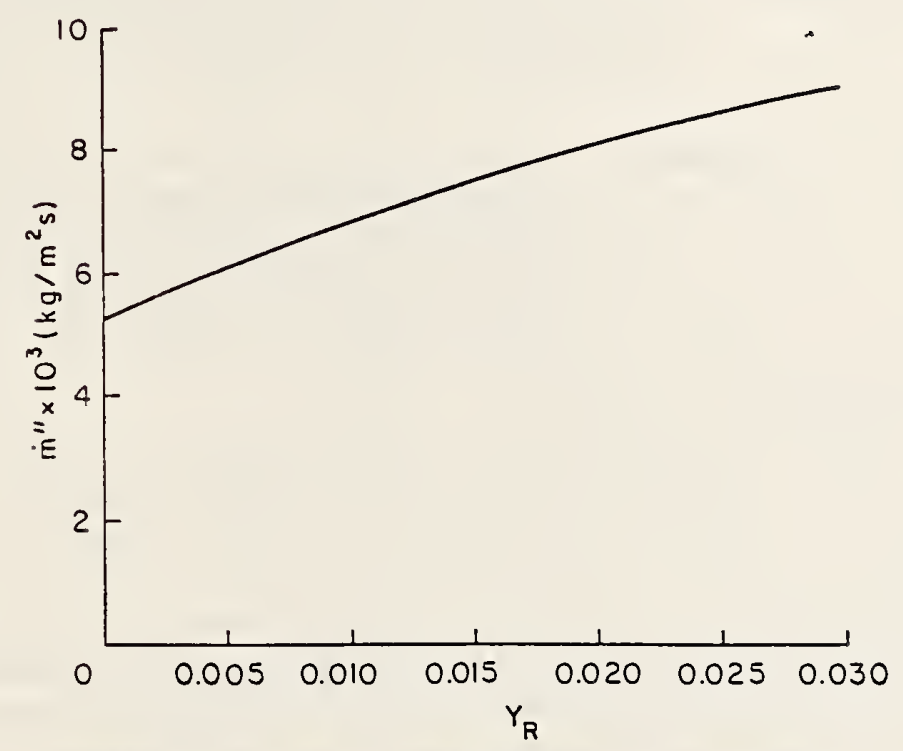

Fig. 3. Mass pyrolysis rate versus retardant concentration.

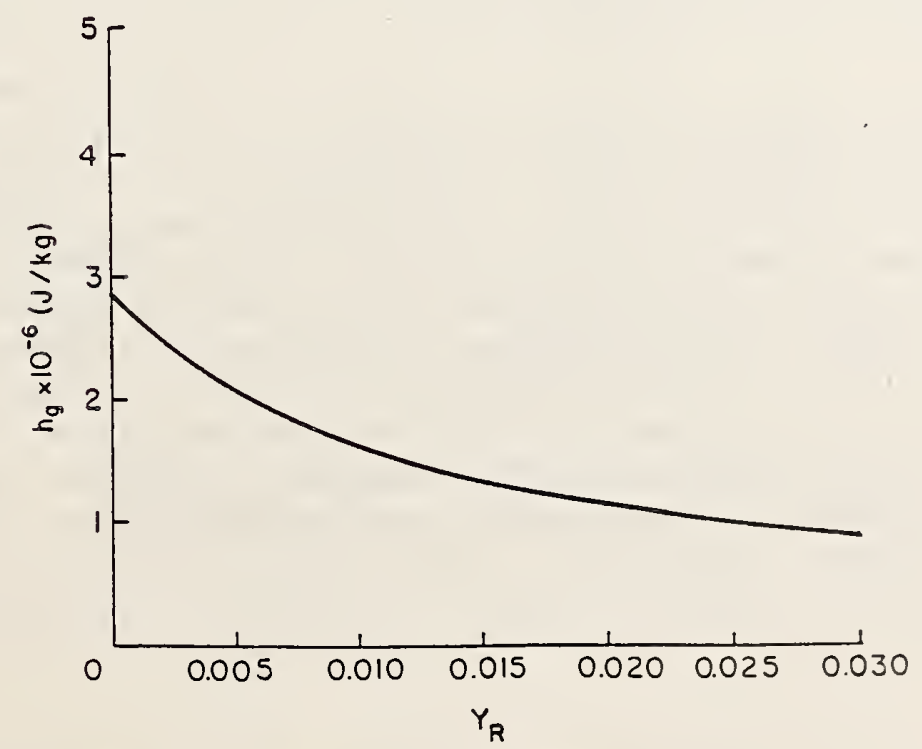

Fig. 4. Heat of gasification versus retardant concentration. 49 


\section{ANNUAL CONFERENCE ON FIRE RESEARCH}

CENTER FOR FIRE RESEARCH

NATIONAL BUREAU OF STANDARDS

GAITHERSBURG, MARYLAND

october 11-16, 1985

Institution:

Grant No.:

Grant Title:
California Institute of Technology

NBS Grant NB82NADA3033

Experimental Study of Environment and Heat Transfer in a Room Fire

Principal Investigator: Professor Edward E. Zukoski $301-46$ California Institute of Technology Pasadena, CA 91125

Other Professienal Personnel: Professor Toshi Kubota

Michael Chobotov, PhD Candidate Stephen Toner, PhD Candidate California Institute of Technology Pasadena, CA 91125

NBS Scientific officer: Dr. Walter Jones

Dr. J. G. Quintierre

\section{Technical Abstract:}

Smoke which is produced by a fire spreading through a building can act to aid in the spread of the flame by the transport of hot and perhaps combustible gas, and can be harmful to occupants because of its temperature and toxicity or because its opacity hinders the rapid movement of the occupants through the building. We are interested in developing models for the production and movement of smoke in complex structures and have been studying several processes which will be described below. These processes cannot be described analytically because the flows are turbulent and are strongly influenced by turbulent mixing between streams in which buoyancy forces are predominant. Under certain circumstances, the combustion of the fuel produced in the fire can occur under conditions in which the concentration of oxygen in the ambient gas is far below normal and a fuel rich mixture can be produced in the smoke which can burn later in an adjacent space. The aim of the research work described here is to develop sufficient understanding of the fluid dynamic and chemical processes that rational models can be developed for the use in two layer fire codes. 


\section{FLOW AND HEAT TRANSFER IN GRAVITY CURRENTS}

During the past year we have been primarily involved in an experimental investigation of the flow field produced by the transient motion of smoke in a horizontal hallway-like structure. The aim of this work is to obtain an understanding of the flow of hot smoke along a ceiling during the transient period in which the smoke moves as gravity current. Heat transfer from the current to the wall can affect these flows and studying the heat transfer process is an important part of the present work. A final report on the current status of this work will be available in october and a qualitative description of the apparatus and results is given here.

We have carried out experiments in which a gravity current of salt water flow through a duct fulled with fresh water and a second set of experiments in which the gravity current of hot air flows through a duct filled with cool air. The tests in air included both viscous and heat transfer effects and they will be discussed here.

The tests in air were carried out by creating a transient flow of hot gas along the ceiling of a square duct with a constant temperature ceiling. The velocity of the front produced by this flow, the rate of heat transfer to the ceiling, and the velocity and temperature fields of the flow are being measured.

APPARATUS: The channel used in the gas flow experiments is a duct $0.5 \mathrm{~m}$ in height and width, and 8.6 meters in length. Hot gas can supplied to this duct at one end from a small furnace at temperatures up to $500 \mathrm{~K}$ and with a large range of metered flow rates. Cool air in the tunnel which is displaced by the hot "smoke" can be withdrawn from the tunnel at a number of positions so that a number of interesting flow situations can be modeled. In the work reported here, the downstream end of the duct is completely open. The side walls of the channel have been made of heat treated glass to allow observation of the flow through shadowgraph photography or direct observation of smoke which is added to the hot gas.

We have developed for our application a smoke-wire technique for velocity measurements which gives a good qualitative measure of the local gas speed. However, the measurements are affected by the buoyancy of the smoke relative to the cooler gas in the flow and do not give an easily interpreted measure of the gas speed. In typical test, six velocity profiles at a single station and at predetermined times can be obtained.

Thermocouples, with a diameter of about $0.01 \mathrm{~mm}$ and consequently with a fast time response, are used alone or in a rake to make gas temperature measurements and thin film heat transfer gages have been installed to measure heat transfer rates. 
SURFACE CONDITION: The ceiling of the apparatus in its current state is a $1.27 \mathrm{~cm}$ thick aluminum plate which was used because conduction into the plate is fast enough to keep the plate temperature rise below one degree. Thus, the surface temperature is kept far below the initial temperature of the gas in the duct and does not enter the problem.

Given the heat transfer rates observed in these experiments, the temperature rise at the surface of a wall composed of an insultor, say one with the propertiers of plasterboard, would be in the range of 20 to 50 degrees after a period of 10 to 15 seconds. Thus, the rise would still be small after the period required for the front to reach the end of our test section. However, we are very much interested in the effects of the temperature of the wall and the wall boundary layer on the heat transfer process and are modifying our apparatus to allow measurements of this type.

TYPICAL FLOW: The initial conditions for a typical experiment include, temperature of $520 \mathrm{~K}$, initial layer thickness of $6 \mathrm{~cm}$ and an initial velocity of of the front $0.5 \mathrm{~m} / \mathrm{s}$. At the downstream end of the duct, the corresponding conditions are a temperature of $280 \mathrm{~K}$, a thickness of $12 \mathrm{~cm}$, and a velocity of the front of $0.2 \mathrm{~m} / \mathrm{s}$. The Richardson number based on layer thickness is about 0.9 throughout the length of the duct and the initial value is about one so that no initial hydraulic jump is required.

HEAT TRANSFER RATES: The rate of heat transfer to the constant temperature wall measured in these experiments varies from values as large as $3000 \mathrm{~W} / \mathrm{m}$ to values as low as $60 \mathrm{~W} / \mathrm{m}$, and the maximum values are observed at the upstream end of the duct where the hot current is introduced. Because the total enthalpy flux in the current is typically 1.0 to $2.5 \mathrm{~kW}$, it is not surprising that the heat flux to the wall has a large influence on the temperature of the current and its motion.

Heat transfer rates, expressed in the form of a Nusselt number based on local layer thickness have been found to vary linearly with the Reynolds number based on the layer thickness and local velocity. This result suggests that the flow is laminar. However, the measured Nusselt numbers are some ten times higher than the values estimated for a laminar wall jet with the same Reynolds number. In addition, we have observed 10 to 15\% fluctuations in gas temperature at all positions in the layer and similar fluctuations in the heat transfer rates at all positions along the ceiling. These results suggest that something more complex than a simple laminar flow is present in our experiments and this feature of the flow is being investigated currently.

MODELING: We are developing a computational scheme which will be used to describe the flow described above and the data are being used to guide its development. The model uses an integral method to describe the transient motion of the gravity current in terms of a partial differential equation in which the time and the 
position along the ceiling are the variables. The boundary layer approximation is used in the description of the flow and the effects of buoyancy, heat transfer, and viscosity are being taken into account.

\section{SALT WATER MODELING EXPERIMENTS}

In addition to the experiments described above, we have carried out a number of experiments to explore in a qualitative manner buoyancy driven flows in several other situations. For example, we have investigated the flow through circular orifices in openings in horizontal walls due to buoyancy or applied pressure differences and the flow of gravity currents in long rectangular ducts which were tilted away from the horizontal.

ORIFICE FLOWS: The orifice flows were found to have the expected flow coefficients regardless of the differences in densities of the fluids above and below the opening as long as the Richardson number for the opening was less than one. That is as long as

$R_{i}=\left(\Delta \rho \& D /\left(\rho v^{2}\right)<1.0\right.$

This is the expected result, and we have not yet been able to make accurate enough measurements to determine what differences, if any, exist when the Richardson number is much less than one where we might expect to see a difference.

SLOPING CORRIDORS: We have recently carried out several experiments to determine the influence of tilting the whole hallway so that the floor and ceiling lie at an angle with respect to the horizontal. In these tests the ceiling and floor were held at a 30 degree angle with respect to the horizontal, and the test fluid, salt water, was introduced at the high end so that it experienced an acceleration as it flowed down the "ceiling" wall.

In the horizontal case, the current mass flux and velocity, and head geometry were constant; in contrast when the ceiling was tilted, these parameters grew rapidly with distance from the origin. The height of the head quickly reached an appreciable fraction of the duct height, and then strong mixing occurs between the fluid in the head and the ambient fluid flowing over the head. This leads to a strong contamination of the fluid in the duct with the fluid in the gravity current.

Reports and Papers

Zukoski, E. E., Cetegen, B. M. and Kubota, T., "Visible Structure of Buoyant Diffusion Flames," presented at 20 th Combustion Symposium, Aug. 12-17, 1984 . 


\section{CENTER FOR FIRE RESEARCH \\ NATIONAL BUREAU OF STANDARDS \\ FY85}

Institution: Case Testern Reserve University

Contract Namber: NB82NADA3028

Contract Title: Experimental and Analytical Study of Fire Sprinkler Scaling Laws

Principal Investigator: Joseph M. Prahl, Ph.D., P.E.

Professor of Engineering

Department of Mechanical and Aerospace

Engineering

Case Western Reserve University

Cleveland, Ohio 44106

Other Professional Personnel: Bruce Tendt, M.S. Candidate

Htun Win, M.S. Candidate

Case Western Reserve University

Cleveland, Ohio 44106

NBS Scientific Officer: David D. Evans

Technica1 Abstract:

The objective of this project is to develop an experimental base that will delineate the relevant scaling parameters that govern the performance of a wide class of fire sprinklers. The sheet trajectory, sheet breaknp, and subsequent droplet size distribution and droplet trajectories are related to the mechanical and thermal properties of the 1 iquid and gaseous fluids, the geometry and the initial dynamics of the liquid and gaseous streams.

Experimental data for water has been obtained on an apparatis developed to study the axisymmetric jet impingement on a flat disk which can be vibrated axial 1 y at a given frequency and chosen amplitade. The sheet of water leaving the disk is allowed to breaknp withont interference over the full $360 \%$, whereas the discharge subsequent to sheet breaknp is masked off to a $22.5^{\circ}$ sector for the purpose of determining the droplet radial discharge distribution. The sheet breakup radins is determined by direct observation and the radial discharge from the sector is collected in a series of rain gutters spanning the floor of the sector normal to the midangle radial direction. Variation of disk size and disk surface characteristics show no measurable effect on either sheet breaknp radial location or on the measured discharge distribution. 
The experimental apparatus can accommodate a variety of commercial sprinkler heads to test the spray pattern and compare the flow distribution to that of the axisymetric disk. The performance of the commercial heads are not arisymmetric as can be seen in Fignre 1. For the same flow conditions the axisymmetric disk impingement produces a spray distribution than the pendant-type sprinkler as can be seen in Figure 2 .

The sprinkler flow distributions shown in Figures 1 and 2 , are presented in a non-dimensional form which emphasizes the sprinkler's ability to uniformly spread the volume flow rate of water over the maximum possible floor area. The maximum radial extent of the sprinkler system is represented as $\delta 2 \mathrm{y} / \mathrm{g}$, where $U$ is the jet velocity, $y$, the distance of the disk from the floor and g, gravity. The non-dimensional application rate is the measured 'rain rate' from the gutter collection system, normalized with respect to the 'ideal rain rate', the total flow rate from the nozzle divided by the maiximum possible floor area.

By driving the disk at various frequencies and amplitudes, dramatic differences in flow distribution can result from the nature of the 1 iquid sheet breaknp induced by the choice of driving frequency. If the driving frequency is near the frequency for largest growth of sinnons waves on the sheet, large waves appear before sheet breaknp occurs and a broad distribution of droplets results from the flapping sheet. If the sheet is driven at frequencies away from those for maximum growth of sinnons waves, the sheet remains quite flat until breakup and it is proposed that the growth of symmetric waves on the sheet are the dominant mechanism of breakap. Since the sheet is not flapping, the droplet distribution is far narrower under these conditions.

Figure 3 il 1 ustrates the point that the ratio of the sheet breakup radius at a given driving frequency to that at zerodriving frequency appears to correlate with the ratio of the driving frequency to the frequency formaximum growth of sinuous waves, for a given amplitude of disk oscillation. Figures $4 a-b$ illustrate the apparent correlation of flow distribution with ratio of driving frequency to frequency of maximum growth of sinuous waves.

The droplet trajectory model combined with a Rosin-Rammler distribution function for the droplet diameters gives qualitative agreement with measured flow distributions. The model is sensitive to the initial conditions of the droplets at the point they leave the sheet oreakup location. If the sheet is flapping sinuouslywith large amplitude, it canses the flow distribution to be much broader than if the sheet is relatively flat at the breakup point as can be seen by predicted flow distributions from the computer model shown in Figures $5 a-b$.

\section{Reports and Publications:}

1. B. Wendt and J. M. Prahl, 'Flow Rate Distribution Performance for an Axisymmetric Vibrating Impact Fire Sprinkler Head' Department of Mechanical and Aerospace Engineering, Case Testern Reserve Oniversity, C1eveland, Ohio 44106, Dec. 1983. 

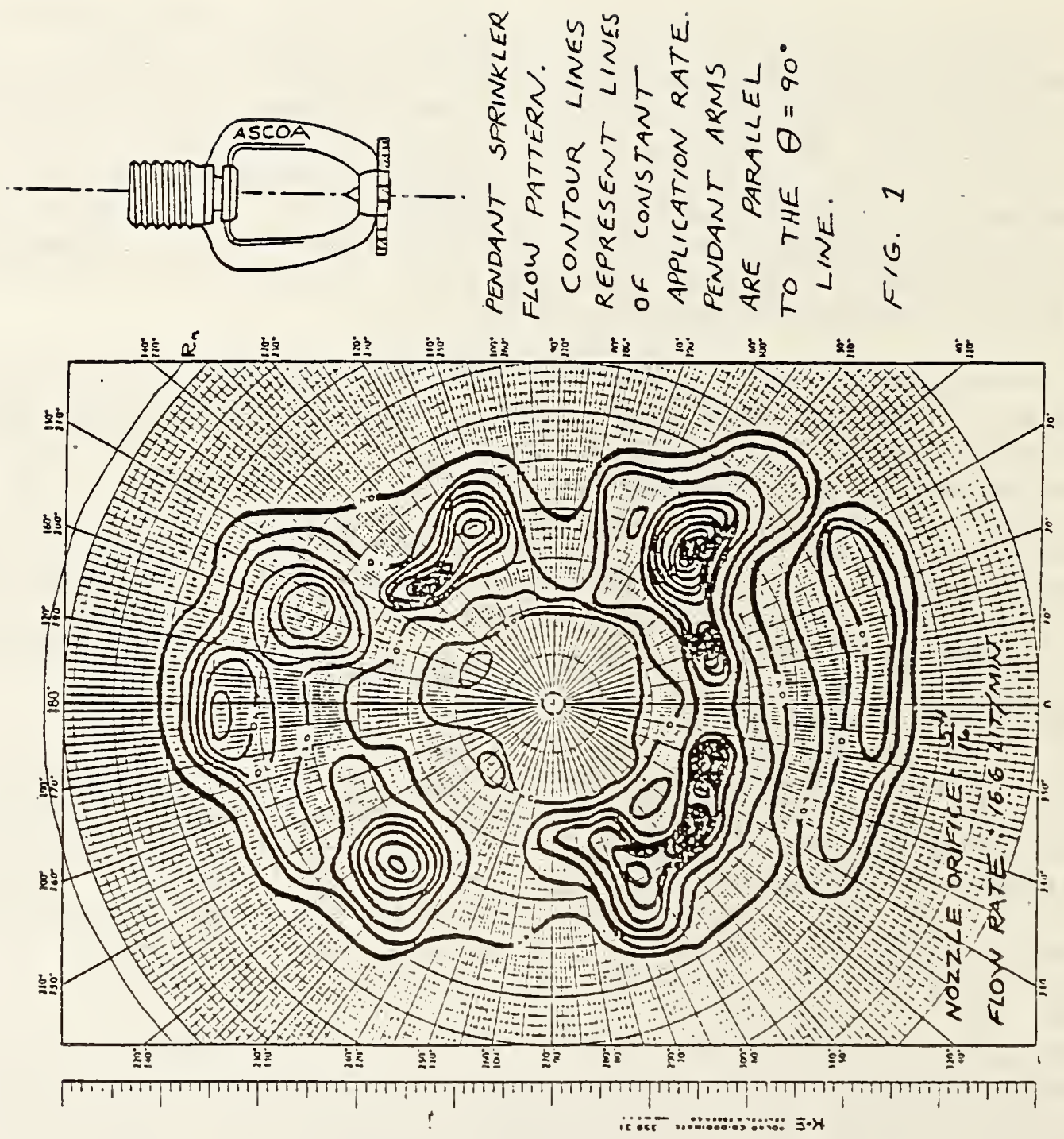


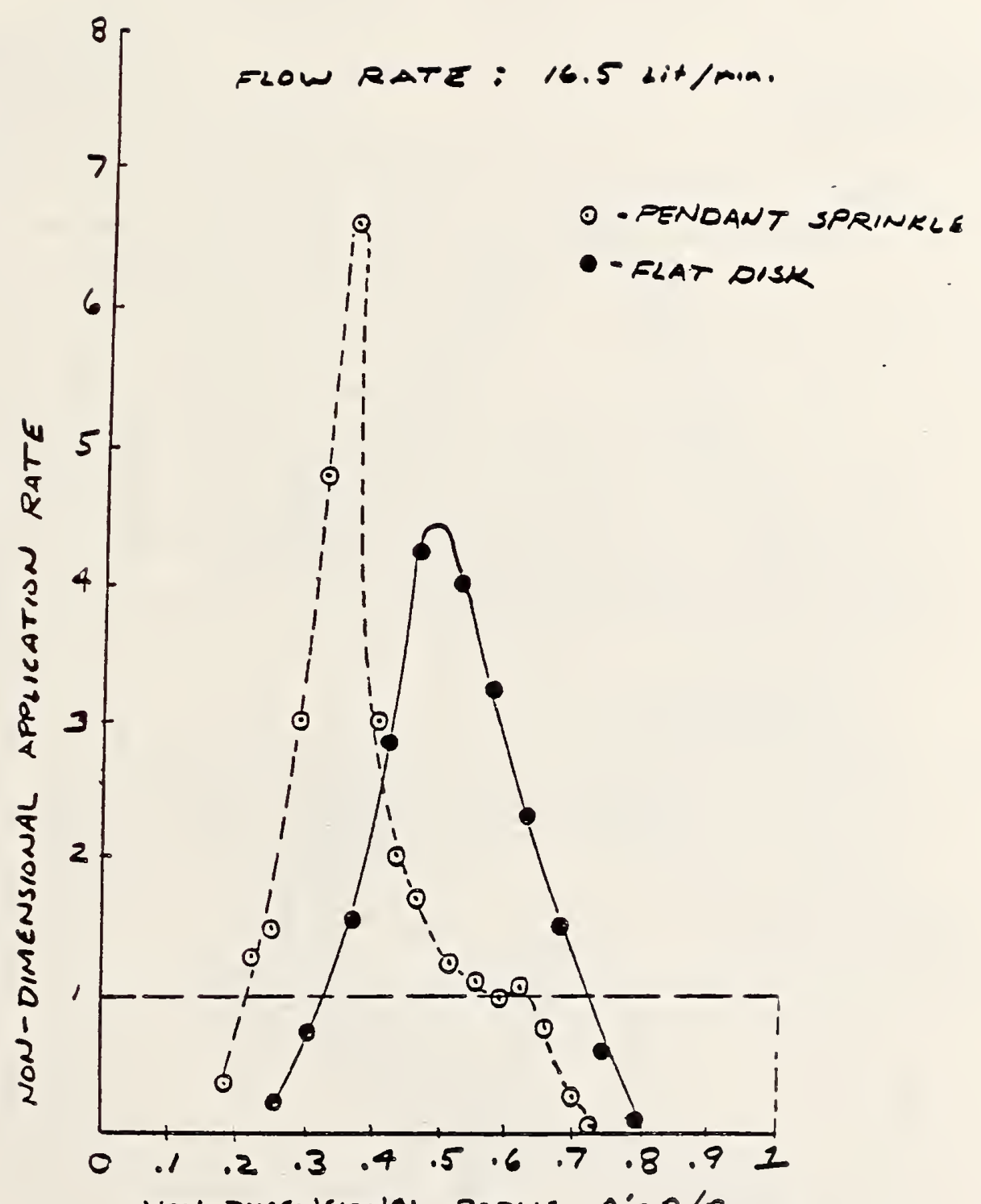

Fib. 2

NON-dimCNSIONAL RAOUS $r^{\prime}=r / r_{\text {max }}$ APPLICATION RATE PERFORMANCE HOR FLAT OISK WS. PERRARMANEE FOR PENOANT SPRINELER (AUERAGEP WITH $\theta$ )

57 


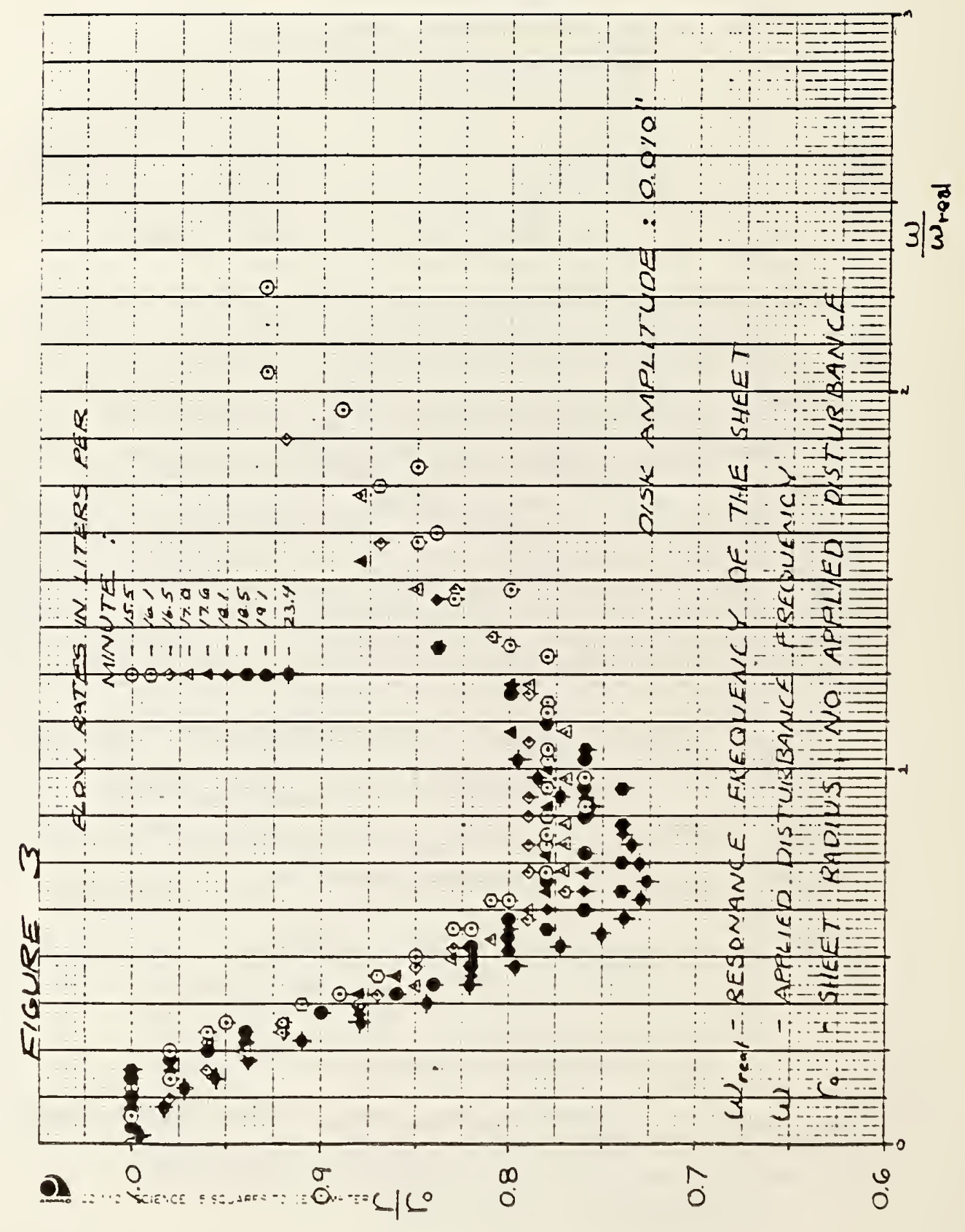



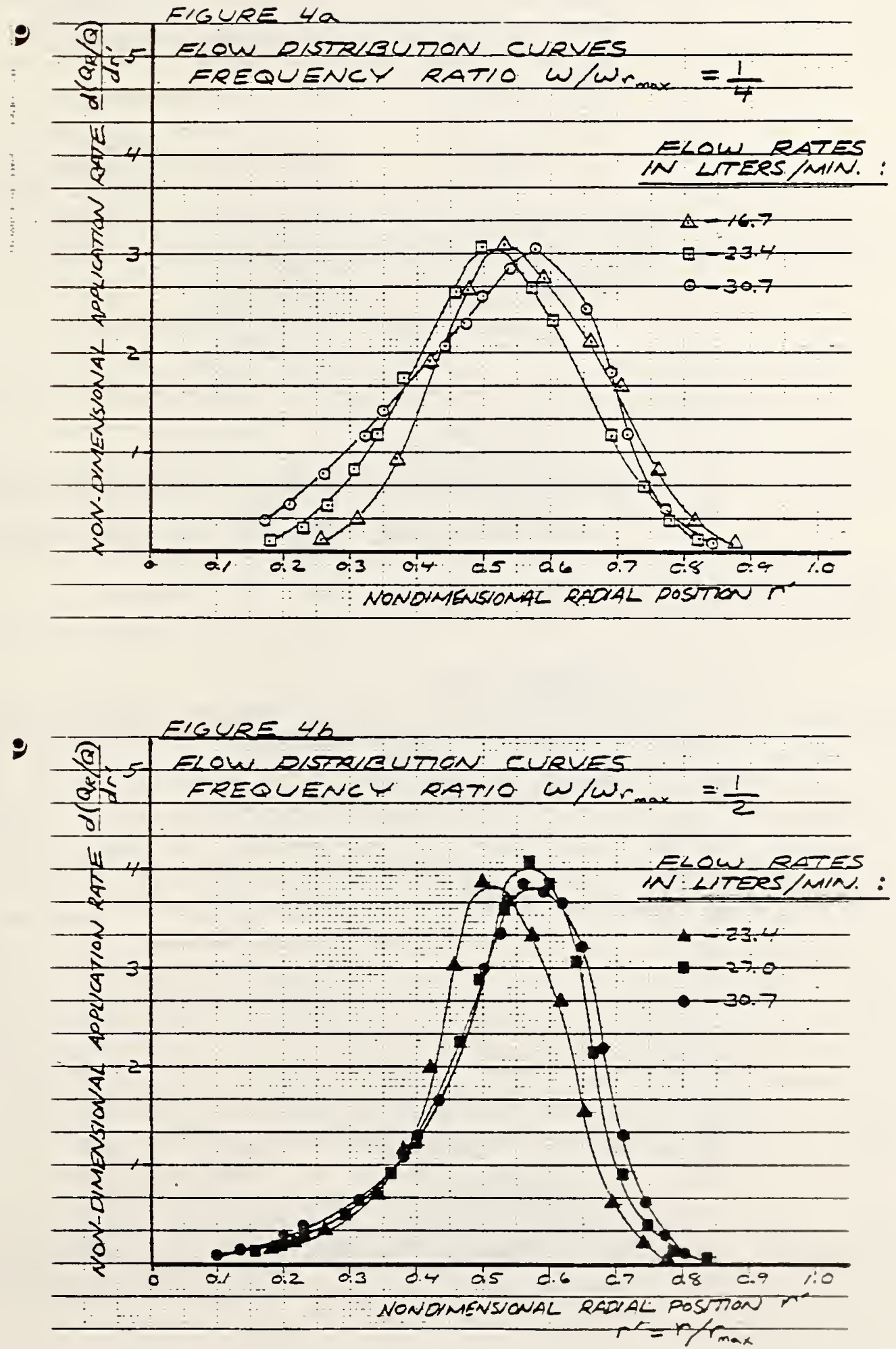

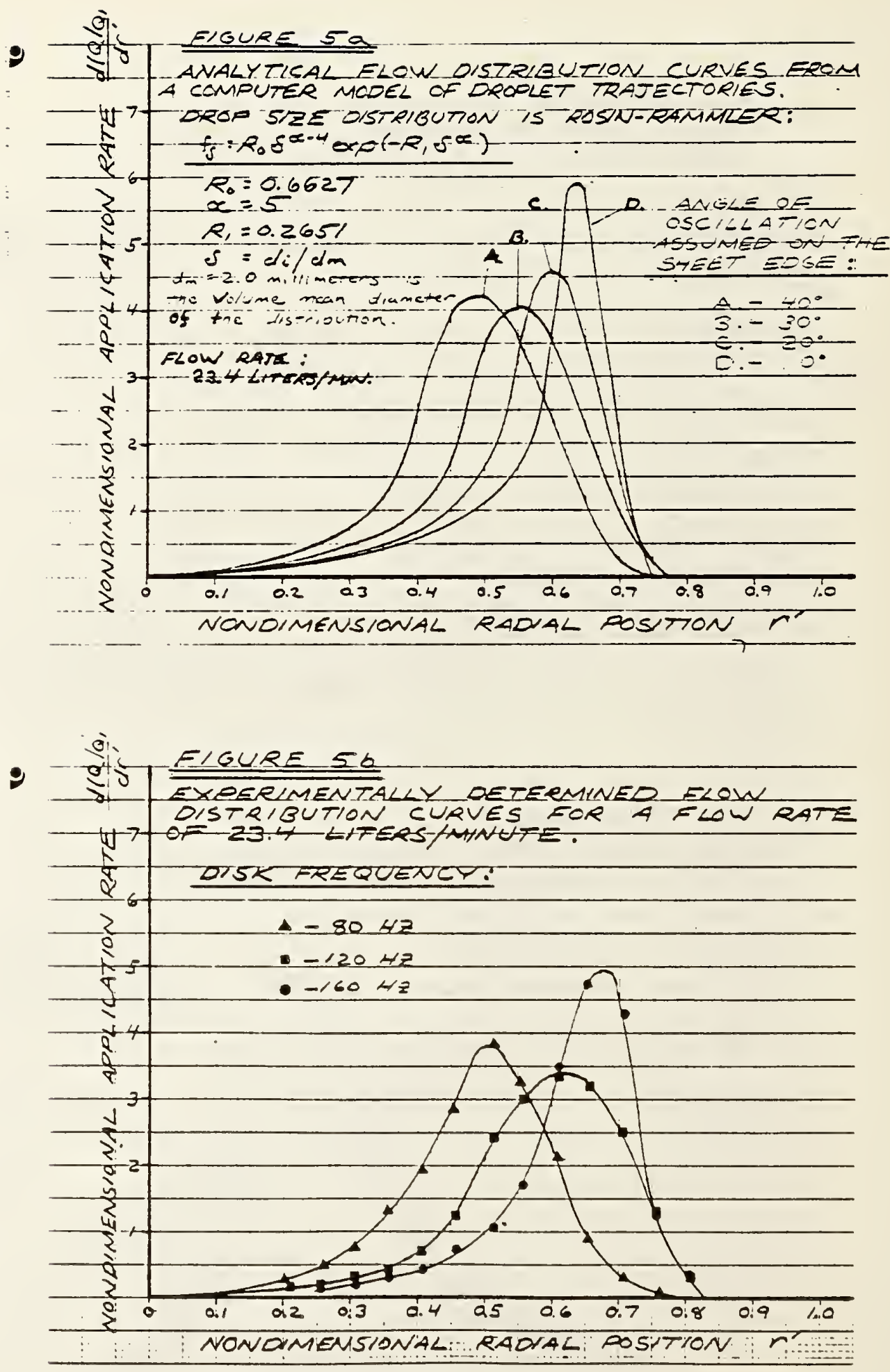
CENTER FOR FIRE RESEARCH

NATIONAL BUREAU OF STANDARDS

FY 85

Institution: Case Western Reserve University

Grant No.: $\quad$ 60NANB4D0013

Grant Title: Flame Spread Limits

Principal Investigator: Professor James S. T'ien

Department of Mechanical and Aerospace Engineering

Case Western Reserve University

Cleveland, Ohio 44106

Telephone: (216) 368-4581

Other Professional Personnel: Charlie Chen (Graduate Student)

Ait Messaoudene (Graduate Student)

NBS Scientific Officer: Dr. James G. Quintiere

Technical Abstract:

The overall objective of this research program is to develop a basic understanding on flame spread limits. The two tasks performed to achieve this goal are described in the following:

Diffusion Flame Stabilization at the Leading Edge of a Fuel Plate (Ref. 2). A theoretical model of a diffusion flame at the leading edge of a fuel plate in a forced convective flow is solved numerically to study the flame stabilization and blowoff phenomena. The system of governing equations consists of the two-dimensional Navier-Stokes' momentum, energy and species equations with one-step overall chemical reaction and second-order, finite rate Arrhenius kinetics. The computation is performed over a wide range of Damkohler numbers. For large Damkohler numbers, envelope flames are found to exist where the computed fuel evaporation rate, the flame stand-off distance and the velocity profile show certain similitude. As Damkohler number is lowered, a transition to open-tip flame takes place where the flame becomes stabilized on the sides of the fuel plate. Further decreasing of the Damkohler number pushes the diffusion flame downstream out of the leading edge region. In this work, the flame structures of the envelope and the open-tip flames are presented together with a description of the transition sequence. The implication of this work to downstream boundary layer combustion is also discussed.

Determination of the Kinetic Rate Constants for PMMA in a Semi-Global Reaction Model (Ref. 3). A numerical study of the combustion and extinction in the stagnation point boundary layer of a condensed fuel (PMMA) has been performed using a three-step semi-global reactions model. In the first step considered, fuel is oxidized to form carbon monoxide and water vapor. In the second, carbon monoxide is oxidized to form carbon dioxide, and in 
the third reaction, carbon dioxide decomposes into carbon monoxide and oxygen, which is the reverse of the second reaction. Use has been made of Howard, et. al., kinetics constants for the forward reaction of CO (second reaction), and constants calculated from equilibrium considerations for the backward reaction (third reaction). Comparing the extinction results with experimental data, good agreement was found for $\hat{B}_{\mathrm{F}}=4.43 \times 10^{13} \mathrm{ml}^{3} / \mathrm{g}$ mole. sec. and $\hat{\mathrm{E}}_{\mathrm{F}}=32000 \mathrm{cal} / \mathrm{mole}$, which are respectively the preexponential factor and the activation energy for the rate of the first reaction.

\section{Reports and Papers:}

1. Chen, C.H. and T'ien, J.S., "Fire Plume along Vertical Surfaces: Effect of Finite-Rate Chemical Reactions," Journal of Heat Transfer, Vol. 106, pp. 713-720, November 1984.

2. Chen, C.H., "Diffusion Flame Stabilization at the Leading Edge of a Fuel Plate," Ph.D. Thesis (expected August, 1985), Case Western Reserve University, to be submitted as a NBS report.

3. Ait Messaoudene, $N$. and T'ien, J.S., "Determination of the Kinetic Rate Constants for Polymethylmethacrylate in a Semi-Global Reaction Model," Submitted to be a NBS report. 
Center for Fire Research

Vational Bureau of Standards

FY 85

Institution: Clemson University

Grant No.: 60 NANB4D0033

Grant Iitle: Ternary Reactions Among Polymer Substrate-OrganohalogenAntimony Oxides in the Condensed Phase Under Pyrolytic, Oxidative and Flaming Conditions.

Principal Investigator: Dr. M. J. Drews

School of Textiles

Clemson University

Clemson, South Carolina 29634-1307

Other Professional Personnel: Dr. C. W. Jarvis, Co-Principal Investigator

Dr. G. Lickfield, Post-doctoral Research

Associate

Ms. K. McCoy, Graduate Assistant

NBS Scientific Officer: Dr. W. Schaub

Technical Abstract:

The objective of this work is to determine the chemical mechanisms for the solid phase interactions which occur in antimony oxide/organohalogen/ thermoplastic polymer substrate compositions during combustion. The formation of intermediate flame retardant decomposition products and the role of the polymer substrate in the generation of volatile antimony compounds are of special interest, with respect to the importance of the observed solid state interactions to the overall chemistry during degradation. Data on the comoustion chemistry will be obtained from laboratory scale flaming combustion experiments conducted at the Center for Fire Research of the National Bureau of Standards. The combined degradation and combustion experiment data sets are to be used in an atcempt to develop a comprehensive model, integrating condensed phase chemistry and combustion performance for flame retarded thermoplastics. One possible important utilization of such a model, in addition to flame-retardant formulation efficiency optimization, might be in risk and hazard analysis.

The small scale degradation studies employ isothernal and dynamic thermal analysis, as well as isothermal tube furnace experiments. Sample sizes range from the milligram to gram scale depending on the apparatus. Antimony analysis and bromide ion monitoring are used to develop a cemperature profile of the antimony volatilization and to measure the extent of reaction. During the current project year, the use of capillary gas chrcmatograpiic analysis of the trapped volatiles has been initiaced. The basic experimental sequence consists of a study of the individual components, Eollowed by the binary mixtures (polymer/organohalogen, polymer/antimony oxide, anc organohalogen/antimony oxide) followed by the ternary mixture. 
Three polymers and three organobromine compounds of significantly different thermal stabilities and primary decomposition pathways were initially chosen as model polymer substrate and halogen sources. The polymer substrates were polyethylene terephthalate (PET), polypropylene (PP) and polymethylmethacrylate (PMMA) and the organobromine compounds were decabromodiphenyl oxide (DBDPO), tetrabromobisphenol-A (TBBPA) and hexabromocyclododecane (HBCD). During the current project year one additional polymer substrate, linear high density polyethylene (HDPE), has been included, as we11 as several additional halogen sources including an acyclic organochlorine and the chlorinated analog of DBDPO. Finally, the investigation has been extended to include other metals and a variety of modified antimony oxides.

In the previous antimony/halogen literature, at least three different mechanisms have been proposed to account for the antimony volatilization which has been observed in degradation and combustion studies. These reaction sequences can generally be separated into two categories according to whether or not the organohalogen component can undergo intramolecular dehydrohalogenation. For those compounds which can undergo intramolecular dehydrohalogenation, the principal route to the generation of volatile antimony species has been thought to involve the direct reaction of $\mathrm{HX}$, formed by the thermal decomposition of the halogen source, with the antimony oxide. For intramolecular dehydrohalogenation, alternative reaction sequences involving either the indirect formation of $\mathrm{HX}$ or unspecified intermediates have been proposed. Even in these alternative schemes, the necessity for HX formation is implied if not explicitly included.

Based on the results obtained from the small scale degradation experiments, it is now possible to conclude that a previously unreported mechanism exists for antimony volatilization which does not involve HX formation. Antimony volatilization, similar to that measured for ternary mixtures, has been observed from compositions which contain no source of hydrogen at temperatures comparable to those previously reported for pyrolyzing polymers substrates during combustion $\left(\simeq 400^{\circ} \mathrm{C}\right)$. Other experiments have indicated that this reaction is not unique to antimony and may be rather general for certain organohalogen structures. In addition, the small scale degradation data with HBCD as the halogen source, strongly suggest that even with halogen sources which do undergo intramolecular dehydrohalogenation, the reactions leading to antimony volatilization may include more than the simple reaction of $H X$ with the antimony oxide.

Based on a comparison of results obtained in the tube furnace to those from thermogravimetric analysis experiments, it would also appear that the extent of the organohalogen/antimony oxide/polymer substrate reaction can be greatly affected by physical factors related to the preparation of the reaction mixture. Consequently, these data may be utilized in the future to propose a quantitative explanation for observations which have been made in the literature regarding the efficiency difference between the pentoxide and the trioxide. 
During the final quarter of this year's project, the laboratory scale combustion experiments will be carried out. In addition to the burning parameters which have been measured during the previous combustion experiments on these samples, the current burns will include a trapping experiment to be used for volatiles analysis. These data will form the basis for a comparison of the combustion efficiency of not only the polymer substrate, but also the organohalogen volatiles generated during the burns. These data are potentially significant for certain organohalogen sources from an overall fire safety, risk and hazard assessment perspective.

The results of this systematic investigation will contribute new, basic information with respect to fire retarded and fire resistant thermoplastics; the mechanisms for the formation of volatile antimony species from the reactions of antimony oxides and other antimony containing compounds in the presence of organohalogens; and the first systematic study on the controlled combustion of thermoplastics containing this important class of flame retardants. The systems description which this research seeks to develop should make it possible to model more accurately the combustion performance of these materials in a real fire situation, as well as lead to a greater understanding of the thermal and chemical characteristics necessary for the more efficient flame retardation of thermoplastics. 


\section{CENTER FOR FIRE RESEARCH \\ NATIONAL BUREAU OF STANDARDS \\ FY 85}

Institution:

Grant No:

Title:

Principal Investigator:

Other Professional Personnel:

NBS Scientific officer:
Factory Mutual Research Corp., Norwood, MA 02062 NB83-NADA-4014

Calculated Interaction of Water Droplet Sprays with Fire Plumes in Compartments

Dr. Ronald L. Alpert

Basic Research Department

(617) 762-4300, ext. 2776

Dr. Mary Delichatsios

Ms. Mary K. Mathews

Dr. John de Ris

Dr. Bernard McCaffrey

Technical Abstract:

The objective of this program, which started in July 1983, is to predict mathematically, through the use of computer solutions, how a water spray interacts with the buoyant, turbulent gas flow induced by fires in compartments. Our goal is to obtain general interaction correlations reiating spray penetration and cooling of the fire environment to controlling spray and fire plume parameters.

During the last two years of our research effort, two separate tasks have been proceeding in parallel. The first task involves the study of a simplified axisymmetric problem that models the behavior of a downward facing droplet spray in the presence of an upward flowing plume from a fire. Calculations of the gas flowfield and of spray penetration and cooling are being performed using an existing numerical spray code (TEACH-T coupled to the particle-source in cell technique) now in use at FMRC. The second task involves the development of major improvements in the gas calculation algorithm of the spray code so that more accurate, transient flow solutions can be obtained reliably with the minimum usage of computer time. An efficient and accurate numerical algorithm is essential in order to obtain reliable results for a broad range of sprinkler, fire and compartment configurations in the future.

Applied Calculations with the Existing Computer Code

A number of enhancements to the existing spray code have been completed. The most important of these improvements has been the simulation of a fire plume through the use of uniformly distributed volumetric heat sources in a cylindrical region. Both the heat source intensity $\left(800-1200 \mathrm{~kW} / \mathrm{m}^{3}\right)$ and the height to diameter ratio of the heat source cylinder are made consistent with our previous measurements of pool fires. Peak gas temperatures and velocities calculated with the simulated fire source are in general agreement with known properties of turbulent flames. This new fire source replaces the hot-gas jet used previously as a plume source and allows the attainment of realistic nearceiling gas temperatures in the flow solution.

About 20 steady, axisymmetric flow field computer solutions were obtained initially with a crude, $16 \times 16$ mesh and a spray directly above either the hot gas jet or simulated fire plume sources. Correlations were then developed 
linking the efficiency of spray cooling as well as the spray penetration through the plume to the relative magnitudes of characteristic spray and plume momenta. A wide range of initial droplet injection velocities and water flow rates were considered but with only one droplet size and fire heat release rate. Results of this initial spray interaction study were presented at ASME and NBS conferences, an SFPE seminar ${ }^{?}$ and have been published in the Journal of Heat Transfer ${ }^{2}$ and in Fire Safety Journal ${ }^{3}$.

More recently, several hundred flow field solutions have been obtained using more accurate $22 \times 22$ and $32 \times 32$ computational grids. These solutions (typical streamline plots are shown in Figure 1 for the $32 \times 32$ grid) involve variations in plume heat release rates from $1 / 2$ to $4 \mathrm{mw}$, variations in ceiling clearance ( 3 or $6 \mathrm{~m}$ ) and a range of spray characteristics bracketing those typical of modern, high performance sprinklers. Analysis of the recent results with finer computational grids is now in progress.

There have been several other enhancements of the existing spray fire code during the current project. These include: 1) the addition of a curtain wall to obstruct the ceiling (or floor) boundary, if desired; 2) an initial improvement of the contour-plotting routine for streamlines, isotherms, etc. (further improvements are planned); 3) refinement of the droplet integration routine to allow for complete evaporation of small droplets without causing numerical instability; and 4) inclusion of an improved method for calculation of water flux distributions to surfaces in the flow field.

\section{Improvement of the Gas Phase Calculation Algorithm}

The large amount of computer time required by the present code is due to the large number of iterations required to converge to the solution of the flow field. Furthermore, the solution obtained is only first-order accurate (errors are proportional to the grid spacing, $\Delta \mathrm{x}$ ) which may be inadequate for our problems. This necessitates the use of finer grids. Which further slows down convergence. In many cases, numerical instability, rather than excessive computer time, prevents the calculation of any flow solution at all. To remedy these problems, we have undertaken to make fundamental changes to the current TEACH-T code to improve both its accuracy and efficiency while retaining its full flexibility for treating the wide range of physical phenomena required for engineering applications.

We have examined several higher order accurate algorithms for transient flows. We have analyzed the relative importance of the various physical phenomena involved and have identified a general solution approach based on operator "splitting". Our proposed approach essentially decouples the different physical interactions, such as velocity-pressure-buoyancy interactions, thus simplifying the solution procedure, while preserving accuracy and stability.

A different technique for obtaining the pressure field has also been examined. The existing TEACH computer code uses a pressure correction equation, which is derived by satisfying the conservation of mass. This velocitypressure coupling is often a major cause of slow convergence in the iterative technique. We wili use a technique suggested by $H$. Baum of NBS for finding the pressure field based on solving a Poisson equation, which is derived by taking the divergency of the momentum equation. The code, a fast eliptic 
solver developed at NBS in 1975, has been transferred to our HP1000 minicomputer and has been run successfully in a sample program.

The stability of the code is essential for practical problems where the code ruggedness is very important. In practical problems, stability constraints can severely impact computational efficiency by requiring many small time steps which must become ever smaller as one reduces the spatial mesh size in an attempt to establish the solution accuracy. Our suggested scheme (Alternating Direction Implicit algorithm) is expected to be unconditionally stable and satisfies most of our practical needs for accuracy and efficiency while it avoids constraints on the time step.

Finally, temporal accuracy is important in transient flow problems. Although complete transient solutions are not needed for this study, a transient algorithm is necessary to check if periodic flows are obtained in fire and spray interactions. Otherwise, a physical solution with periodic motions may be interpreted as nonconvergence of a steady-state numerical scheme.

The proposed algorithm which is implicit in time and unconditionally stable for large time steps has an accuracy of order $(\Delta x)^{2}$ at steady-state and of order $(\Delta t)^{2},(\Delta t) \cdot(\Delta x),(\Delta x)^{2}$ during the transient flow. Further improvements in the efficiency and/or accuracy of the transient flow calculations can be made by sacrificing the unconditional stability of the algorithm. The conditions imposed on the maximum allowable time step in this case are much less restrictive than they are for explicit algorithms and are expected to be acceptable for a wide range of our applications.

All of the improvements in stability, spatial accuracy, transient temporal accuracy and an efficient "splitting" of the pressure, velocity and buoyancy coupling, are expected to provide the ruggedness and accuracy needed for costefficient fire/spray calculations.

Conclusions and Future Plans:

Sample problems involving interactions of droplet sprays with buoyant flows have been solved numerically. Calculated properties of the interaction flow field in many cases appear to depend on a ratio of droplet spray momentum to that induced by the buoyancy source. It is expected that improved correlations of this type, developed from more extensive calculations, should prove to be very useful for the optimization of automatic sprinkler water spray protection against both residential and industrial enclosure fires.

Reports and Papers

1. Alpert, R.L., "Numerical Modeling of the Interaction Between Automatic Sprinkler Sprays and Fire Plumes," paper presented at a Symposium on Computer Applications in Fire Protection, sponsored by the Society of Fire Protection Engineers, Leesburg, Virginia, March, 1984.

2. Alpert, R.L., "Calculated Interaction of Sprays with Large-Scale Buoyant Flows," Journal of Heat Transfer, Vol. 106, No. 2, p. 310, May, 1984.

3. Alpert, R.L., "Numerical Modeling of the Interaction Between Automatic Sprinkler Sprays and Fire Plumes," Fire Safety Journal, Vol. 9, No. 1-2, pp $157-163,1985$. 
STREAMLINES: $3.8 \mathrm{MW}$ PLUME VS SPRAY

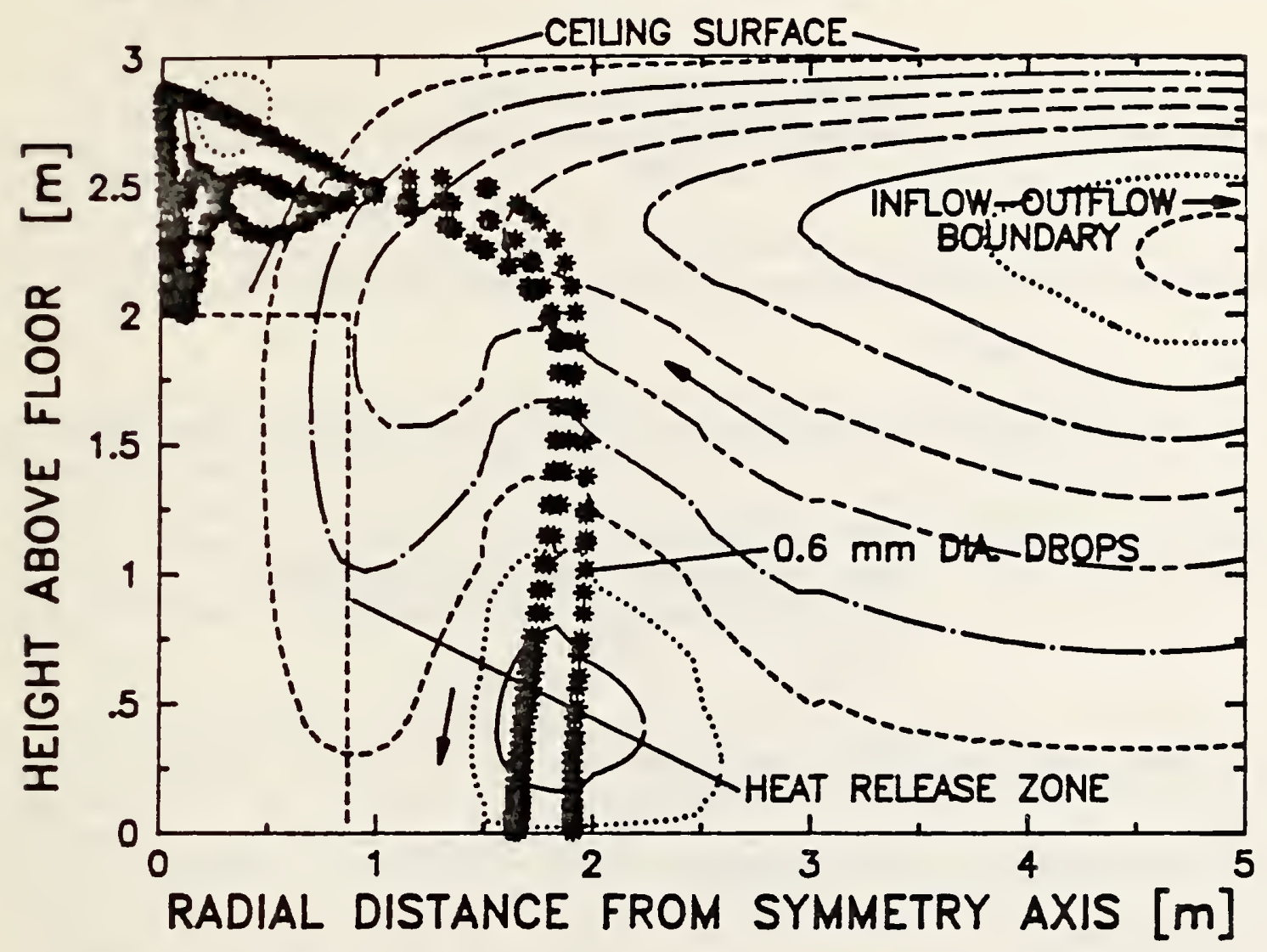

Figure 1a: Spray Conditions: water inflow $4.65 \mathrm{l} / \mathrm{s}$, injection velocity $8 \mathrm{~m} / \mathrm{s}$.

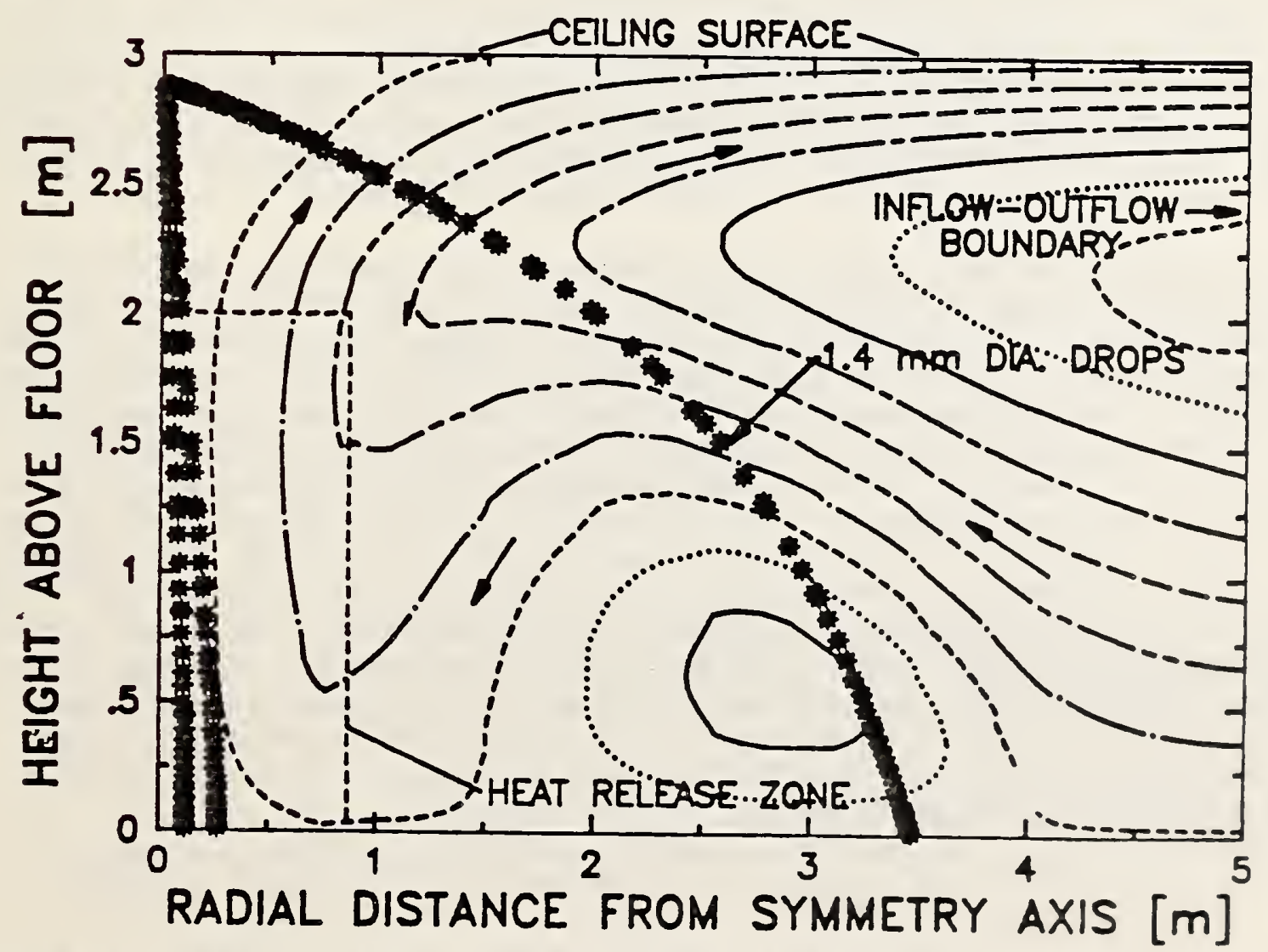

Figure 1b: Spray Conditions: water inflow $7 \mathrm{l} / \mathrm{s}$, injection velocity $8 \mathrm{~m} / \mathrm{s}$. 
CENTER FOR FIRE RESEARCH

NATIONAL BUREAU OF STANDARDS

FY85

Institution: Factory Mutual Research Corporation, Norwood, MA 02062

Grant No.: $\quad$ 60NANB4D0043

Title: Development of a Model to Provide Comprehensive Fire Property Data

Principal Investigator: Archibald Tewarson

Factory Mutual Research Corporation

1151 Boston-Providence Turnpike

No rwood, MA 02062

Telephone: (617) 762-4300

Other Professional Personnel: J.A. Steciak

$S . D$. Ogden

NBS Scientific officer: V。 Babrauskas

Technical Abstract:

The objective of the study is to provide comprehensive fire property data, which will be used as inputs to fire models for the assessment of fire hazard and protection requirements.

In the previous grant studies, the effects of fire ventilation and external and flame heat flux have been examined [1-7]. It has also been shown that the generation efficiencies of heat $\left(X_{i}\right)$ and chemical compounds ( $f_{j}$ ) are independent of the fire scale, if the flames are turbulent $[4,6,7]$.

In the current grant study, the relationships between $X_{f}, f_{j}$ and the atom distributions in the fuel vapors and the nature of the chemical bonds are being examined. A new approach based on the "smoke point height" $\left(l_{s}\right)$ has been used. Experiments were performed in our 10-kW scale apparatus, using a $250 \mathrm{ml}$ Pyrex glass Erlenmeyer flask, attached to a $120 \mathrm{~mm}$ long. $9 \mathrm{~mm}$ ID, Pyrex glass tube, for the samples. The samples were heated either by radiant heaters or by a heating mantle. The heating rates of the sample were controlled for the measurement of: 1) $\ell_{S}$, where a laminar diffusion flame was used; and 2) $X_{i}$ and $f_{j}$, where a turbulent diffusion flame was used. The fuels used were: 1) $\mathrm{C}-\mathrm{H}$ bond (aliphatic) - polypropylene (PP), polyethylene (PE). pentane hexane, cyclo-hexane heptane, and 1so-octane; 2) $\mathrm{C}-\mathrm{H}$ bond (aromatic) - polystyrene (PS) and toluene; 3) C-H-O bond (aliphatic) - polymethyl methacrylate (PMMA), cellulose, methanol, ethanol, iso-propanol, and acetone; 4) $\mathrm{C}-\mathrm{H}-\mathrm{O}-\mathrm{N}$ bond (aliphatic) - nylon 6/6;5) $\mathrm{C}-\mathrm{H}-\mathrm{O}-\mathrm{N}$ bond (aromatic) - rigid polyisocyanurate foam: and 6$) \mathrm{C}-\mathrm{H}-\mathrm{Cl}$ bond (aliphatic) - polyvinyl chloride (PVC) and PE with $36 \%$ chlorine. 
Results are shown in Figure 1 , where $\chi_{i}$, and $f_{j}$ are plotted against $\ell_{s}$. The lines connecting the data points are derived from the regression analyses. Subscripts "conv" and "rad" refer to the convective and the radiative components of the combustion of efficiency, for which the subscript "chem" has been used. Subscript "HC" refers to the total gaseous hydrocarbons, expressed as $\mathrm{CH}_{4}$, Smoke refers to the carbon compounds other than $\mathrm{CO}, \mathrm{CO}_{2}$, and $\mathrm{HC}$.

From the relationships, as shown in Figure 1, and the literature data for over 200 fuels, values of $X_{i}$, and $f_{j}$ were estimated, for aliphatic and aromatic fuels, which include hydrocarbons, alcohols, ketones, esters, and organic nitrogen- and sulfur-containing fuels. An example of the estimated data is shown in Figure 2 for gaseous and liquid aliphatic fuels, where $x_{\text {chen }}$, and $f$ smoke are plotted against the molecular weight of the fuel vapors. The nature of the chemical bonds is identified in terms of the generic nature of the fuels.

Our preliminary findings for the aliphatic fuels are: 1) that the nature of the chemical bonds and the atom distributions in the fuel vapors do govern the values of $x_{i}$, and $f_{j}$. The nature of the chemical bonds appear to be more dominant in affecting $\chi_{i}^{j}$, and $f_{j}$ values than the distributions of the atoms in the fuel vapors; 2 ) that the values of $\chi_{\text {chem, }}$, and $\chi_{\text {conv }}$ decrease and the values of $X_{\text {rad }},{ }{ }_{C O}, f_{H C}$, and $f_{\text {smoke }}$ increase as the number of carbon atoms increase to numbers between 3 and $5 ; 3$ ) that the values of $x_{i}$ and $f_{j}$ become approximately constant for the higher molecular weight fuel vapors with number of carbon atoms greater than 6, except in some cases where the structure is cyclic or branched. It may thus be possible to neglect the size of the molecules in the fuel vapors, an important finding for the polymers, which vaporize mostly as oligomers, rather than as monomers; and 4) that the presence of nitrogen and sulfur atoms in the fuel vapors does not appear to influence $x_{i}$ and $f_{j}$ values, for the fuels examined in this study. The presence of $\mathrm{Cl}^{1}$ atoms in the fuel vapors, however, has a strong effect on $x_{i}$ and $\mathrm{f}_{\mathrm{j}}$ values.

Detalled measurements of major as well as minor chemical compounds, including soot, generated in the fires of the selected fuels, "smoke point height", and elemental compositions of the fuel vapors of the polymers are being continued. The following additional fuels are planned to be added to our study: styrene, methyl methacrylate, an ester, an organic nitrogen, and an organic sulfur-containing fuel. Analyses for the aromatic and halogenated fuels and polymers are also being continued.

\section{$\underline{\text { Ref erences }}$}

1. A. Tewarson, "Experimental Evaluation of Flammability Parameters of Polymeric Materials," Flame Retardant Polymeric Materials Volume 3, ed., M. Lewin, S. M. Atlas, and E. M. Pearce, Plenum Press, New York, NY p. 97,1982 .

2. A. Tewarson, "Physico-Chemical and Combustion Pyrolysis Properties of Polymeric Materials," National Bureau of Standards, Washington. D.C.. Technical Report No. NBS-GCR-80-295, November 1982. 
3. A. Tewarson, J. L. Lee, and R. F. Pion, 18th Symposium (International) on Combustion, The Combustion Institute, Pittsburgh, PA, 1980, p. 563.

4. A. Tewarson, "Quantification of Fire Properties of Fuels and Interaction with Fire Environment," National Bureau of Standards, Washington, D.C., Technical Report No. FMRC J.I. OEON6.RC, April 1982.

5. A. Tewarson, and J. Steciak, Combustion and Flame 53, 123, 1983.

6. A. Tewarson, 20th Symposium (International) on Combustion, The Combustion Institute, Pittsburgh, PA (in press).

7. A. Tewarson, "Scale Effects on Fire Properties of Materials." National Bureau of Standards, Washington, D.C., Technical Report No. FMRC J.I. 0.J4N2.RC, December 1984.

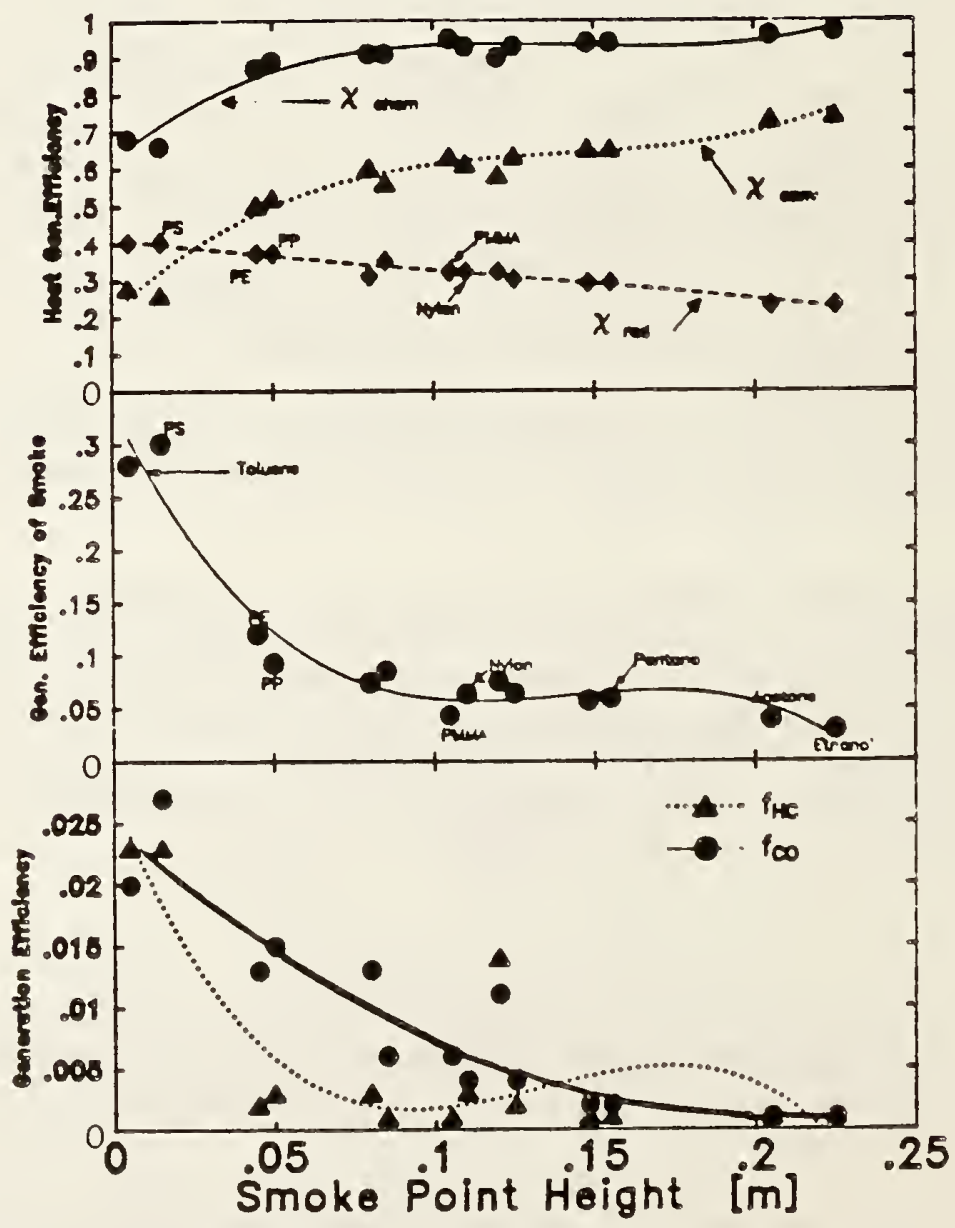

Figure 1. Generatic: etficiencies of heat and compounds as functions of smoke oiat height 


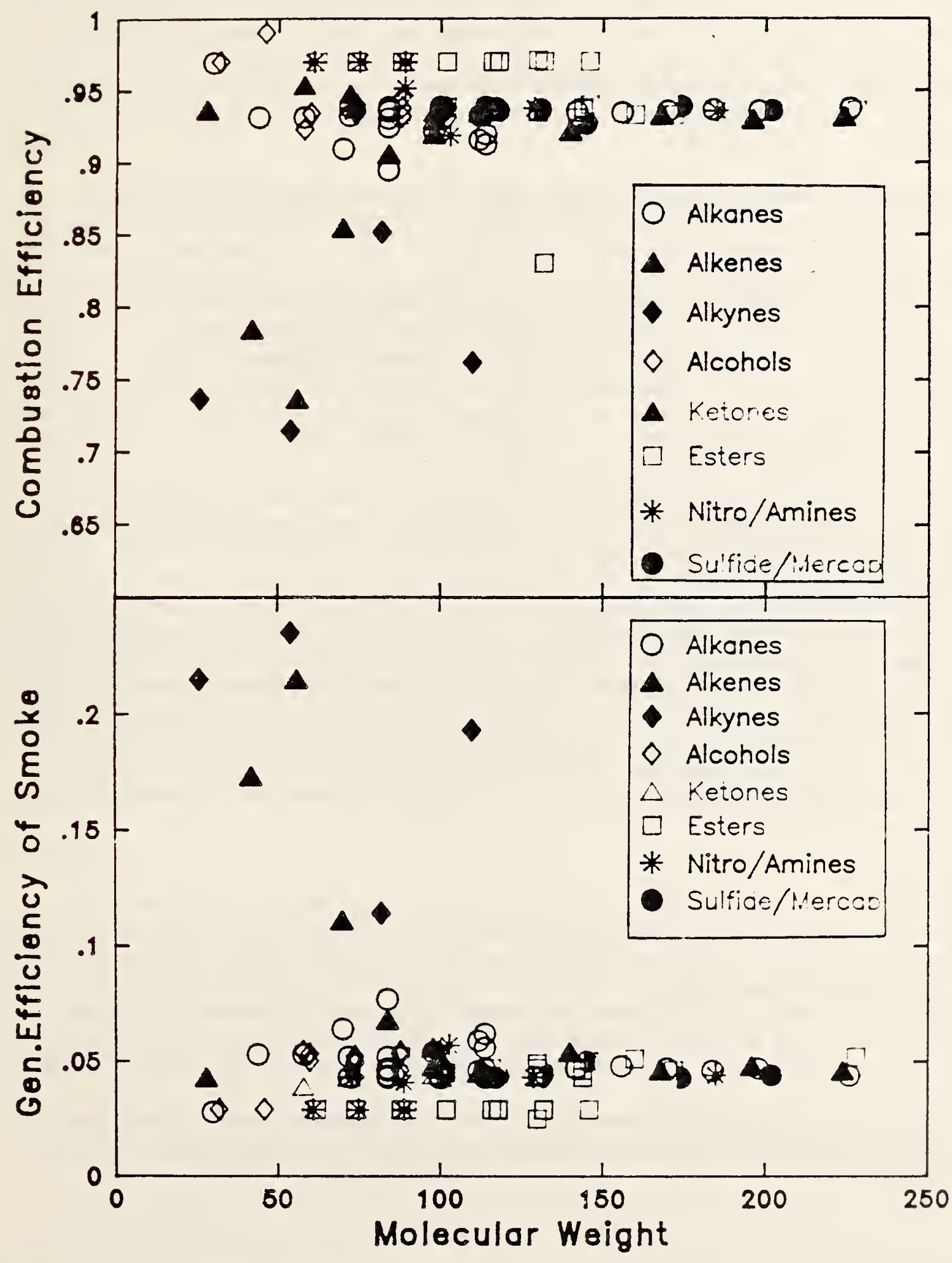

Figure 2. Generation efficiencies of heat and smoke as functions of molecular weight for aliphatic fuels 
CENTER FOR FIRE RESEARCH

NATIONAL BUREAU OF STANDARDS

FY 85

Institution: Factory Mutual Research Corporation

Grant No.: $\quad$ NB83NADA4054

Grant Title: Effects of Water Discharge Rate and Drop Size on Spray Cooling in Residential Fires

Principal Investigator: Hsiang-Cheng Kung

Manager, Applied Mechanics Section

Factory Mutual Research Corporation

1151 Boston-Providence Turnpike

Norwood, Massachusetts 02062

Other Professional Personnel: Dr. Hong-Zeng You

Z. $\mathrm{Han} *$

NBS Scientific Officer: Edward K. Budnick

Technical Abstract:

The objective of this research program is to investigate spray cooling in room fires, and to establish empirical correlations which are readily applicable to fire protection engineering. The study has been focused on: 1) the spray cooling ability in a room, and convective heat flux leaving the room opening as affected by water discharge rate, drop size distribution, fire size, room size and opening area; 2) the temperature of the hot gas layer inside the room; and 3) drop size distribution of sprays of geometrically similar sprinklers.

Experiments

The program is of experimental nature. A total of 25 room fire tests were conducted in a $3.66 \mathrm{~m} \times 7.32 \mathrm{~m} \times 2.44 \mathrm{~m}$ high test room. A $1.22 \mathrm{~m}$ wide $\mathrm{x}$ $2.44 \mathrm{~m}$ high opening was located at the center of the west wall (see Figure 1). The fire source was a heptane spray fire located close to the east wall at equal distance from the north and south walls as shown in Figure 1. A steel plate was used to shield the fire source from direct spray impingment.

In each test only one sprinkler was installed at the ceiling inside the test room at $1.83 \mathrm{~m}$ from the east and north walls. Three geometrically

*Visiting scientist from Tianjin Fire Research Institute, Tianjin, China 
stmilar sprinklers* were used in this program. The orifice diameters of the three sprinklers were $11.0 \mathrm{~mm}, 8.3 \mathrm{~mm}$ and $6.9 \mathrm{~mm}$. The water flow to the nozzle was controlled by a solenoid valve upstream of the nozzle. A simulated sprinkler link (brass disk) was installed in the vicinity of the sprinkler nozzle to actuate the solenoid valve through a temperature controller when the link temperature reached $100^{\circ} \mathrm{C}$ above its initial temperature. The disk was constructed from brass shim stock, having a diameter of $25.4 \mathrm{~mm}$ and a thickness of $0.41 \mathrm{~mm}$.

A calorimeter (fire products collector) was constructed over the room opening to collect the combustion gases exiting from the opening and to measure convective heat flux at the opening. The calorimeter consisted of a 2.44 $\mathrm{mm}$ diameter hood, a $0.61 \mathrm{~m}$ diameter stack, and other duct work. An electric blower was installed at the duct outlet. A $0.36 \mathrm{~m}$ diameter orifice plate was installed at the stack inlet to achieve uniform flow inside the stack at about $3 \mathrm{~m}$ (fire stack diameter) downstream of the orifice plate. An instrumentation station was located at $3.05 \mathrm{~m}$ downstream of the orifice plate to measure temperature, velocity, and gas concentrations ( $\mathrm{CO}, \mathrm{CO}_{2}, \mathrm{O}_{2}, \mathrm{H}_{2} \mathrm{O}$ and total hydrocarbon) of the stack gases.

To determine the heat loss rate through the wall and ceiling surface, surface heat flux gages were installed at the ceiling, east wall and upper portion of the south wall, and a pair of thermocouples were used to measure the inside and outside surface temperature of the lower portion of the south wa11. The heat transfer rates through the lower portion of the south wall were calculated by numerically solving the pertinent transient heat conduction equation with the inside and outside surface temperatures as boundary conditions. To measure the radiative heat flux through the room opening, a wide-angle radiometer was placed outside the room, $2.0 \mathrm{~m}$ from the opening.

Test variables included sprinkler discharge rate, $W$, heptane flow rate, $M_{\text {fuel }}$, and sprinkler nozzle diameter, $D$, as presented in Table 1.

Results

The period of investigation was limited to $80 \mathrm{~s}$ during which a steadystate condition was reached. Both the heat release rate of the fire and the convective heat flux through the opening were measured with the calorimeter. The heat release rate was derived from the $\mathrm{CO}$ and $\mathrm{CO}_{2}$ and THC measurements of the combustion gases collected by the calorimeter. The convective heat flux through the opening was based on the measurements of gas temperature and volumetric flow rate through the calorimeter.

The heat losses through the ceiling and wall surface were estimated from the heat transfer rates through the ceiling, east wall and south wall,

*Kung, H-C., "Cooling of Room Fires by Sprinkler Spray, Journal of Heat Transfer, Vo1. 99, No. 3, pp. 353-359, 1977. 
assuming that heat fluxes are symmetrical with respect to the vertical symmetrical plane of the test room shown in Figure 1. It was also assumed that the heat loss to the floor was mainly due to radiation from the fire source. In order to estimate the radiative heat flux to the floor, the radiation source of the fire was considered as a point source at the flame center and the radiation intensity of the fire was estimated from the radiometer measurement. The total radiation flux to the floor was thus calculated by integrating the directional radiation incidence throughout the floor area. Table 1 provides the heat release rate of the fire, $Q_{a}$, the convective heat flux leaving the room opening, $Q_{C}$, and the heat absorption rate of the spray, $\mathrm{Q}_{\text {cool }}$. The last quantity, $\mathrm{Q}_{\text {cool }}$, was obtained by the difference between the heat release rate of the fire and the sum of 1 ) the heat loss through the ceiling and the wall surfaces, 2) the radiative heat loss to the floor, and 3 ) the convective and radiative heat losses through the room opening.

Empirical correlations for the heat absorption rate of the spray and the convective heat flux through the room openings have been established from the data obtained in this study, in terms of 1) the heat release rate of the fire; 2) the heat loss to the ceiling, walls, and floor; 3) room opening geometry; 4) sprinkler discharge rate; 5) water discharge pressure; and 6) sprinkler orifice diameter (see Figures 2 and 3 ). These correlations were applied to the experimental data of Kung* for a $3.05 \mathrm{~m} \mathrm{x} 3.66 \mathrm{~m} \mathrm{x} 2.44 \mathrm{~m}$ high enclosure and to data of Morgan and Baines** for a $5.60 \mathrm{~m} \mathrm{x} 17.40 \mathrm{~m} \mathrm{x} 3.10 \mathrm{~m}$ high enclosure. It appears that both Kung's and Morgan and Baine's data follow the same correlations developed in this study, as shown in Figures 2 and 3.

The temperature of the hot gas layer at the room opening was correlated with the following variables: 1) the heat release rate of the fire; 2) the heat loss rate to the ceiling, walls and floor; and 3) the heat absorption rate of the spray. Figure 4 presents the correlation of the excess gas temperature at the opening with the above variables.

Currently the drop size distribution of the sprinkler sprays employed in this study are being measured using the FMRC drop size measuring instrument. It is expected that the result of this research program will improve the understanding of sprinkler spray and spray cooling in room fires, and provide useful input to fire protection engineering.

\footnotetext{
*Kung, H-C, "Cooling of Room Fires by Sprinkler Spray", Journal of Heat Transfer, Vol. 99, No. 3, pp. 353-359, 1977.

**Morgan, H.P. and Baines, K.. "Heat Transfer From a Buoyant Smoke Layer Beneath a Ceiling to a Sprinkler Spray, Part 2 - An Experiment," Fire and Materials, Vol. 3, No. 1, pp. 34-38, 1979.
} 
Kung, H.C., You, H-Z and Han, Z., "Effects of Water Discharge Rate and Drop Size on Spray Cooling in Room Fires", presentation at the Fall Technical Meeting, the Eastern Section of The combustion Institute, Clearwater Beach, Florida, Dec. 3-5, 1984.

\section{TABLE 1}

Test Variables: Heat Release Rates, Convective Heat Flux Through Room Opening, and Heat Absorption Rates of Spray

\begin{tabular}{rrrrrrr} 
Test No. & $\begin{array}{c}\dot{M}_{\text {fuel }} \\
(\mathrm{cc} / \mathrm{s})\end{array}$ & $\begin{array}{c}\mathrm{W} \\
(1 \text { iter/min) }\end{array}$ & $\begin{array}{c}\mathrm{D} \\
(\mathrm{mm})\end{array}$ & $\begin{array}{c}\mathrm{Q}_{\mathrm{a}} \\
(\mathrm{kW})\end{array}$ & $\begin{array}{c}\mathrm{Q}_{\mathrm{c}} \\
(\mathrm{kW})\end{array}$ & \multicolumn{1}{c}{$\begin{array}{r}\mathrm{Q}_{\mathrm{cool}} \\
(\mathrm{kW})\end{array}$} \\
& & & & & & \\
1 & 5 & 45.4 & 6.9 & 150 & 24 & 103 \\
2 & 4.9 & 68.2 & 6.9 & 148 & 5 & 125 \\
3 & 10.3 & 45.4 & 6.9 & 314 & 65 & 208 \\
4 & 10.1 & 68.2 & 6.9 & 306 & 23 & 253 \\
5 & 16.2 & 45.4 & 6.9 & 494 & 122 & 323 \\
6 & 16.0 & 68.9 & 6.9 & 486 & 58 & 385 \\
7 & 4.9 & 40.1 & 8.3 & 149 & 54 & 69 \\
8 & 4.7 & 68.2 & 8.3 & 140 & 15 & 105 \\
9 & 10.0 & 45.4 & 8.3 & 304 & 101 & 156 \\
10 & 10.4 & 68.2 & 8.3 & 316 & 57 & 220 \\
11 & 14.8 & 45.4 & 8.3 & 447 & 163 & 204 \\
12 & 15.6 & 68.2 & 8.3 & 472 & 104 & 313 \\
13 & 5.1 & 0 & 11 & 134 & 91 & 0 \\
14 & 5.3 & 45.4 & 11 & 135 & 73 & 31 \\
15 & 4.9 & 68.2 & 11 & 137 & 40 & 76 \\
16 & 4.9 & 98.4 & 11 & 136 & 16 & 106 \\
17 & 10.3 & 0 & 11 & 246 & 173 & 0 \\
18 & 10.4 & 45.4 & 11 & 282 & 164 & 58 \\
19 & 10.3 & 68.2 & 11 & 282 & 103 & 125 \\
20 & 10.5 & 98.4 & 11 & 285 & 54 & 203 \\
21 & 16.6 & 0 & 11 & 396 & 228 & 0 \\
22 & 16.2 & 45.4 & 11 & 418 & 220 & 91 \\
23 & 16.2 & 68.2 & 11 & 460 & 158 & 230 \\
24 & 16.3 & 68.2 & 11 & 474 & 157 & 241 \\
25 & 16.4 & 98.4 & 11 & 453 & 96 & 311
\end{tabular}




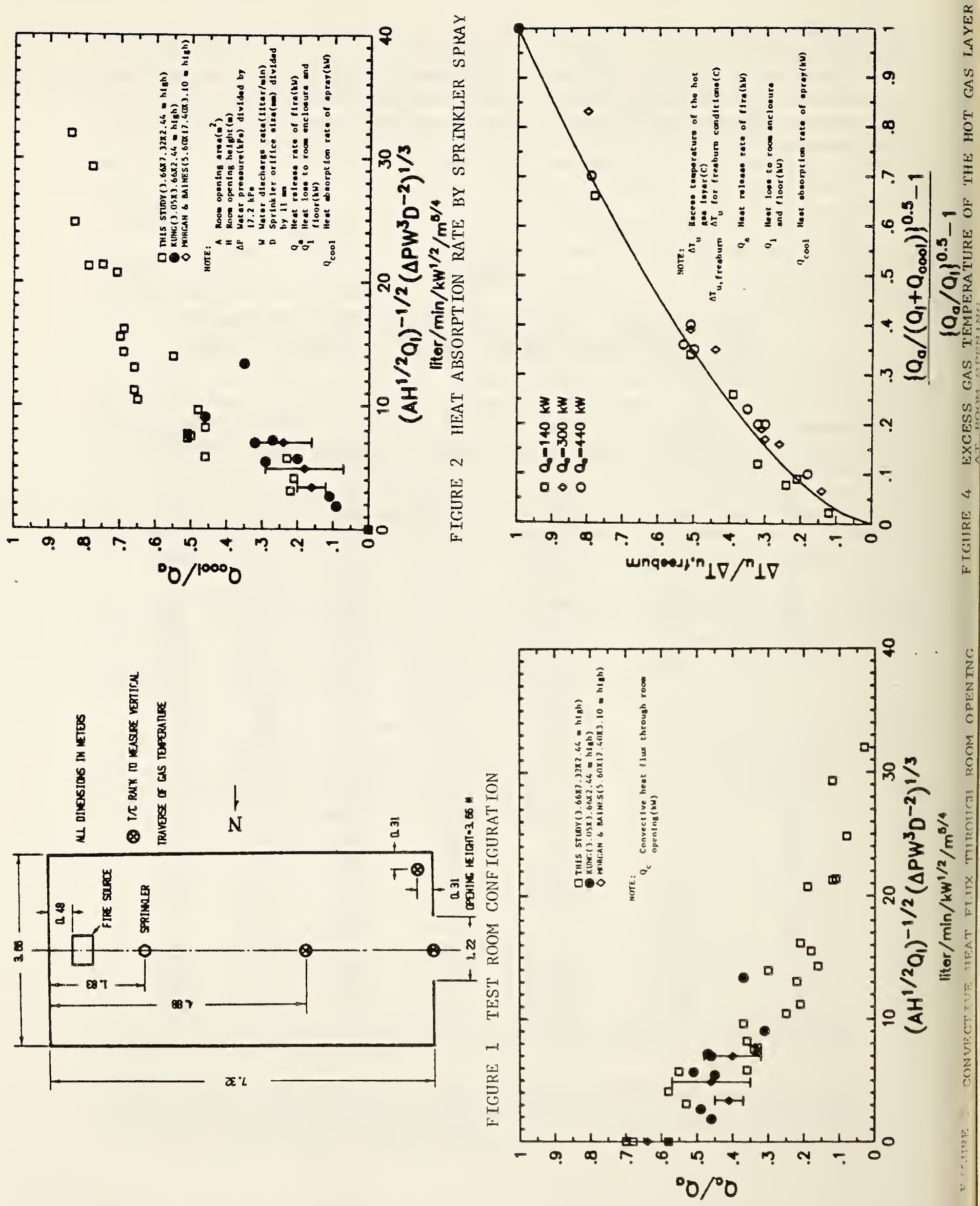




\section{CENTER FOR FIRE RESEARCH \\ NATIONAL BUREAU OF STANDARDS \\ FY 1985}

\section{Institution: Factory Mutual Research Corporation}

Grant No.: NB83NADA4046

Grant Title: Experimental Fire and Smoke Verification Data for Multiroom and Corridor Conditions

Principal Investigator: Dr. Gunnar Heskestad

Factory Mutual Research Corporation

1151 Boston-Providence Turnpike

No rwood, MA 02062

Telephone: (617) 762-4300

Other Professional Personnel: Mr. John P. Hill

NBS Scientific Officer: Mr. Edward K. Budnick

Technical Abstract:

The objective is to establish a data bank on multiroom fire situations with particular emphasis on health care facilities. The data will be available for testing fire modeling and engineering calculations carried out at the Center for Fire Research and by the fire research community at large. A number of fire and related life-safety issues were to be addressed in the program: ceiling jet in burn room, descent of smoke layer in burn room and buildup of pressure gradients: escape of smoke through open or closed door to corridor; propagation of smoke front underneath corridor ceiling and buildup of smoke layer; penetration of smoke and toxic gases into patient rooms communicating with corridor through closed or open doors; passage of smoke through ventilation ducting; and response of sprinklers and fire detectors. Both pre-flashover and post-flashover situations were to be included.

The experimental part of the program has now been completed and a report is under preparation. In addition to the report, a complete data printout (at one scan per second) has been sent to NBS along with tapes of the reduced data.

Facility. Figure 1 shows a layout of the basic facility with indications of instrumentation. There is a "burn room" and two so-called "target rooms". each measuring $3.66 \mathrm{~m}$ square, attached to a $2.44 \mathrm{~m}$ wide $\times 18.90 \mathrm{~m}$ long corridor. Three access doors to the enclosure were provided, but are not shown; these were sealed tight during the tests. Each of the three rooms was provided with a vent to the outside near floor level. The vent mass flow was monitored, both in the case of natural ventilation and forced ventilation (into the enclosure) with fans; in the case of forced ventilation, air was returned to the outside via a vent in the right end wall of the corridor. Gypsum board on wood studs was used throughout. In addition, the walls and 
ceiling of the burn room were overlain with Marinite (Johns Manville) to harden against repeated fire exposure. All three doors were braced when in closed position to prevent warping due to heat; door cracks were characterized for leakage in special experiments.

Most of the instrumentation indicated in Figure 1 was fairly standard except the "brass disks" and "turbidimeters." The brass disks were $0.5 \mathrm{~mm}$ thick, $25 \mathrm{~mm}$ in dia.. and provided with thermocouples to measure thermal response, simulating heat detectors and also providing some measure of the gas velocity when coupled with the response of an adjacent thermocouple. The turbidimeters measured the turbidity (optical density) of the smoke at three discrete wavelengths. Eight wall pressure taps were provided for measuring six pressure differentials, including that between the burn room and the exterior of the facility. Depending on the experiment, between 125 and 130 data channels were monitored.

Experiments. Three types of fire sources were employed: 1) steady propylene fires at approximately 60 and $500 \mathrm{~kW}$ using "sandbox" burners; 2) propylene fires programmed under computer control to grow parabolically with time, reaching and surpassing $1 \mathrm{MW}$ in one, two, four, or eight minutes; and 3 ) a naturally growing fire in a configuration of so-called "Standard Plastic Commodity " (FM test fuel consisting of corrugated boxes with polystyrene tubs in compartments).

In the basic experiments, various combinations were investigated of fire source, open and closed doors, open or closed windows in burn room, and natural or forced ventilation in all rooms ( 40 runs). Then followed a series of fire experiments with a sealed corridor partition and ceiling vents on either side of the partition, ducted to a common supply or common return plenum; here, it was the intent to investigate smoke migration in certain ventilation situations (10 runs). Next. a continuously weighed polyurethane slab was installed as a target for flashover ignition in the burn room, both in the horizontal and vertical orientations and with the intent of comparing flashedover mass loss rates with previously measured freeburn mass loss rates ( 9 runs). Finally, a single fire with the "Standard Plastic Commodity" was conducted to explore generation and dispersion across open and closed doors of carbon monoxide in a pyrolyzing enclosure fire.

Sample Data. Extracts of the large body of data that may be of immediate interest are presented in Figures 2, 3, and 4. Figure 2 shows the times the smoke front under the ceiling crosses the three corridor instrument stations with photometers (Stations 6, 4, 2; see Figure 1). Runs 1, 2, and 3 were replicates with a $0.30 \mathrm{~m}$ diameter fire source at $60 \mathrm{kl}$, closed windows in the burn room, door open from burn room to corridor. and doors to target rooms closed. Runs 16 and 17 were duplicate runs with a $0.91 \mathrm{~m}$ diameter burner at $500 \mathrm{~kW}$, but otherwise the same conditions as Runs 1, 2, and 3. Figure 3 is limited to Run 17 and shows values of temperature rise versus time at varinis levels $\mathrm{y} / \mathrm{H}$ (where $\mathrm{y}$ is the distance beneath the ceiling and $\mathrm{H}$ is the ceiling height) at Station 4. Note that plume fluid arrives simultaneously at elevations $\mathrm{y} / \mathrm{H}$ beneath the ceiling of $0.021,0.042,0.104$, and 0.229 , corresponding to arrival of the forward smoke front. The forward smoke front is reflected at the end of the corridor to form a return smoke front filling the remaining 
clear space above the floor, as evidenced by visual observations and the approximate simultaneous rise in Figure 3 of temperatures at $\mathrm{y} / \mathrm{H}$ levels of $0.395,0.562,0.729$, and 0.896. Figure 4 is also 11 mited to Run 17 and shows optical densities $\left(d^{-1} \ln \left(I_{0} / I\right)\right.$, where $d$ is beam length, $I_{0}$ and $I$ are photometer signals without and with smoke) at the level $\mathrm{y} / \mathrm{H}=0.562$ midway in the cerridor (Sta. 4), in the closed target room nearest the burn room (Sta. 8), and in the most distant closed target room (Sta. 1).

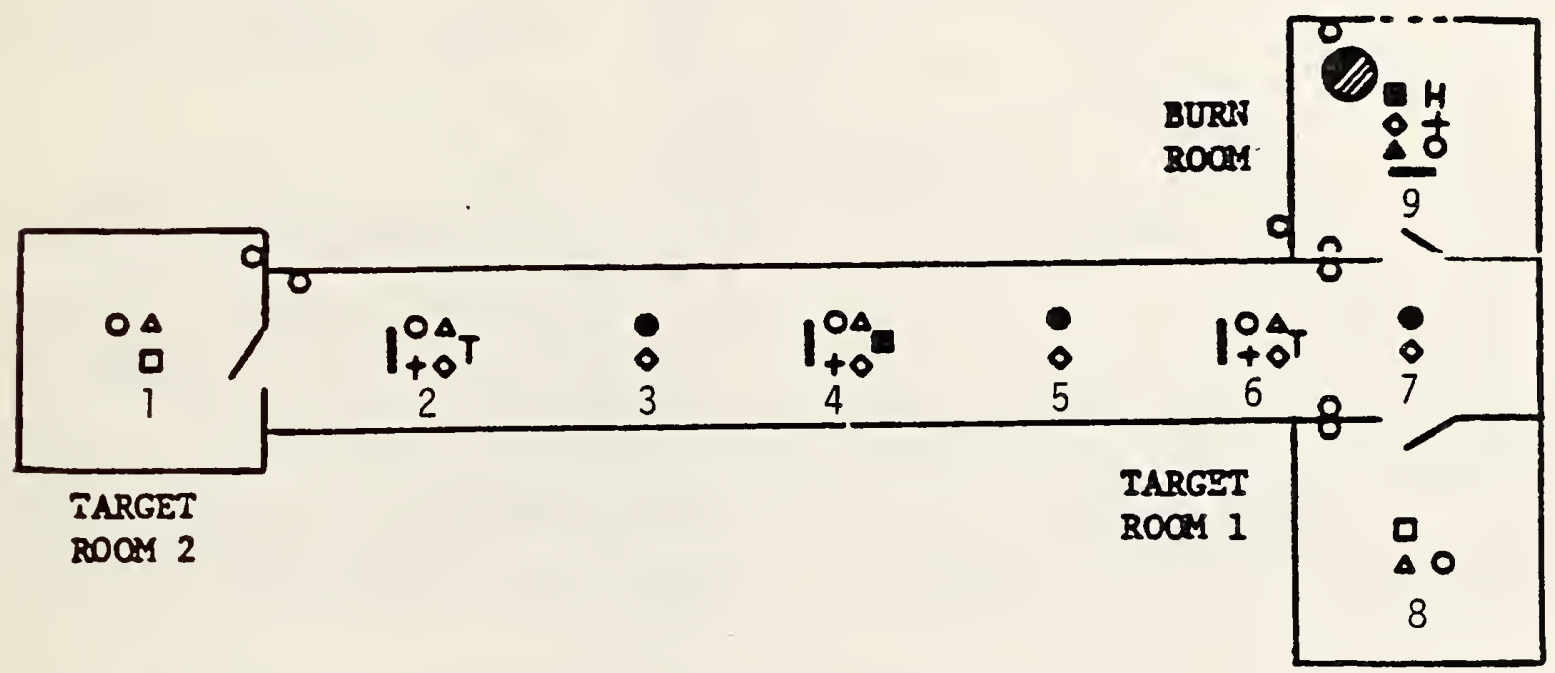
Oire Source
- Vertical thermocouple Array (8 Levels)
- Vertical Photometer Array (4 Leve1s)
+ Celling Thermocouple (Imbedded in Ce1l. Surf. Layer)
- Brass Disk Under Celling (S1mulates Heat Detector)
H Bldirectional Flow Probe Under Celling
- Eye-Level Sampling of $\mathrm{O}_{2}, \mathrm{CO}_{2}, \mathrm{CO}$
- Ionlzation-Photoel. Palr of Smoke Detectors
- Celling Gas Thermocouple
- Eye-Level Sampling of $\mathrm{CO}_{2}, \mathrm{CO}$
$T$ Turbldimeter Under Celling
- Wall Pressure Taps (0.39 m From Ce11ing)

F1gure 1. Fac1lity with instrumentation. Corridor measures $2.44 \mathrm{~m}$ $x 18.9 \mathrm{~m}$, and each room measures $3.66 \mathrm{~m} \times 3.66 \mathrm{~m}$. Celling helght $182.44 \mathrm{~m}$. 


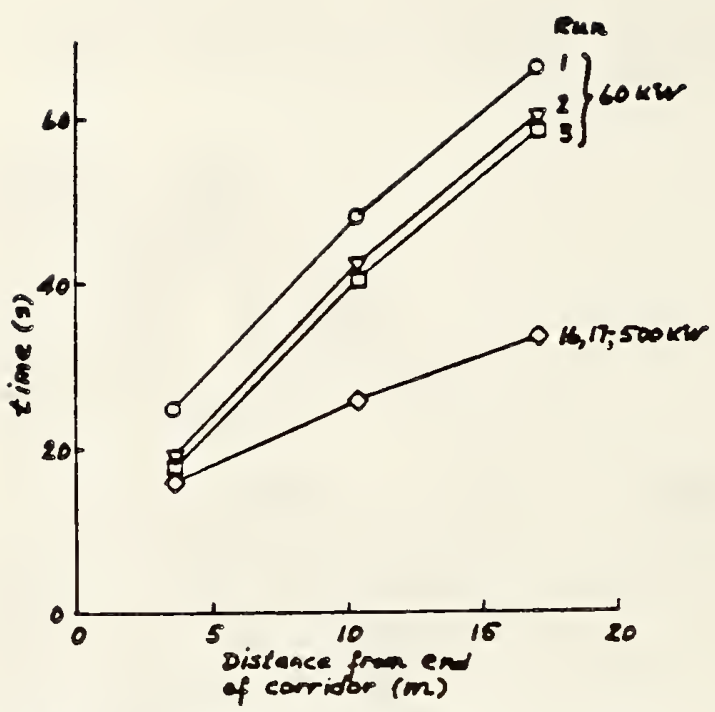

F1 gure 2. Poeltion of aotie front under celline $(y / u-0.021)$ as function of tine.

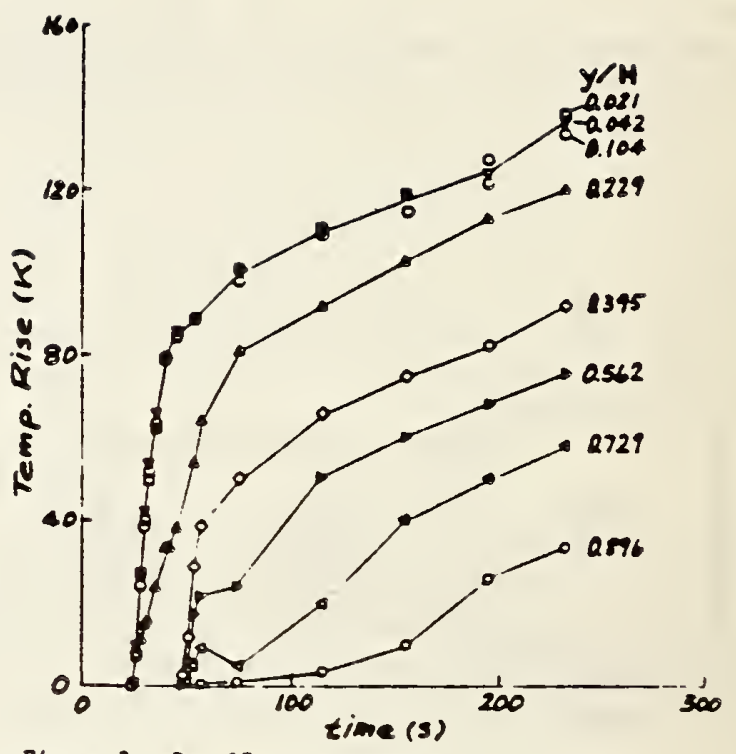

Figure 3. Run 17: Temperature rlse at Sta. 4.

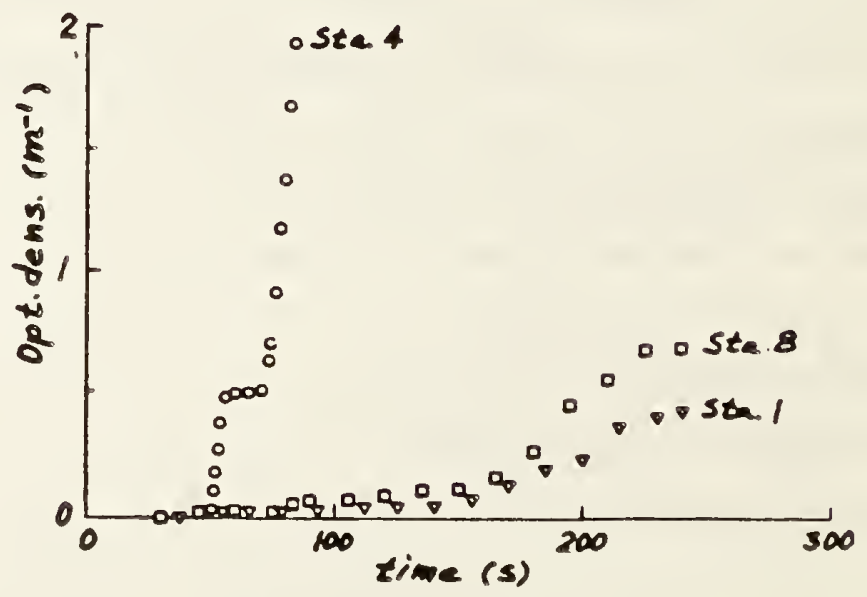

Figure 4. Run 17: Opelcal denste1es, $y / \mathrm{II}=0.56$. 


\section{CENTER FOR FIRE RESEARCH \\ NATIONAL BUREAU OF STANDARDS \\ FY85}

Institution:

Grant No:

Title:

Principal Investigators:

Other Professional Personnel:

\section{NBS Scientific Officers:}

Factory Mutual Research Corp., Norwood, MA 02062 NB82 NADA 3030

Prediction of Fire Dynamics

\section{Technical Abstract:}

The objectives are to improve the scientific understanding of fire and provide useful inputs to fire safety engineering. The four current tasks are: develop a computer code for predicting development of a fire in a building; measure radiant fraction emitted from turbulent buoyant jet flames as functions of vitiation and fuel source temperature; study radiation in turbulent wall fires and relation to soot-point; and develop a technique for studying transient pyrolysis and flame radiation of charring fuels.

Task 1. The Prediction of Fire Growth in Buildings

The objective of this task is to deveiop the quantitative understanding of building fire growth phenomena and to incorporate this knowledge into the Harvard Computer Fire Code.

The year's effort has been focused on the transient ceiling jet. As a fire starts and grows, the hot gas and flame plume rises to the ceiling of the room or corridor and gradually moves forward. The time scale of movement is such that in a small room, $6 \mathrm{~m}$ or so, the spread rate can be ignored. In a larger room or corridor, it cannot since the spread time controls the time of ignition of ceiling or low fuels so that, for fuels more distant from the fire origin, the ignition is significantly delayed.

The currently available ceiling jet theories are all on steady ceiling jets as are the available experimental results. The only related work on transient salt water intrusion into fresh water and atmospheric cold fronts have mostly been on small scale while the theory which shows that the process must involve dissipative processes makes considerable progress but leaves many questions unanswered.

A new treatment, making minimum use of nondissipative flow relations, shows that, in a corridor, the specification of the hot layer density

$R=\rho / \rho_{a}$, jet flow $M_{u}=\dot{m}_{u} / \rho_{a} w H \sqrt{g H}$, the lower flow $M_{D}=\dot{m}_{D} / \rho_{a} w H \sqrt{g H}$ is 
sufficient to specify the jet depth $\Delta=\delta / H$ and spread rate $C=V / \sqrt{g H}$ of the transient front. Present steady state ceiling jet theories assume that the jet depth is controlled by the jet gas source, a fire plume or vent flow plume. If the source depth is identical to the transient jet depth, given by $R, M_{u_{i}}, M_{D_{i}}$, the transient gas moves out in a smoothly changing sheet (depth variations caused by friction, heat transfer, and entrainment). If the depths do not agree an adjustment in the form of jet acceleration or a hydraulic jump is required.

The theory of the jump which involves both the jet and lower fluid has been developed and connected with the transient front. Depending upon the 4 initial parameters $R, M_{u_{i}}, M_{D_{i}}, \Delta_{i}$, there are $0,1,2$, or 3 solutions. The jet front always moves away from the hot gas source. The jump which occurs behind the front will have a velocity away from the source in 0,1 or 2 cases. When the jump velocity is toward the source, it moves back swamping the source or changing it depending upon circumstances. When it is away from the source, the ceiling jet moves away with a bulbous front which grows in size as it proceeds. (Literature reports of small scale experiments are contradictory since it is said that the bulbous front of fixed size follows the leading edge which moves at a velocity less than that of the supply fluid--an impossibility.)

In a separate study the theory of jet widening, entrainment, friction, heat transfer, ceiling pyrolysis, and reaction has been developed and is about to be coupled with the perfect fluid results described above.

The proposed book on Prediction of Fire Growth in Buildings is being advanced by preparation of the chapter on vent flows.

Presentations on fire have been given; The Beverly Hills Supper Club Fire ( 4 times in China), The Science of Fire--The New Fire Safety Engineering $(6$ times in China), Fire Modeling for Toxic Gas Control (Meeting of Fire Retardant Chemical Assoc.), Fire Modeling (Akron University), Toxic Gas Standards (Mass. Legislative Committee, Maine Legislative Committee)

Home Fire Reports have been issued:

\#65 Note on the Solvability of Math Models of Fire

\#66 The Needed Fire Science

非67 Fire Modeling for Toxic Gas Control

\#68 The Science of Fire--The New Fire Safety Engineering

非9 Diffusion Flame Energy Transfers--Craig Beyler 
Task 2. Radiative Properties of Vitiated Flames

One of the most prominent achievements in recent fire research has been the development of a computer code[1] for the prediction of fire growth in enclosures, such as rooms and buildings. These computer codes employ zone models which consist of sub-models describing components of the room fire. One of these components is flame radiation, which strongly influences the burning rates and fire spread in the enclosure. In the existing codes, the flame radiative output is calculated as a fixed fraction of the heat release rate. This technique is based on experimental studies of fires in an open laboratory. However, the air entrained into fires in an enclosure is vitiated by products of combustion.

Several experimental studies ${ }^{[2-6]}$ have described some of the major features of vitiated burning and fuel dilution: (1) There is a consistent decrease in radiative power per unit height measured across the flame length; (2) The radiative fraction of the total heat release rate decreases as oxygen depletion increases; (3) However, there appears to be no significant effect on longitudinal distributions of combustion heat release rates, $\mathrm{CO}$ or $\mathrm{CO}_{2} \mathrm{flow}$ rates, and Schmidt radiation temperature; (4) Effects on burning behavior due to diluted (with $\mathrm{N}_{2}$ or $\mathrm{CO}_{2}$ ) supplied fuel are more pronounced than corresponding vitiation of the air supply. These results strongly suggest that fuel dilution or ambient oxygen depletion suppresses soot formation, but we have no direct proof of this assertion.

Previous studies $[5,6]$ presented flame vitiation trends in pool fires, particularly in terms of effects on the radiative fraction. These relationships need to be generalized for practical materials involved in an enclosure fire. This task would be difficult to accomplish if an approach starting from first principles is taken. Fortunately, a significant breakthrough in modeling flame radiation has been made during the past two years at FMRC. This discovery has led to a promising procedure for predicting flame radiation from a given material burning in a vitiated environment.

It has been established over a broad range of fuel mixtures that the smoke point length in laminar flames correlates with the radiant fraction obtained for corresponding turbulent fires[7,8]. We would thus expect to obtain similar correlations for flames with diluted fuel or vitiated ambient. Similarly, the effect of fuel temperature on flame radiation could be predicted from smoke height measurements in laminar flames. Such a correspondence would also allow the modeling of radiation in wall fires [9] where cooling of the flames by the wall is equivalent to a corresponding change in the temperature of the fuel supplied to a turbulent buoyant diffusion flame.

The present study is directed towards determining the effect on radiative output due to fuel dilution and ambient vitiation with $\mathrm{N}_{2}, \mathrm{CO}_{2}$, and $\mathrm{H}_{2} \mathrm{O}$, and of fuel preheating, and the correlation of this data with corresponding smoke point measurements undertaken by Markstein in Task 3. Establishment of these correlations can thus lead to a significant improvement in our ability to model the radiative behavior of specified fuels in enclosure fire situations from small-scale measurements of the smoke point length. 
Turbulent burning behavior is under study in the $1.2 \mathrm{~m}$ inner diameter, $2 \mathrm{~m}$ high cylingrical double-walled enclosure used in the previous FMRC vitiation studies $[5,6]$ with modifications insuring a more highly quiescent air supply. The enclosure configuration is shown in Fig. 1. Two hot-water furnaces deliver combustion products mixed with ambient air to the enclosure via a heat exchange that maintains the air supply temperature within $0.5 \mathrm{C}$ of the water circulating between the enclosure walls. This arrangement allows reduction of 0, molar concentrations to $15 \%$ while suppressing buoyant convection currents on the inner wall of the enclosure. An independent supply of steam permits investigation of the respective effects of $\mathrm{H}_{2} \mathrm{O}$ and $\mathrm{CO}_{2}$ in the vitiated air supply on flame radiation. The composition of the vitiated air supply is monitored during the experiment with $\mathrm{O}_{2}, \mathrm{CO}_{2}, \mathrm{CO}$, and $\mathrm{H}_{2} \mathrm{O}$ analyzers.

Figure 2 shows the stainless steel burner constructed for this study. The burner was designed to prevent induction of significant flow disturbances in the externally supplied air and issuing fuel flow, minimize radiant emission from the burner surfaces, and to provide a highly isothermal preheated fuel supply. The burner includes a cartridge heater with feedback temperature regulation for preheating the fuel up to 300C. Fuel composition changes due to preheating were prevented by avoiding direct contact between the fuel/ diluent mixture and the hot cartridge. The burner was carefully designed to deliver a highly isothermal exit flow from the nozzle. Interchangeable nozzles with exit diameters ranging from 11 to $35 \mathrm{~mm}$ can be mounted on the burner column. This feature allows investigation of nozzle diameter effects on the radiation from 2-50 kW buoyancy-controlled jet flames. The top $18 \mathrm{~mm}$ of the nozzle is gold-plated to present a low-emissivity surface to the radiometers. This part of the nozzle stands clear of the burner superstructure preventing attachment to adjacent surfaces by weakly buoyant flames. A streamlined water-cooled flat black sheath covers the remainder of the burner.

Two slit radiometers view the vertically traversing flames at respectively different flame heights. The use of two radiometers permits coverage of the entire flame length in a single $1 \mathrm{~m}$ vertical traverse. Flame radiative output is obtained by integrating slit radiometers over the flame length. A wideangle radiometer provides an alternative measurement of the flame radiation. These results are verified by extensive cross-checking of data from the respective radiometers, and by comparison of baseline measurements in ambient air with Markstein's $[10]$ earlier study of buoyant jet flames. Effects of radiant absorption by $\mathrm{H}_{2} \mathrm{O}$ and $\mathrm{CO}_{2}$ along the radiometers' optical path through the vitiated ambient are accounted for by applying the simplified nonspectral model developed by Groshandler and Modak $\left.{ }^{11}\right]$.

Preliminary measurements are currently in progress, with thorough cross checking and verification of results. The experimental study will then proceed to systematic investigation of the effects of ambient vitiation, fuel dilution, and fuel preheating.

We have recently completed a study of the chemical modeling of pool fires. In that study it was shown that major chemical species concentrations from large fires can be predicted from laminar-type experiments and from a modeling theory for turbulent mixing and combustion in large fires. These results are 
consistent with chemical species measurements in room fires (A. Tewarson) and in the hot gas ceiling layers studied by $C$. Beyler at Harvard.

\section{REFERENCES}

1. H.W. Emmons, Seventeenth Symposium (International) on Combustion, The Combustion Institute, p. 1101 (1979).

2. K. Muller-Dethlefs, and A.F. Schlader, Combustion and Elame, 27, 205 (1976).

3. S.R. Gollahalli, Combustion Science and Technology, 15, 147, (1977).

4. S.R. Gollahalli, Combustion and Flame, 34, 141 (1979).

5. G. Santo, and F. Tamanini, Eighteenth Symposium (International) on Combustion, The Combustion Institute, 619 (1980).

6. G. Santo, and M.A. Delichatsios, Fire Safety Journal, 2, 159, (1984).

7. G.H. Markstein and J. de Ris, "Radiant Emission and Absorption by Laminar Ethylene and Propylene Diffusion Flames," Twentieth Symposium (International) on Combustion, The Combustion Institute (in press).

8. G.H. Markstein, "Relationship Between Smoke Point and Radiant Emission from Buoyant Turbulent and Laminar Diffusion Flames," Twentieth Symposium (International) on Combustion, The Combustion Institute (in press).

9. J. de Ris, "Effects of Dilution on Cooling in Flame Radiation," Appendix B, NBS Proposal, "Prediction of Fire Dynamics," March 1984.

10. G.H. Markstein, Sixteenth Symposium (International) on Combustion, The Combustion Institute, p. 1407 ( 1977.

11. W.L. Grosshandler and A.T. Modak, Eighteenth Symposium (International) on Combustion, The Combustion Institute (1981).

12. L. Orloff, J. de Ris, and M.A. Delichatsios, "Chemical Modeling of Gaseous Species in Turbulent Fires," Factory Mutual Research Corporation Technica? Report RC85-BT-4, 1985. 


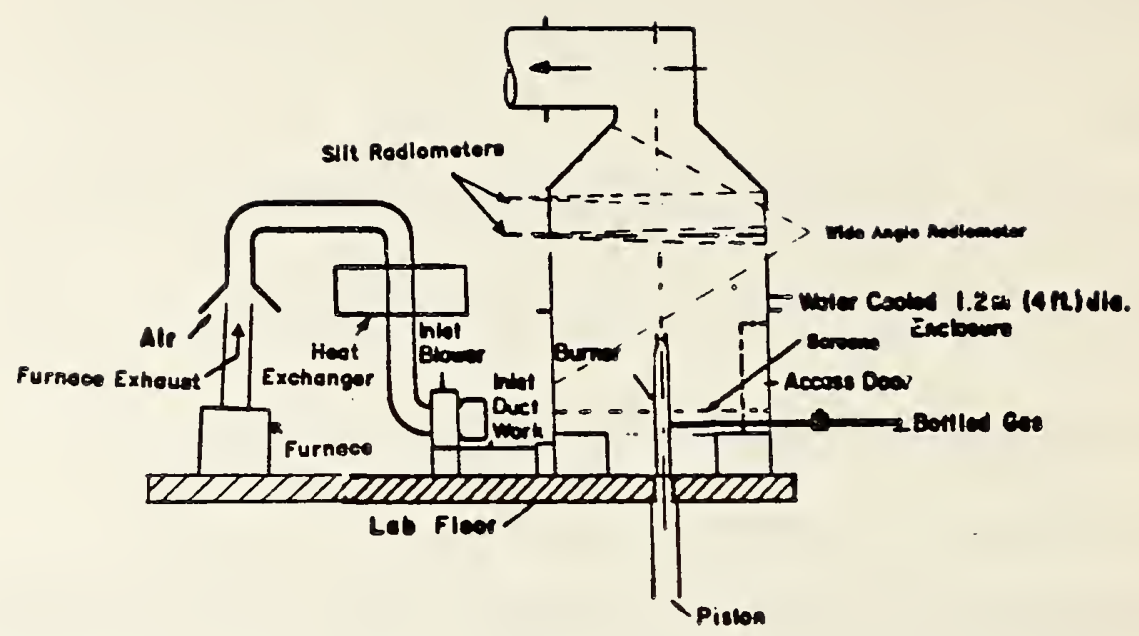

Figure 1: Diagrammatic Layout of Vitiated Burning Experiments.

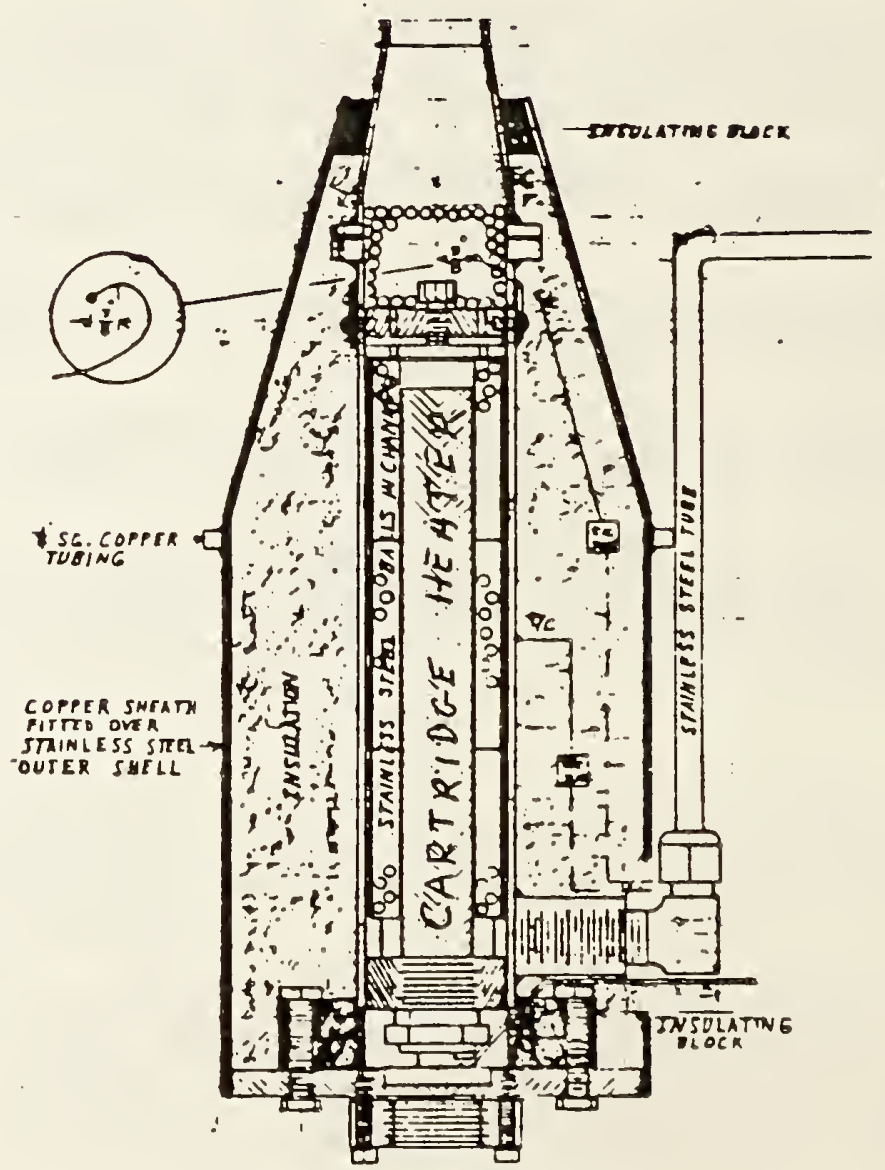

Figure 2: Design of Turbulent Diffusion Flame Burner. The fuel is preheated by a cartridge heater. 
Task 3. Wall Fire Flame Radiation

The main objective of this task is the extension of previously established relationships for fire radiation to fires burning on vertical walls. The significance of studies of fire radiation rests on the fact that in many fires energy transfer from the flame to the fuel and to the surroundings occurs predominantly by thermal radiation. The rate of fire growth and the spread of fire to new fuel elements depends critically on this energy transfer, and its quantitative assessment is thus essential for estimating fire losses and threat to life safety.

Previous work has revealed important quantitative relationships between radiant emission from both turbulent and laminar diffusion flames and the sooting tendency of the fuel. The latter is customarily measured by the flame height of a laminar diffusion flame at which soot just begins to issue from the flame tip, i.e. the so-called smoke point.

The results of the earlier work may ultimately make it possible to predict the radiant emission of fairly large turbulent diffusion flames from measurements of the smoke point performed with small laminar flames.

For this reason, although this task is now concerned with radiation from turbulent wall fires, studies of laminar diffusion flames have until recently been continued, with emphasis on the relationship between the smoke point and radiant emission. To generalize previous results, the work was continued with binary fuel mixtures. By adding nitrogen diluent to the fuel mixture and either nitrogen or oxygen to the ambient air, the adiabatic flame temperature and the stoichiometric oxidizer-to-fuel mass ratio were varied independently. Results obtained with propylene-ethane and acetylene-ethane mixtures showed that the radiative fraction at the smoke point depended only on the adiabatic flame temperature but was independent of mixture ratio (i.e. fuel type) and stoichiometric mass ratio. As an example, Figure 1 shows the results for a constant adiabatic flame temperature of $2400 \mathrm{~K}$, but varied fuel composition and stoichiometric mass ratio $S$. The plot of radiant power vs total rate of heat release, both at the smoke point, shows that all the data fall on a straight line, with the slope of 0.292 representing the radiative fraction. As in earlier work the non-zero intercept of the plot was tentatively interpreted as a small correction for heat loss at the burner.

Similar results were obtained for other values of the adiabatic flame temperature, but with the radiative fraction increasing with increasing temperature. The results are summarized in Figure 2, which also includes earlier data obtained with olef in (iso-butene, propylene, and ethylene), and with 1,3butadiene.

Because heat loss and flame quenching are important aspects of wall fires, some work on laminar flames was also performed in which.the heat transfer at the flame base was varied by working with different burner diameters and wall thicknesses but under otherwise identical conditions. Thus far, only a limited amount of results have been obtained which seem to indicate that the data cannot be interpreted solely as heat transfer effects. Thus, the "heat-loss" intercepts of plots analogous to Figure 1 varied only by a factor of about 
three for a change from a $2.4 \mathrm{~mm}$ diameter $0.075 \mathrm{~mm}$ wall to a $9.5 \mathrm{~mm}$ diameter $0.75 \mathrm{~mm}$ wall stainless steel tube. A significant change occurred in the radiative fraction, which increased from 0.24 to 0.26 at an adiabatic flame temperature of $2200 \mathrm{~K}$ when the tube diameter was increased from 2.4 to $9.5 \mathrm{~mm}$, regardless of wall thickness. The latter result may be a kinetic rather than a heat transfer effect, caused by lower flow velocity and thus larger residence time at the flame base for the larger diameter, which may allow formation of a larger initial amount of soot. This quantitatively small effect has not been fully explained.

Work on laminar flames will be continued primarily under other sponsorship, but some studies of laminar flames may be performed under this task if they are pertinent to the understanding of wall-fire radiation.

In the work on wall fires, a previously developed burner consisting of water-cooled porous sintered-metal vertical panels is being used with gaseous fuels. The heat transferred to each panel by the flame is measured from the temperature rise of the cooling water. The transferred heat, combined with the fuel mass flow, in turn defines an effective mass transfer number ( $B-$ number), so that solid or liquid fuels of given $B$-number can be simulated by adjusting the flow rate of the gaseous fuel. In the present work, the fuel flow to each panel is set by an electronic flow controller. The control voltage is in turn determined from the specified $\mathrm{B}$-number and the measured heat transfer rate through a digital control loop.

In addition to a conventional wide-angle radiometer which measures the total radiant emission by the wall fire, a newly designed scanning slit radiometer is being used in this work. This instrument allows recording of the vertical distribution of the radiant emission from horizontal slices across the fire by repetitive rapid scans. The scans are recorded individually and can be subsequently evaluated in terms of average distribution of radiant emission, as well as of its turbulent fluctuations and other statistical characteristics.

Preliminary measurements on ethane wall fires have started. In agreement with earlier results, it was found that the radiative fractions of wall fires is appreciably reduced, compared to that of free-burning turbulent flame jets of the same fuel. Thus, the radiative fraction of a buoyant ethane jet is about 0.20 , while a wall fire for a $B$-number of 1.0 had a radiative fraction of about 0.11 .

In the continuing work on wall fires, both the B-number and the fuel-flow configurations will be varied, the latter by choice of the number and location of the burner panels that participate in the fuel flow. The results will be used for comparison with existing experimental studies (Kulkarni) and theoretical models (Mitler, Delichatsios) of wall fire combustion and possible modification of such models, as well as for extension of earlier correlations between flame radiation and smoke points to wall fires. 


\section{Publications:}

G.H. Markstein and J. de Ris, "Radiant Emission and Absorption by Laminar Ethylene and Propylene Diffusion Flames," Twentieth Symposium (International) on Combustion (in press), also, FMRC Technical Report No. RC84-BT-7, 1984.

G.H. Markstein, "Relationship Between Smoke Point and Radiant Emission From Buoyant Turbulent and Laminar Diffusion Flames," Twentieth Symposium (International) on Combustion (in press), also, FMRC Technical Report No. RC84-BT-8, 1984.

G.H. Markstein, "Radiant Emission and Smoke Points for Laminar Diffusion Elames of Fuel Mixtures," presented at the Technical Meeting, Eastern Section of the Combustion Institute, Clearwater Beach, Florida, Dec. 1984. 


\section{LAMINAR DIFFUSION FLAMES}

Smoke-Point Dato

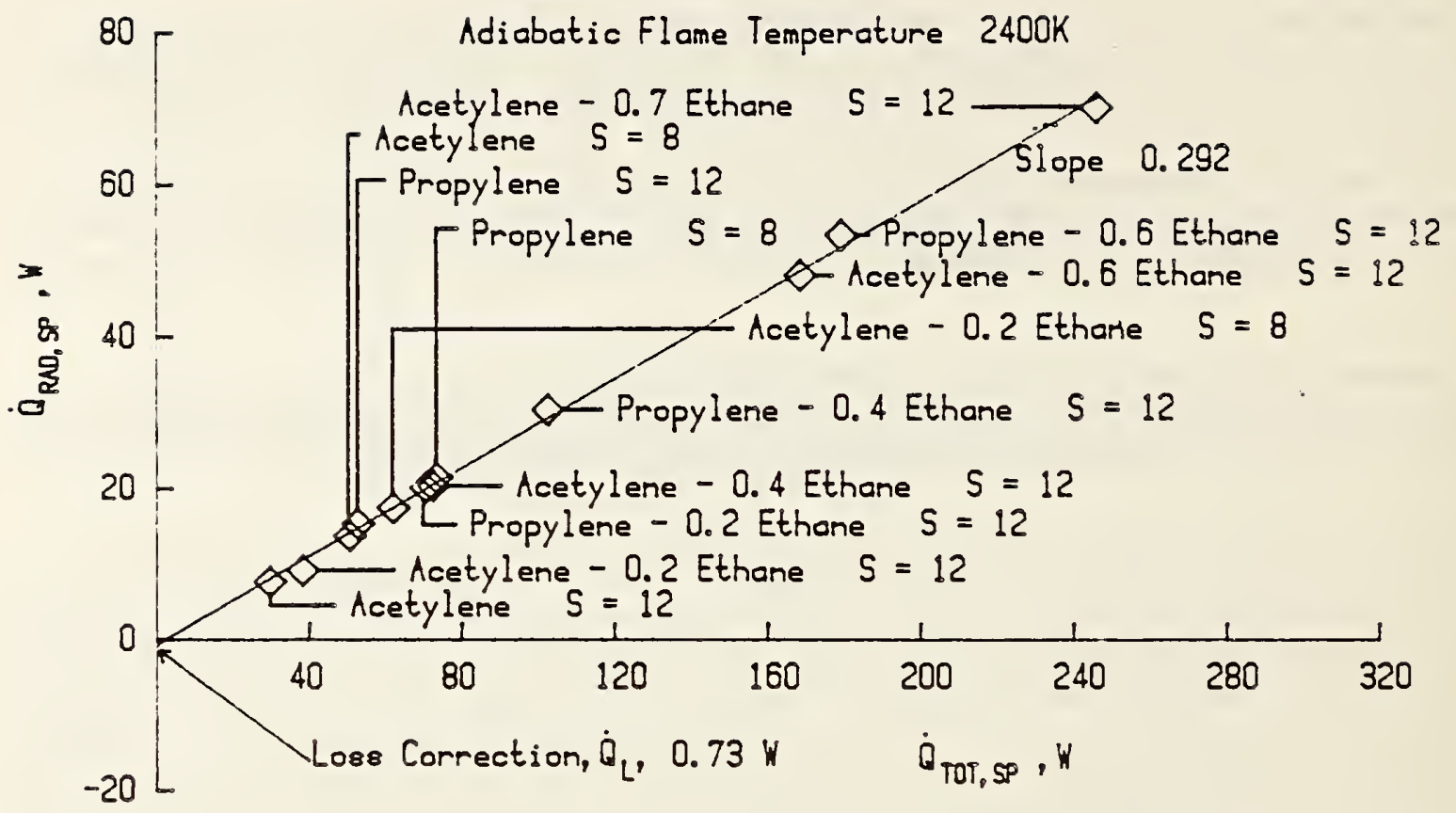

Figure 1: Radiant Power vs. Heat Release Rate at the Smoke Point for Binary Fuel Mixtures at Constant Adiabatic Flame Temperature of $2400 \mathrm{~K}$. $S=$ Stoichiometric Oxidizer-to-Fuel Mass Ratio

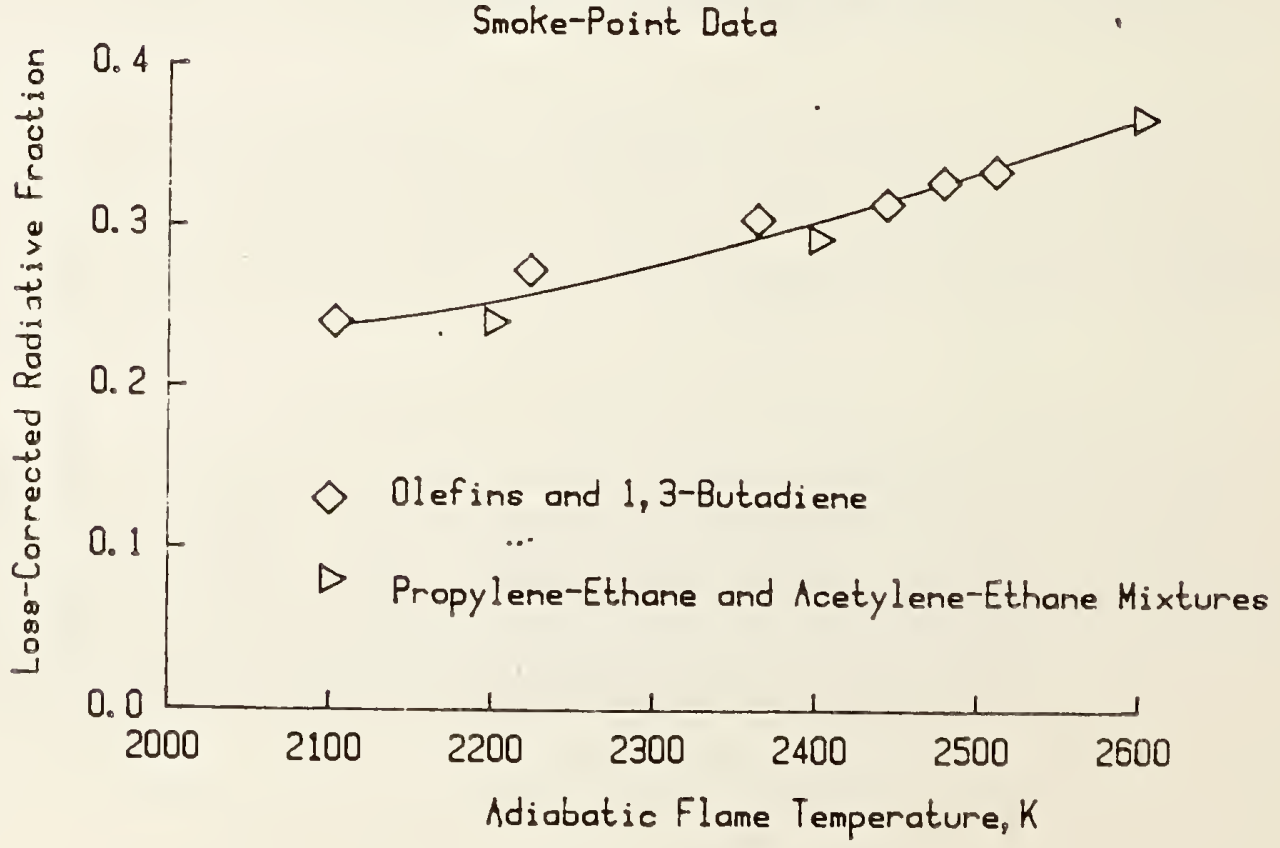

Fieure 2: Smoke-Point Radiative Fraction vs. Adiabatic Flame Temperature 
Task 4. Flame Radiation and Transient Pyrolysis of Charring Fuels

To predict fire growth and assess flammability risks, one needs to know the "key flammability" properties of the materials that may be involved in a fire as well as modeling techniques to account for varying geometries, scales and ambient conditions (e.g. vitiation). Long experience with fire test methods has demonstrated that it is difficult to decide which are the flammability properties of materials that are essential in characterizing ignition, rate of burning and fire spread. It is helpful to mention that the essence of the fire problem may be summarized into two questions, 1) how fast a material can burn and release heat, and 2) whether a fire is sustained and can spread. Future test methods must somehow provide the information for specifying the material properties needed for answering these two critical questions. Two key flammability measurements involve 1) the rate of pyrolysis of a material exposed to a given heat flux, and 2) the flame radiation of the pyrolyzing gases as they burn with ambient air.

The present task has been designed to develop a test and a methodology for measuring and characterizing the pyrolysis rates and flame radiation of practical materials. Emphasis has been given to charring materials because they have a transient pyrolysis history even when exposed to a constant heat flux. For noncharring materials (e.g. PMMA), a steady rate of pyrolysis can be calculated by using a heat of gasification and a pyrolysis temperature, which can readily be measured. (Effects of oxygen on the pyrolysis of PMMA are currently being investigated at NBS.)

The transient pyrolysis of a charring material is a rather complicated process for which our previously developed numerical models (SPYVAP) describe the heat and mass transfer from an engineering viewpoint. These numerical models, however, require material property data which are very difficult to obtain directly from transient pyrolysis histories of practical fuels. The models are too complicated and depend on too many parameters to deduce reasonable estimates of individual property values. In order to overcome this problem, we have developed a series of approximate analytical solutions (1) for transient pyrolysis at various times following the imposition of a constant applied surface heat flux to a sample. (The approximations involve the assumptions of high pyrolysis activation energy and small char specific heat per unit volume.) The analytical formulas should allow the use of graphical procedures for evaluating "equivalent" transient pyrolysis properties from the pyrolysis history curves for several levels of imposed heat flux. We have also recently developed an analytical asymptotic solution for the initial transient pyrolysis of noncharring materials (e.g. PMMA), which may be helpful in the interpretation of experimental data on pyrolysis rates:

$$
\Delta \mathrm{H}_{v} \dot{\mathrm{m}}^{\prime \prime} / \dot{\mathrm{q}}_{0}^{\prime \prime}=\frac{2}{\pi} \sqrt{\frac{\mathrm{t}-\mathrm{t}_{\mathrm{p}}}{\mathrm{t}_{\mathrm{p}}}}
$$

where $\dot{q}^{\prime \prime}$ is a constant applied net heat flux, $\Delta \mathrm{H}_{\mathrm{v}}$ is the heat of vaporization, $t_{p}$ is the time to reach a pyrolysis temperature. Note also that the time required to reach the steady state pyrolysis rate $\left(\equiv \frac{\dot{q}_{0}^{\prime \prime}}{\Delta H_{v}+C_{S}\left(T_{p}-T_{0}\right)}\right)$ 


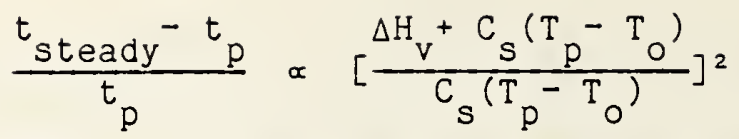

Here $T_{p}$ is the pyrolysis temperature, $T_{O}$ is the initial temperature and $C_{S}$ is the specific heat of the virgin material. The proportionality factor in eq (2) is of order one.

These analytical results have been used to systematically test a new rigorous numerical model of transient pyrolysis. We have developed a new computer program to calculate transient pyrolysis of charring materials under the assumption of a thin pyrolysis zone (which implies an infinitely fast pyrolysis reaction). Currently available pyrolysis codes (e.g. SPYVAP) are inaccurate in the limit of high activation energies for which we have approximate analytical solutions which need to be verified numerically. Cubic splines are used to represent the spatial variations and transform the partial differential equations to FDE by collocation at the nodes. The accuracy of the scheme is second order in both time and space. The computer program is currently being used to validate our analytical model for the charring pyroly$\operatorname{sis}(1)$.

The emphasis of this present program is to find techniques for evaluating in-situ transient pyrolysis properties of practical fuels for use in overall flammability assessment models. The examination of actual transient pyrolysis data will inevitably raise more fundamental questions about the pyrolysis of specific materials; however, our present focus is on providing "equivalent" property data for use in global fire development models.

Our recent advances in understanding of flame radiation from fires suggests that flame radiation for various fuels can be correlated by the fuel's so-called "normal smoke-point". The "normal smoke-point" is defined here as the maximum soot-free flame height for a candle-like flame burning in ambient air with both reactants supplied at normal ambient temperatures. Since it is impractical to supply pyrolysis vapors from solid fuels at normal ambient temperatures, we must identify a temperature correction procedure for interpreting smoke-point data for solid fuel vapors supplied at their relatively high pyrolysis temperatures. A postulated procedure has been developed from our ongoing work with laminar flows and is being tested in Tasks 2 and 3 .

We are measuring the radiant fraction of the buoyant turbulent flame supplied by the fuel jet of hot pyrolysis vapors, rather than measuring smokepoint directly at this time. From the simpler measurement of radiant fraction, radiant emission in full-scale wall fires (see Task 3) as well as the normal smoke point can be inferred. Eventually, we would like to make direct smoke-point measurements, but for now we plan to first gain experience by measuring the radiant fraction of charring fuels.

The experiments will be performed in a single test apparatus (see Figure 1) constructed to measure both the "equivalent" transient pyrolysis properties as well as the radiant fraction of the burning pyrolysis vapors. The apparatus consists of a pyrolysis chamber which subjects a $12 \mathrm{~cm}$ dia (up to $18 \mathrm{~cm}$ dia can be accommodated) fuel sample to a suddenly imposed constant 
heat flux in a hot inert $\left(\mathrm{N}_{2}\right.$ and/or $\mathrm{CO}_{2}$ environment. Two very different radiant heat sources will be used in this study. One source, a cone shaped, black body radiator developed at NBS/CFR will be used primarily to determine plloted ignition and pyrolysis properties of the materials. The effective heat of gasification of the sample will be inferred from the peak pyrolysis rate; while the thermal resistance of the growing char layer will be inferred from the subsequent decrease in the pyrolysis rate. A second radiant source produces much shorter infrared wavelengths but is of high intensity and isolated from the sample by cooled quartz windows. The second source will be used primarily to study the radiation properties of the fuel vapors since the isolating windows prevent reactions such as those that could occur on hot blackbody elements. The pyrolysis vapors produced by the quartz-isolated heater will exit through an orifice at the top of the chamber, be ignited by a pilot, and subsequently burn in a buoyant turbulent jet diffusion flame. It will also be possible to compare results obtained with both types of radiant heaters.

The pyrolysis chamber is being placed in an existing water-cooled ( $4 \mathrm{x} 4 \mathrm{x}$ $7 \mathrm{ft}$ ) enclosure (see Figure 1) whose exhaust system can measure the instantaneous chemical heat release rate of the flames over a range of 0.5 to $100 \mathrm{~kW}$. The enclosure can also be supplied with a vitiated ambient gas. A wide-angle radiometer will provide corresponding measurements of the radiant heat release rate from the flames. The radiant fraction will be inferred from these radiation and total heat release measurements.

From knowledge of the temperature of the pyrolysis gases exiting the pyrolysis chamber, we hope to infer their "normal soot-point" using laminar flame relationships now being developed. Work in progress on measuring the vertical distribution of wall fire radiation will also allow the radiant fraction measurements obtained with the pyrolysis gas fuel jet to be applied directly to the prediction of radiant emission from flames spreading on a full-scale wall. For scientific completeness, the apparatus includes measurements of the sample weight loss and surface temperature histories. Initially, we will concentrate our efforts on measuring one, or at most two simple fuels until the measurement procedures are established.

\section{REFERENCES}

1. M.A. Delichatsios and J.'de Ris, "An Analytical Model for the Pyrolysis of Charring Materials," The Modeling of Pre-Flashover Fires, edited by P.H. Thomas, Fire Research Station, BRE, 177 (1983); also Factory Mutual Research Corporation Technical Report, RC84-BT-4 (1984). 
EXHAUST SYSTEM

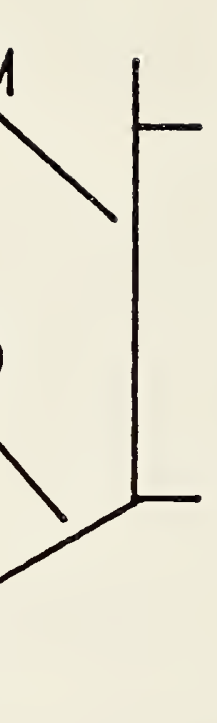

PYROLYSIS

ENCLOSURE

CHAMBER

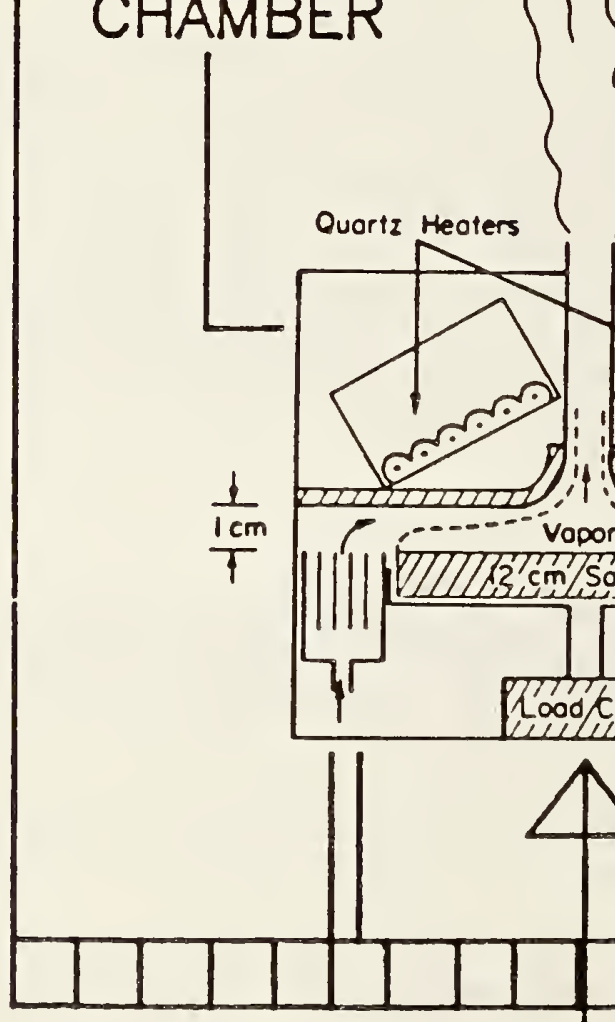

CONTROLLED INFLOW OF

AMBIENT OR VITIATED AIR

Fig. I A sketch of the pyrolysis apparatus inside the water cooled enclosure. 
NATIONAL BUREAU OF STANDARDS

FY 1985

Institution: The Pennsylvania State University

Grant No.: $\quad$ 60NANB4D0037

Grant Title: A Model for Vertical Wall Fire in Stratified Atmosphere

Principal Investigator: Professor A. K. Kulkarni

Department of Mechanical Engineering

The Pennsylvania State University

University Park, PA 16802

Telephone: (814)865-7073

Other Professional Personnel: J. J. Hwang (Ph.D. student)

NBS Scientific Officer: Mr. Ken Steckler

Technical Abstract:

In a typical compartment fire, a layer of hot, oxygen-lean gases exists on the top of a layer of cold, oxygen-rich gases with a relatively steep vertical gradient of temperature and composition separating them. The effect of such a stratified atmosphere on a burning vertical surface is being studied in this project. The natural convection flow of reacting gases in the wall fire is expected to be significantly affected by the strong influence of the stratified atmosphere on the buoyancy and the oxidizer diffusion. The basic approach is to first develop a comprehensive but laminar mathematical model for the flow situation and obtain numerical solutions. Influence of various types of stratification (such as a stepchange in temperature, continuous temperature variation, and a combination of both the thermal and oxidizer concentration stratification) on important characteristics of the wall fire will be studied and compared with the nonstratified cases. It will be particularly interesting to check if simple, linear superposition of results from nonstratified cases can be used to predict the results for various stratified cases.

A schematic of the proposed model is shown in Figure 1. Fire on a vertical wall in a stratified atmosphere is simulated by a natural convection, laminar, boundary layer flow of gases. Effects of stratified ambient atmosphere, surface radiation, and gas radiation are included in the boundary conditions and governing equations. The height-dependent buoyancy term is modeled using ideal gas law. The thin flame sheet model is used initially for combustion; however; finite rate chemistry will be included later in the model. The model results in a set of coupled, nonlinear, nonhomogeneous, second order, partial differential equations and boundary conditions.

A slightly modified Keller Box numerical algorithm is used to obtain numerical solutions. It involves a transformation of the orizinal set of 
governing equations to a system of nine first order partial differential equations; quasilinearization of nonlinear terms; formation of a coefficient matrix using a finite difference scheme; and its solution using the block-tridiagonal-elimination method.

Preliminary results have been obtained assuming no radiation for three different cases of the ambient temperature distribution as shown in Figure 2. In the stratified case, the temperature, $T_{\infty}$, is assumed to be constant up to the first $40 \%$ of the total height. Then it linearly increases to $60 \%$ of the height by $175^{\circ} \mathrm{C}$, after which it remains constant up to the top. This stratification model is derived based on available data from a room fire experiment with certain openings. Results for the other two cases are presented for comparison, having constant $\mathrm{T}_{\infty}$ of $25^{\circ} \mathrm{C}$ and $200^{\circ} \mathrm{C}$ respectively. Properties of polymethylmethacrylate (PMMA) were used for the vertical surface in the analysis.

Figure 3 shows variation of the mass burning rate, $\dot{m}^{\prime \prime}$, of the wall as a function of the normalized height (distance from the leading edge), $x / L$, for the three cases. Predicted burning rates for cases of constant $T_{\infty}$ equal to $25^{\circ} \mathrm{C}$ and $200^{\circ} \mathrm{C}$ agree very well with previously obtained results in the literature. For the stratified case, the burning rate is initially between the burning rates for $\mathrm{T}_{\infty}=25^{\circ} \mathrm{C}$ and $200^{\circ} \mathrm{C}$, but then falls below that for $T_{\infty}=200^{\circ} \mathrm{C}$ as $\mathrm{x} / \mathrm{L}$ continues to increase. Apparently the influence of the upstream flow causes the burning rate to drop further in the upper layer. (In separate calculations, the influence of the lower layer was found to diminish completely when the upper layer was sufficiently thick compared to the lower layer.) Figures 4 and 5 show variation of the flame temperature and shear stress at the wall. Here the results for the stratified case remain well within the limits set by the $\mathrm{T}_{\infty}=25^{\circ} \mathrm{C}$ and $200^{\circ} \mathrm{C}$ cases. However, from this study it appears so far that the results of the stratified case cannot be simply obtained by a linear combination of results for the $\mathrm{T}_{\infty}=$ constant cases. This study is in its early stage and more numerical solutions are needed to draw any definite conclusions.

Several other cases of thermal and oxidizer concentration stratification will be studied using this numerical model. Approximate analytic solutions also will be sought. Simple experiments will be performed in the next phase for comparison with predicted results. The insight and information obtained from this study will be useful, for example, as an input to larger zone models of the fire spread and extinction in multiroom structures.

\section{Reports and Papers:}

1. A. K. Kulkarni and J. J. Hwang, "Natural Convection Over an Isothermal Vertical Surface Immersed in a Thermally Stratified Fluid," to be presented at the 23rd National Heat Transfer Conference, August 4-7, 1985.

2. A. K. Kulkarni and J. J. Hwang, "Burning of a Vertical Surface in a Stratified Ambient Atmosphere," extended abstract submitted to the AIAA 24th Aerospace Sciences Meeting, January 6-8, 1986. 

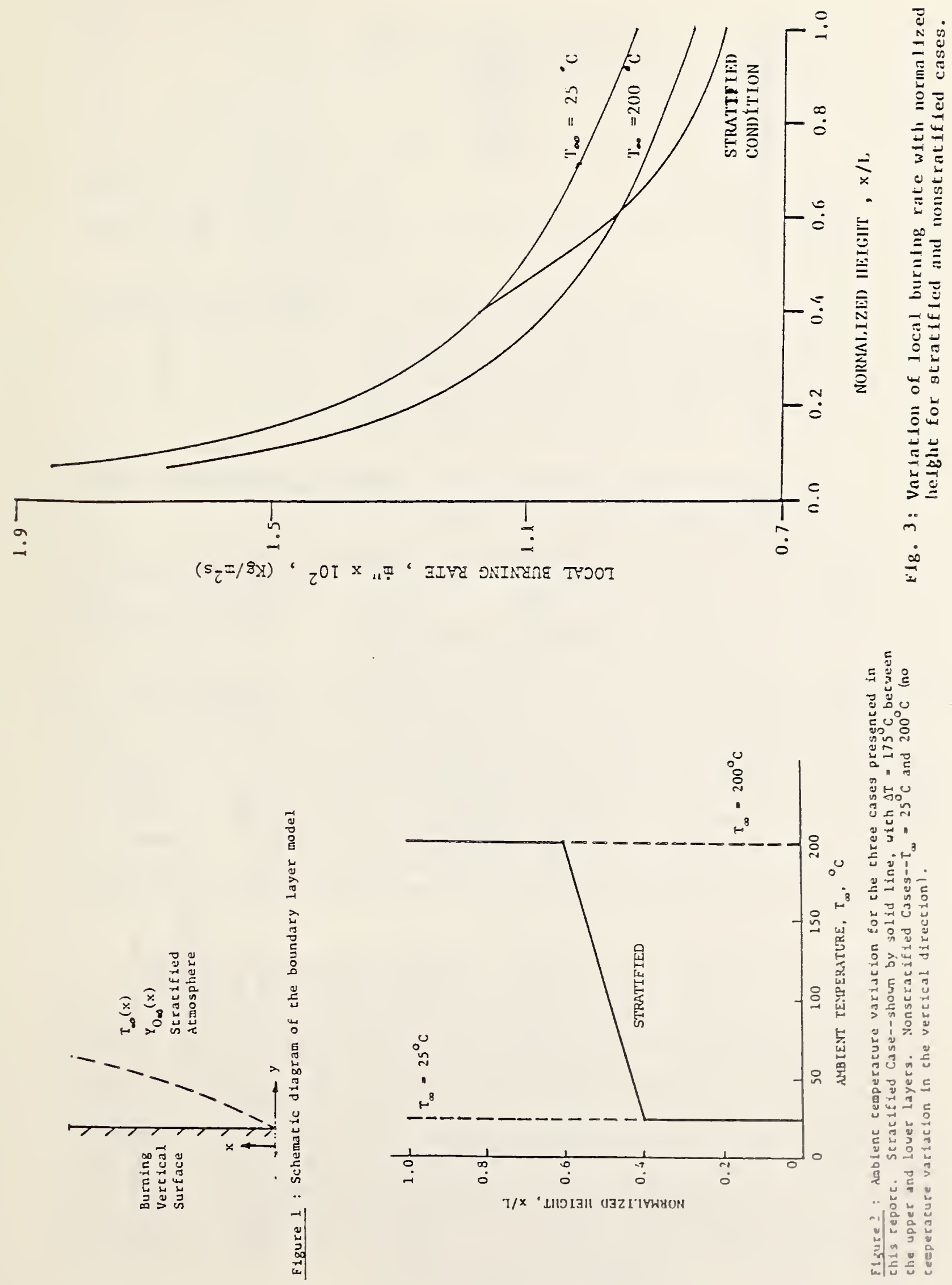

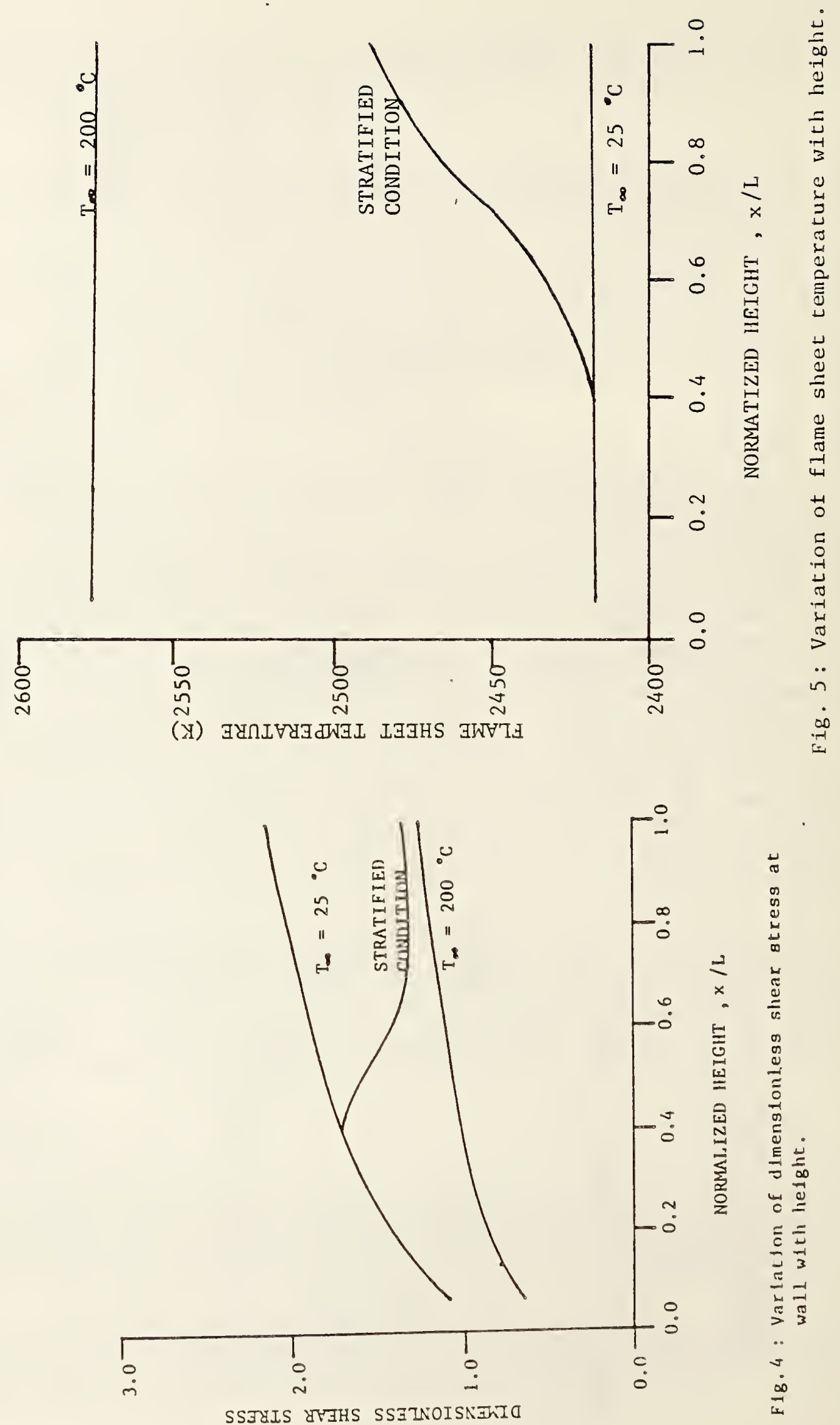
CENTER FOR FIRE RESEARCH

NATIONAL BUREAU OF STANDARDS

FY 85

Institution: The Pennsylvania State University

Grant No.: 60 NANB 400032

Grant Title: An Investigation of Turbulent Fires on Vertical and Inclined Walls

Principal Investigator: Professor Gerard M. Faeth

Department of Mechanical Engineering

The Pennsylvania State University

315 Mechanical Engineering Building

University Park, Pennsylvania 16802

Telephone: (814) 865-3743

Other Professional Personnel: J. P. Gore, Research Assistant

S.-M. Jeng, Research Assistant M. - C. Lai, Graduate Assistant

NBS Scientific Officer: Dr. Bernard J. McCaffrey

Technical Abstract:

Introduction. The objective of this investigation is to establish practical methods for predicting radiant and convective heat transfer of fires along surfaces. The fundamental problems are to determine the scalar structure of turbulent diffusion flames and to treat effects of turbulence/radiation interactions. These problems are being approached using the conserved-scalar formalism of turbulent reacting flow, seeking to avoid the difficulties of predicting complex chemistry in a turbulent environment. Present research is focused on two primary topics: (1) structure and radiation properties of free turbulent buoyant diffusion flames, and (2) the properties of noncombusting turbulent buoyant flows along surfaces.

Elame Structure and Radiation. The scalar structure of flames and their radiation properties are closely coupled; therefore, both aspects are being studied. The laminar flamelet concept is being tested as a means of finding scalar properties, without direct analysis of chemical kinetics, within the conserved-scalar formalism. This is based on the observation that scalar properties of laminar flames are primarily a function of mixture fraction (the fraction of mass at a point which originated in the fuel). It is then assumed that turbulent flames exhibit the same property, viewing them as wrinkled laminar flames. We have tested this concept for hydrogen, carbon monoxide, methane, propane and ethylene diffusion flames burning in air, finding that it is satisfied for these flame systems for scalar properties needed for radiation predictions. Figure 1 is an illustration of a typical result, 101 
for an ethylene/air diffusion flame. Clearly, the concentrations of major gas species are nearly universal functions of fuel equivalence ratio (which is simply related to mixture fraction) even though large departures from thermodynamic equilibrium are observed for fuel-rich conditions.

Analysis of spectral and total flame radiation properties, based on the laminar flamelet concept for scalar properties, is being evaluated with experiments. A narrow-band radiation model is being used, both ignoring (mean property method) and considering (stochastic method) effects of turbulent fluctuations. Typical results are illustrated in Figs. 2 and 3 for turbulent hydrogen and ethylene diffusion flames in air. Comparison between predictions and measurement is reasonably good. Effects of turbulent fluctuations, seen by comparing stochastic and mean property predictions, are significant. Findings thus far are encouraging for both nonluminous and soot-containing luminous flames. Current research is exploring whether the predictive methods are robust for a range of fuels and flame conditions.

Noncombusting Flows along Surfaces. Buoyant turbulent flows along surfaces present new difficulties due to surface/turbulence interactions. Experiments are being carried out using laser-Doppler anemometry (LDA) to measure mean and fluctuating velocities and laser-induced fluorescence (LIF) to measure mean and fluctuating mixture fractions. Methods of analysis are similar to those used for free flames, however, a simpler mixing length approximation is also being considered.

Some typical results are illustrated in Fig. 4. The concentration of buoyant fluid is plotted as a function of distance from the surface for various positions along a wall. Measurements are shown for LIF, laser absorption and probes along with the two predictions. The probe measurements are biased near the edge of the flow, highlighting the advantages of the nonintrusive optical methods. The comparison between predictions and measurements is very encouraging, suggesting that methods developed for free flames may adapt successfully for flames along surfaces. Current research is extending the evaluation to turbulence properties and subsequently to wall fires themselves.

\section{Reports and Papers:}

1. S.-M. Jeng and G. M. Faeth, "Species Concentrations and Turbulence Properties in Buoyant Methane Diffusion Flames," J. Heat Trans. 106, $721-727$ (1984).

2. S.-M. Jeng and G. M. Faeth, "Predictions of Mean Scalar Properties in Turbulent Propane Diffusion Flames," J. Heat Trans. 106, 891-893 (1984).

3. S.-M. Jeng and G. M. Faeth, "Radiative Heat Fluxes near Turbulent Buoyant Methane Diffusion Flames," J. Heat Trans. 106, 886-888 (1984). 
4. S.-M. Jens, M-C. Lai and G. M. Faeth, "Nonluminous Radiation in Turbulent Buoyant Axisymmetric Flames," Comb. Sci. and Tech. 40 , $41-53(1984)$.

5. S.-M. Jeng and G. M. Faeth, "Spectral Radiation Properties of Turbulent Ethene/Air Diffusion Flames," Proceedings of 17 th Fall Technical Meeting, Eastern Section of The Combustion Institute, $p p$. $49.1-49.4(1984)$.

6. G. M. Eaeth, S.-M. Jeng and J. P. Gore, "Radiation from Elames," 23rd ASME/AIChE/ANS National Heat Transfer Conferencé (1985).

7. M.-C. Lai, S.-M. Jeng and G. M. Faeth, "Structure of Turbulent Adiabatic Wall Plumes," 23rd ASME/AIChE/ANS National Heat Transfer Conference (1985).

8. M.-C. Lai, S.-M. Jeng and G. M. Faeth, "An Investigation of Turbulent Fires on Vertical Walls: Wall Plume Structure," Department of Mechanical Engineering, The Pennsylvania State University (1984).

9. S.-M. Jeng, J. P. Gore, S. G. Chuech and G. M. Eaeth, "An Investigation of Turbulent Fires on Vertical and Inclined valis: Flame Radiation," Department of Mechanical Engineering, The Pennsylvania State University (1985). 


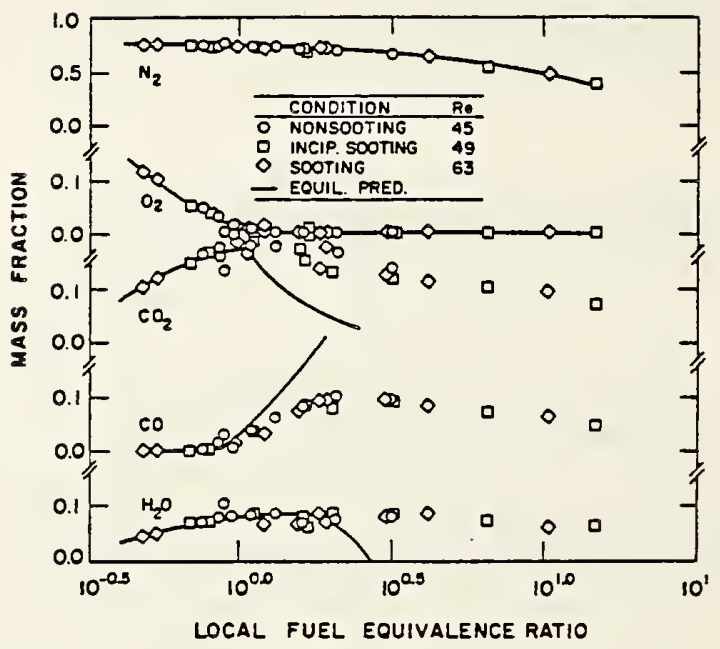

Fig. 1. State relationships for ethylene/air diffusion flames.

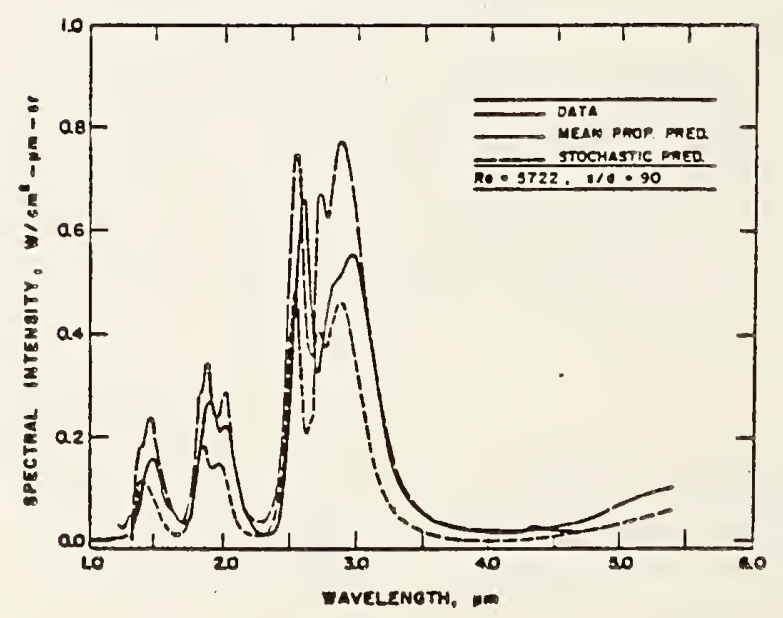

Fig. 2. Spectral radiation intensities for a turbulent hydrogen/air diffusion flame.

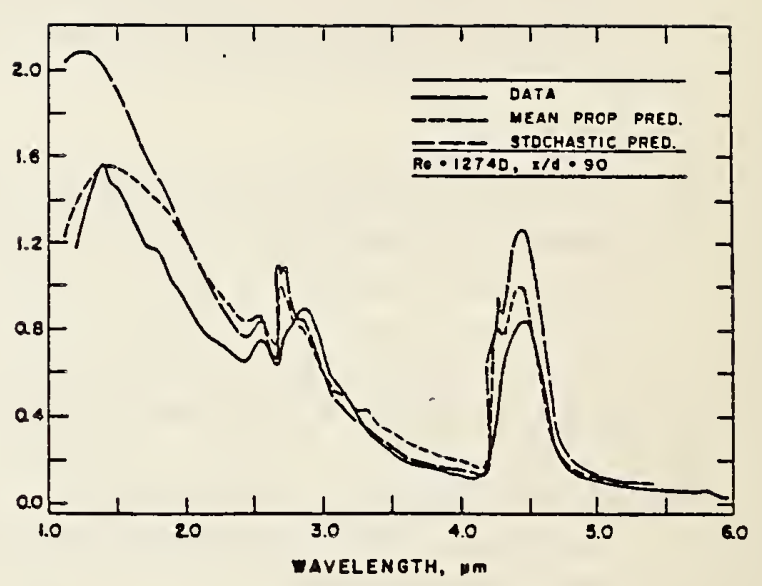

Fig. 3. Spectral radiation intensities for a turbulent ethylene/air diffusion flame.

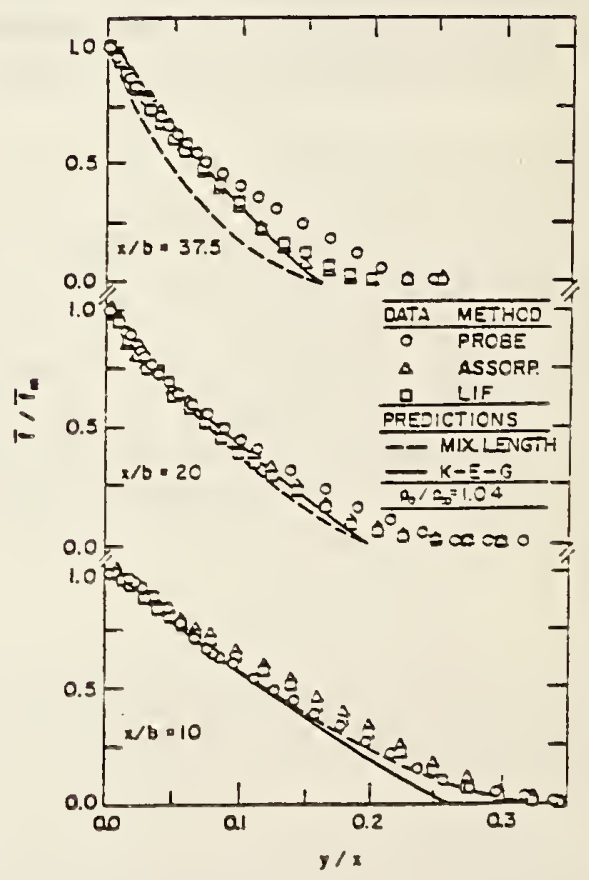

Fig. 4. Profiles of mean mixture fraction in a buoyant turbulent wall plume. 
CENTER FOR FIRE RESEARCH

NATIONAI BUREAU OF STANDARDS

FY 85

Institution:

Contract Number:

Contract Title:

Principal Investigator:
Princeton University

BN83NADA4007

Flow Field Effects on the Sooting Structure of Diffusion Flames

\author{
Irvin Glassman \\ Professor \\ Department of Mechanical and Aerospace \\ Engineering \\ Princeton University \\ Princeton, NJ 08544
}

Other Professional

Personnel:

Harjit Singh Hura (Ph.D. Student)

NBS Scientific Officer: Kermit Smyth

Technical Abstract

Most fires involve the burning of material under diffusion controlled conditions and are accompanied by the production of soot. The release of soot in confined spaces is a serious health hazard as smoke inhalation is a major cause of casualties in fires. Sooty flames have a radiative emissivity and consequently, preheat unburned combustibles and aid the spread of the conflagration. Previous work at Princeton has shown that the pyrolysis rate determines a fuel's tendency to soot. Since fuel pyrolysis is a high activation energy process, the sooting tendency in diffusion flames increases strongly with fiame temperature. Soot formation consists of two distinct processes: particle inception followed by coagulation and surface growth. The bulk of the soot formed in any combustion system is now known to be due to surface growth reactions. Thus, the longer soot particles stay in a high temperature pyrolysis rich region, the larger will be the soot loading. It is, of course, possible for the soot loading to decrease as a result of oxidation reactions if the particles are convected through the flame front by the combustion gases. Therefore, the amount of particulate matter actually emitted by a combustion device depends strongly on the flow configuration. The present program was initiated to evaluate how control of the fluid mechanical situation could affect the extent and character of the soot process.

In many experimental configurations, such as the Parker-Wolfhard and tubular burners, the fuel stream entrains oxidizer at the base of the burner and the interpretation of soot measurements in these arrangements becomes complicated. The addition of trace amounts of oxygen has been known to accelerate the pyroly- 
sis process of many aliphatic fuels. Consequently, it is necessary to have a well-controlled and well-defined flow fleld in which the interaction of the fluid flow and chemistry on soot production in a diffuston flame can be clearly elucidated. For this purpose, the following "opposed jet" diffusion flame was chosen for the program.

Fuel is ejected uniformly from a porous cylindrical, ceramic burner housed in a low turbulence wind tunnel supplied with oxygen and nitrogen. A laminar diffusion flame is stabilized in the forward stagnation zone of the burner. Measurements of the flow and temperature fields are obtained along the stagnation streamline with an LDV system and a radiation-corrected thermocouple. A laser light scattering-extinction measurement yields data on soot particle number density, particle size and soot volume fraction. Measurenents of the soot characteristics are also made along the stagnation streamline from their region of formation on the fuel side of the flame up to the stagnation point. Along the stagnation streamline the flow is one dimensional and the velocity data permt the interpretation of the light scattering measurements in terms of time from the flame front, rather than distance alone. Consequently, rates of formation, surface growth and coagulation in the diffusion flame can be inferred from the data. More complex two dimensional flow fields do not readily permit the interpretation of soot behavior in these terms.

Last year results were reported on the effect of the oxidjzer velocity. This contract year the primary concern was to determine the effect of the add1tion of small amounts of oxygen to the fuel stream on the sooting structure of the counterflow diffusion flame. As before, profiles of temperature, velocity, number density, soot volume fraction $(\phi)$ and mean particle size were obtained. propane $\left(\mathrm{C}_{3} \mathrm{H}_{8}\right)$ and ethylene $\left(\mathrm{C}_{2} \mathrm{H}_{8}\right)$ were used as fuels. In both $\mathrm{C}_{3} \mathrm{H}_{8}$ and $\mathrm{C}_{2} \mathrm{H}_{4}$ flames, the fuel volume flow rate was kept constant while increasing anounts of oxygen (02) (up to $10 \%$ of the fuel rate) were added. Whereas the experiments with $\mathrm{C}_{2} \mathrm{H}_{4}$ were made using air as the oxidizer, the $\mathrm{C}_{3} \mathrm{H}_{8}$ experiments required an enriched alr (oxygen index $=0.25$ ) because of experimental constraints. For all experimental runs the upstream oxfdizer velocity was kept at $30 \mathrm{~cm} / \mathrm{sec}$. The measured flame temperatures (uncorrected for radiation losses) varied from 1760-1805K. Thus, the results are thought to truly reflect the catalytic effect of 02 addition on the particle inception and surface growth processes; the thermal effects are similar in all cases studied.

The main results are presented in Figures 1 and 2. Figure 1 shows a plot of $\phi$ vs. time from the flame front. As can be observed, the addition of 02 to $\mathrm{C}_{2} \mathrm{H}_{4}$ has a very strong accelerating effect on the soot formation processes. The $10 \%$ case having a soot loading almost twice as large as the pure fuel case. For $\mathrm{C}_{3} \mathrm{H}_{8}$, a slight reduction in $\phi$ is measured! This result is quite perplexing because the pyrolysis reactions of $\mathrm{C}_{3} \mathrm{H}_{8}$ are known to produce $\mathrm{C}_{2} \mathrm{H}_{4}$ and therefore, 02 addition should result in increased soot loadings for both fuels. Future work will be directed toward resolving this finding and further determining whether there is an inherent difference in the manner 02 affects the soot processes between olefins and parrafins or there is something unique about the pyrolyses of $C_{3}$ hydrocarbons. Figure 1 also shows that the time derivative of $\phi$ also increases with 02 addition for $\mathrm{C}_{2} \mathrm{H}_{4}$ runs. This result is attributed to the 
Increase in area available for the surface reactions as more and more 02 is added. Figure 2 contains a log-linear plot of the specific surface growth rate vs. $(1 / T)$. The specific surface growth rate is defined as the time derivative of $\phi$ normalized by the total soot surface area. It is interesting to note that all the data points converge to a narrow region around a stralght line. This trend strongly suggests that the surface growth processes are very similar in all the flames studied. An activation energy of $35.4 \mathrm{Kcal} / \mathrm{mole}$ has been inferred from these data. The primary conclusion to emerge from the work to date is that the enhancement of soot formation in $\mathrm{C}_{2} \mathrm{H}_{4}$ flames is definitely a chemical rather than a thermal effect and is intimately linked to the chemfstry leading to particle inception and/or the early stages of surface growth.

Reports and Papers

Vandsburger, U., "Soot Formation In Counterflow Diffusion Flames," Ph.D. Thesis, Dept. of Mech. and Aero. Eng., Princeton U., July, 1985. 
Fig。 1

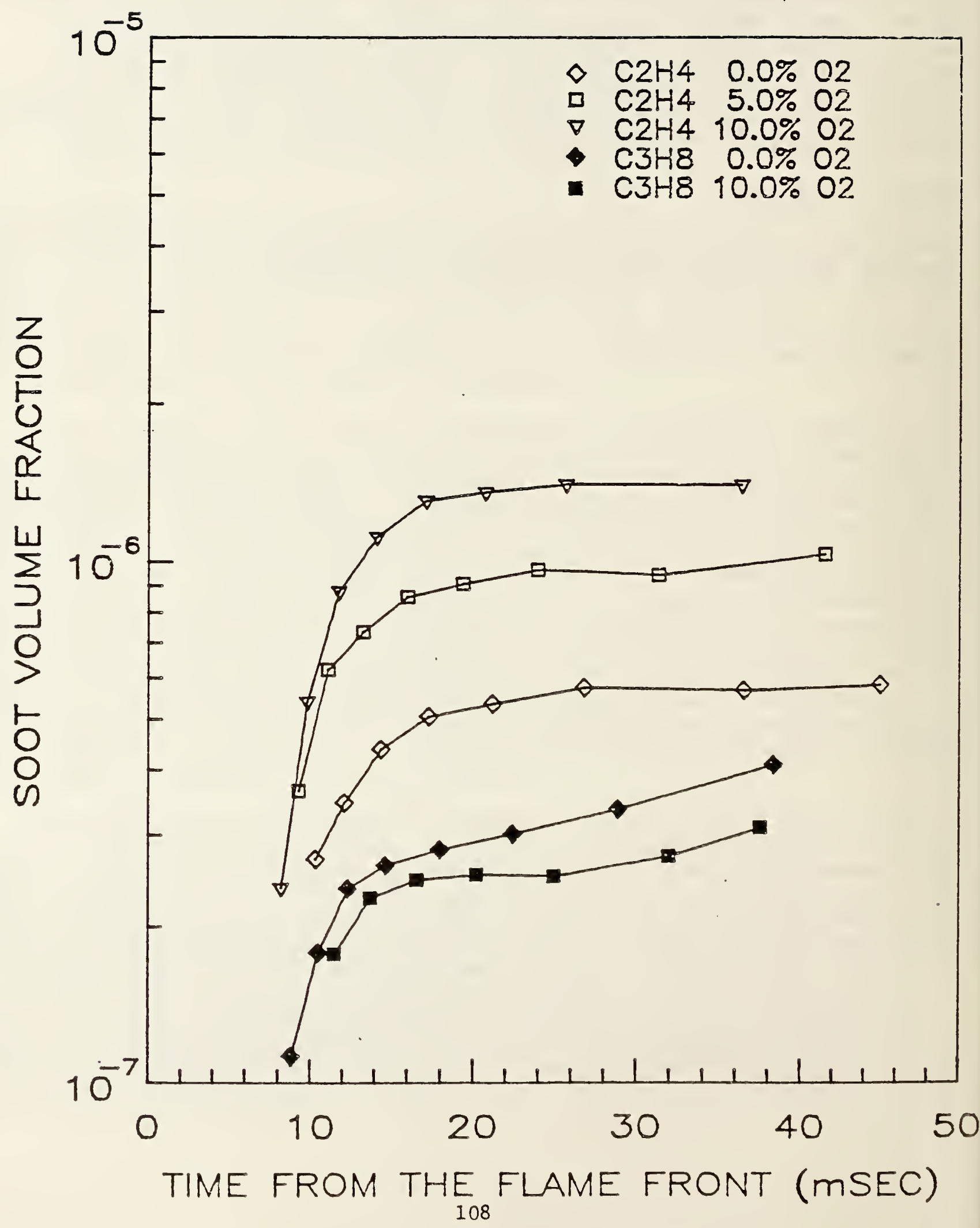


Fig. 2

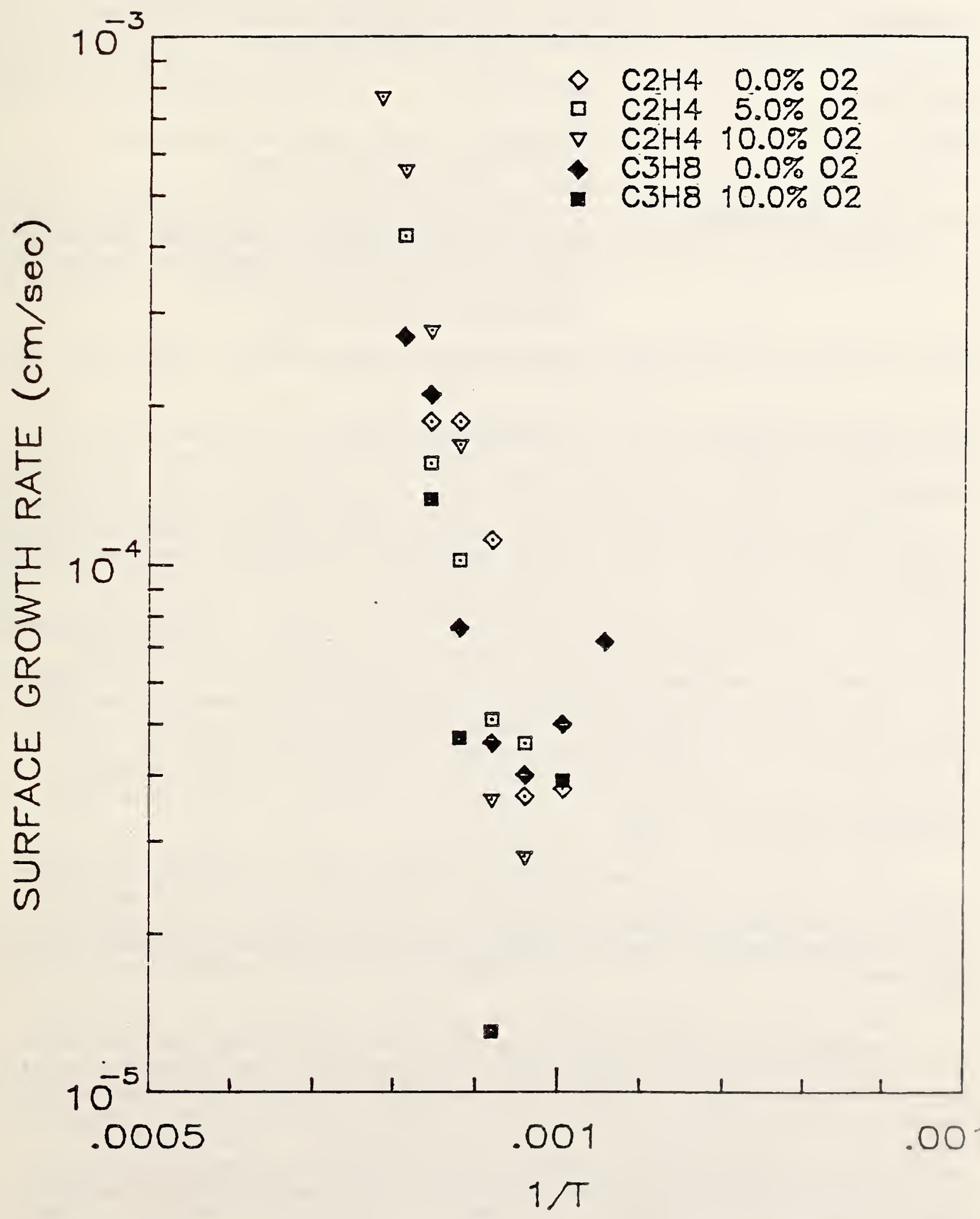




\section{CENTER FOR FIRE RESEARCH \\ NATIONAL BUREAU OF STANDARDS}

FY85

Institution:

Grant No.:

Grant Title:

Principal Investigator:
Rutgers, The State University of New Jersey New Brunswick, New Jersey

\section{NB83NADA4047}

Negatively Buoyant and Penetrative Flows Generated in Enclosure Fires

Professor Yogesh Jaluria

Department of Mechanical \& Aerospace Engineering Rutgers, The State University of New Jersey New Brunswick, New Jersey 08903

Telephone: (201) 932-3652

Other Professional Personnel: D. Goldman (M.S. Student) and A. Abib (Ph.D. Student)

NBS Scientific Officer: Dr. Leonard Y. Cooper

Technical Abstract:

The objective of this project is to study, experimentally, the negatively buoyant and penetrative flows that are generated in enclosure fires, as in the development of the fire. At the early stages, the flow driven by the fire plume spreads over the ceiling and turns downward at the corners. At this point, the wall flow is downward, whereas the buoyancy force acting on the flow is upward. This results in a negatively buoyant situation. Similarly, following the establishment of the two layers, or zones, in an enclosure fire, the relatively cool wall in the upper zone generates a buoyancy-induced downward flow, which is injected across the interface into the lower zone and penetrates to a finite distance due to the upward buoyancy force. The nature of such flows, the penetration into a region in which the flow is negatively buoyant and the transport due to these flows are of particular interest in the mathematical modeling of enclosure fires.

This study considers two-dimensional, heated air jets discharged downward adjacent to a wall, as well as away from it, thus giving rise to a negatively buoyant situation. Of particular interest were the downward penetration of the flow, the entrainment of ambient fluid into the flow and the resulting velocity and temperature fields in the region where the flow is negatively buoyant, see Fig. 1 .

An experimental system for the relevant measurements has been fabricated. Air is sent by a blower through a copper tube, which is heated by means of strip heaters wrapped around it, see Fig. 2. A diffuser is employed to spread out the heated air and discharge the resulting two-dimensional flow into a glass tank, which is $1.5 \mathrm{~m}$ high and $0.4 \mathrm{~m} \times 0.3 \mathrm{~m}$ in cross section. Measurements of velocity and temperature are taken by means of a hot-wire anemoneter and thermocouples, respectively. The side walls of the tank may be removed to simulate an extensive quiescent environment. The flow is visualized by means of smoke introduced into the flow, upstream of the diffuser. 
A substantial amount of data has been taken on the velocity and temperature distributions in the flow, as discussed in detail in the various papers and reports based on this project. The penetration distance $\delta_{p}$ is quantized by defining it as the vertical distance from the jet inflow to the location where the local temperature excess, $T-T_{\infty}$, has dropped to $1 \%$ of the inlet value, $T_{0}-T_{\infty}$. Here, $T_{\infty}$ is the ambient temperature and $T_{0}$ the average jet discharge temperature. Figure 3 shows the typical dependence of $\delta_{p} / D$, where $D$ is the width of the discharge slot, on the mixed convection parameter $\mathrm{Gr} / \mathrm{Re}^{2}=g \beta\left(T_{0}-T_{\infty}\right) D / U_{0}$. Here, $U_{0}$ is the average discharge velocity, $g$ the gravitational acceleration and $\beta$ the coefficient of thermal expansion of the fluid. The data is found to be fairly well correlated by the equation

$$
\delta_{p} / D=4.424\left(G r / R e^{2}\right)^{-0.389}
$$

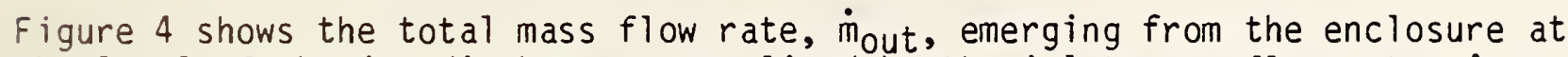
the level of the jet discharge, normalized by the inlet mass flow rate, $\dot{m}_{i n}$, as a function of $\mathrm{Gr} / \mathrm{Re}^{2}$. A very large amount of entrainment into the flow is observed at large values of $\mathrm{Gr} / \mathrm{Re}^{2}$. The data is satisfactorily correlated by the equation

$$
\frac{\dot{m}_{\text {out }}}{\dot{m}_{\text {in }}}=1.074+49.03\left(\mathrm{Gr} / \operatorname{Re}^{2}\right)
$$

Similarly, several other important aspects relevant to these flows have been studied. The heat transfer at the wall, the transient effects in these circumstances and the generation of a two-layer system in an enclosure with an opening are presently under study. Also, the experimental results are being incorporated into the consideration of wall effects in enclosure fires for zone modeling studies.

\section{Reports and Papers}

1. Jaluria, Y., "Buoyancy-Induced Wall Flow Due to a Fire in a Room," NBSIR-84-2841, National Bureau of Standards, Washington, DC, May 1984.

2. Jaluria, Y. and Goldman, D., "An Educed Wall Flow Due to a Fire in a Room," NBSIR-84-2841, National Bureau of Standards, Washington, DC, May 1984.

2. Jaluria, Y. and Goldman, D., "An Experimental Study of Negatively Buoyant Flows Generated by Fire in a Room," 1984 Tech. Meet., East. Sect. Combust. Inst., Florida, Dec. 1984, Paper No. 16.

3. Jaluria, Y. and Goldman, D., "An Experimental Study of Negatively Buoyant Flows Generated in Enclosure Fires," NBS-GCR-85-487, National Bureau of Standards, Gaithersburg, MD, Feb. 1985.

4. Goldman, D. and Jaluria, Y., "Effect of Opposing Buoyancy on the Flow in Free and Wall Jets," to be presented at the ASME Winter Annual Meeting, Miami, Florida, Nov. 1985, and to be published in "Mixed Convection Heat Transfer," Eds. Armaly, B.F. and Yao, L.S., ASME, Heat Transfer Div., Symp. Vo1., 1985.

5. Jaluria, Y., "Natural Convection Wall Flows," to appear in "Quantitative Methods Handbook; Fundamentals Unit," Ed. Beyler, C., Soc. Fire Protection Engrs., 1985. 

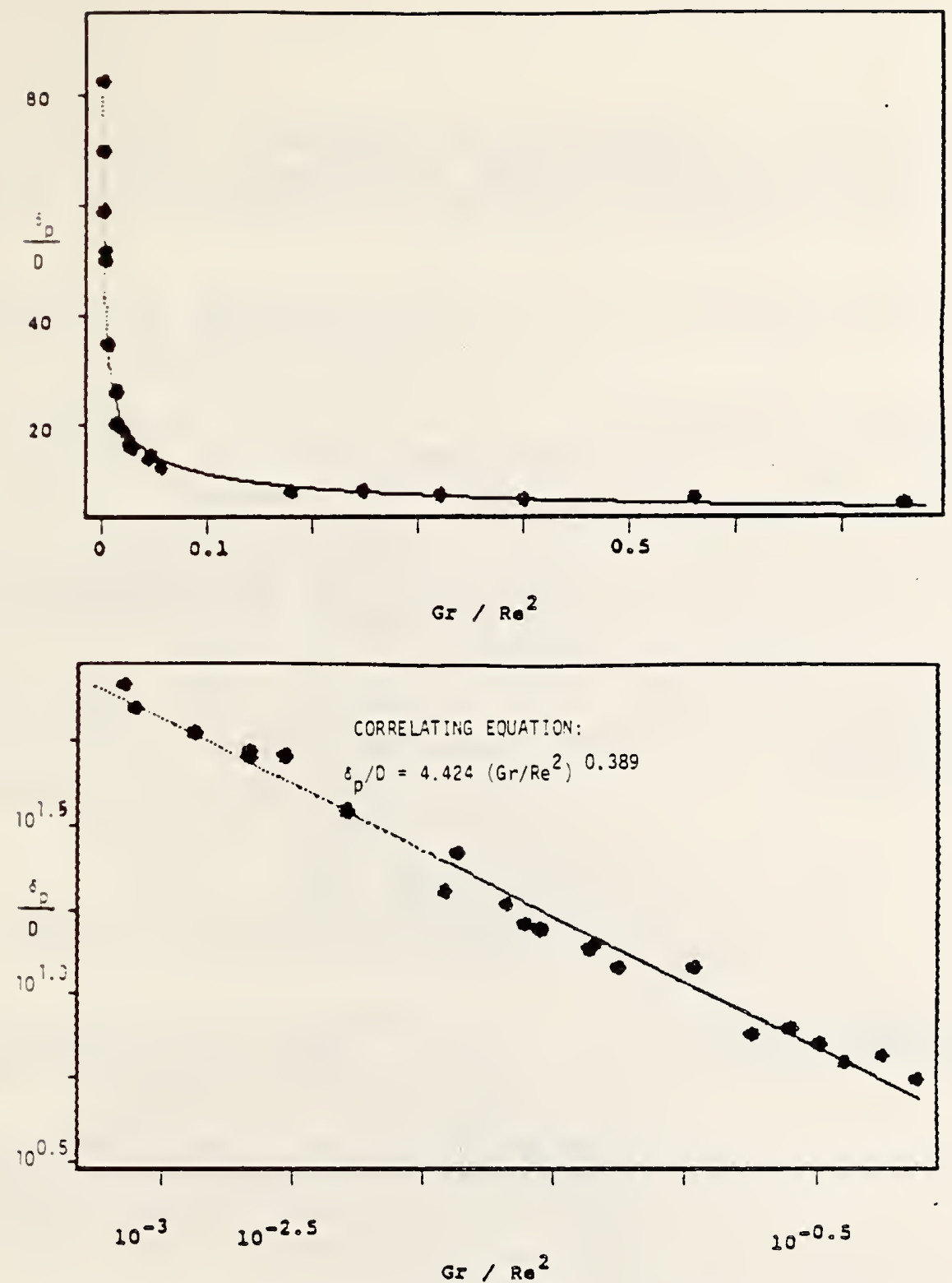

Figure 3. Downward penetration distance $\varepsilon_{p}$ as a function of the parameter $\mathrm{Gr} / \mathrm{Re}^{2}$, for a wall jet.

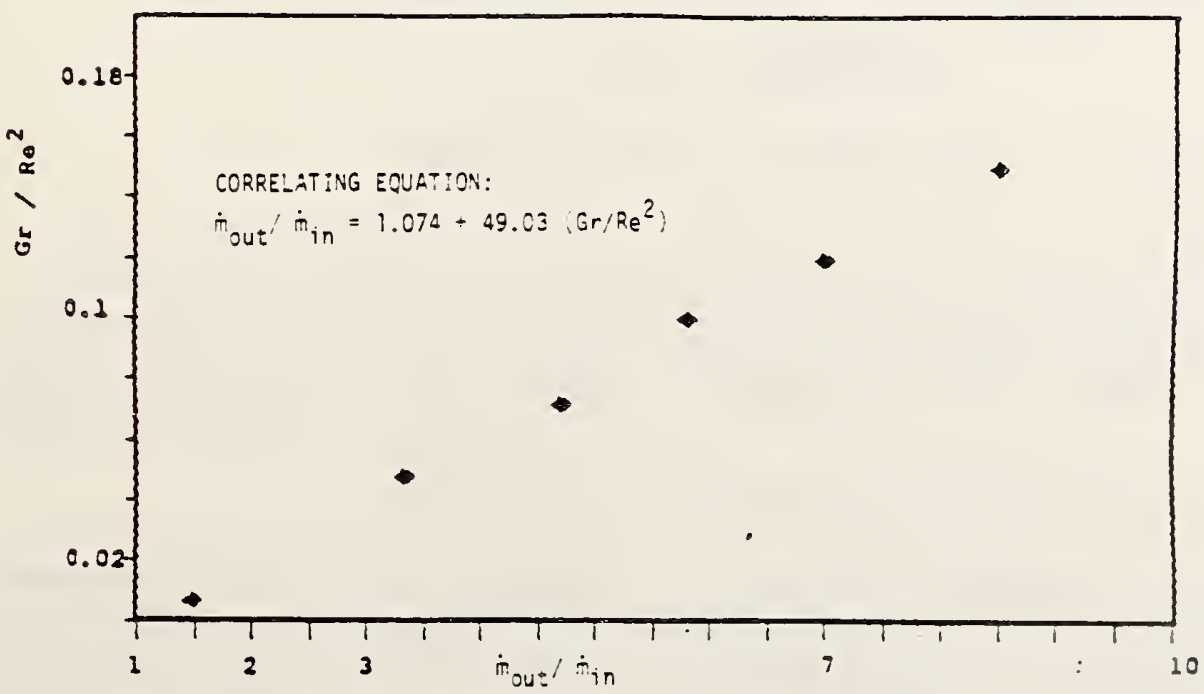

Figure 4. Total flow out of the enclosure, mout, normalized by jet discharge flow rate, $\dot{m}_{i n}$, as a function of $\mathrm{Gr} / \mathrm{Re}^{2}$, for a negatively buoyant wall jet. 
CENTER FOR FIRE RESEARCH

NATIONAL BUREAU OF STANDARDS

FY 85

Institution:

Grant No.:

Grant Title:

Principal Investigator:

Other Professional Personnel:

NBS Scientific Officer:

\section{Southwest Research Institute}

\section{NB83NADA4015}

Analysis of Hazards to Life Safety in Fires: A Comprehensive Multi-Dimensional Research Program

Dr. Gordon E. Hartzel1

Director, Department of Fire Technology

Southwest Research Institute

6220 Culebra Road

San Antonio, Texas 78238

Telephone: $512 / 684-5111$ ext 3038

\section{Dr. Arthur F. Grand (Staff Scientist)}

Or. Harold L. Kaplan (Manager, Applied Environmental Toxicology)

Deggary N. Priest (Senior Research Scientist)

Howard W. Stacy (Research Scientist)

Waiter G. Switzer (Research Scientist)

Dr. Steven C. Packham (Consultant)

Dr. Barbara C. Levin

Technical Abstract:

The overall objective of this research program has been to develop methodology to assess toxicological hazards to human life based on the time course of analytical data as provided by a fire model. Research work under this objective was reported in a final report under four major subject areas.

\section{INCAPACITATING EFFECTS OF NARCOTIC FIRE GASES}

From an extensive review of methodologies for assessment of the incapacitating effects of the narcotic fire gases, both with rats and with non-human primates, it was concluded that the rat appears to be sensitive to approximately the same range of accumulated doses as may be deemed potentially 
hazardous to human subjects. Thus, for both carbon monoxide and hydrogen cyanide, the rat is expected to be a reasonably appropriate model for the development of methodology for estimating toxicological effects on humans.

\section{MATHEMATICAL MODELING OF INTOXICATION OF RATS BY CARBON} MONOXIDE AND HYDROGEN CYANIDE

A mathematical approach, based on experimental concentration-time data, was developed for the prediction of both incapacitating (loss of leg flexion shock-avoidance response) and lethal effects on rats exposed to carbon monoxide and hydrogen cyanide. The model, illustrated in Figure 1, utilizes continuous summation of "fractional effective doses" to estimate the time of greatest probability of the occurrence of a toxicological effect. Examples were given for computer simulation of the development of toxic hazards in fires and comparisons made with actual experimental results. These comparisions showed that computer-predicted times to toxicological effects were within the standard deviations of experimental mean values.

\section{MODELING OF TOXICOLOGICAL EFFECTS OF FIRE GASES}

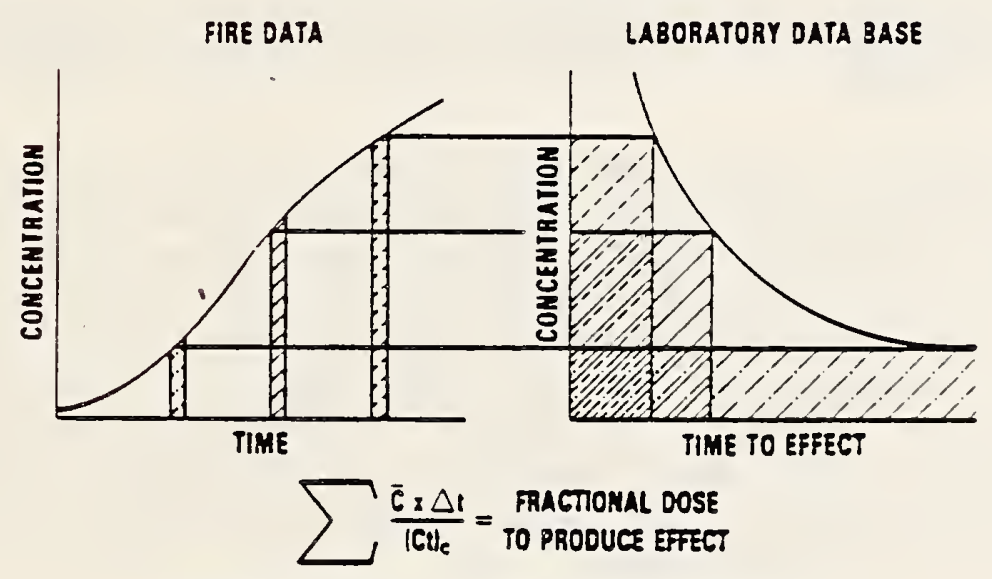

EFFET OCCURS AT TME I WHES $\sum$ FRACTIONAL DOSES = 1

Figure 1

III. QUANTIFICATION OF POST-EXPOSURE LETHALITY OF RATS FROM EXPOSURE TO HCl ATMOSPHERES

The post-exposure lethality of rats from exposure to hydrogen chloride atmospheres was quantified. A plot of $L C_{50}$ (post-exposure) values as a function of exposure time is shown in Figure 2. Experimental L(Ct) 50 values for $\mathrm{HCl}$ varied from about $80,000 \mathrm{ppm}-\mathrm{min}$ (5-min exposure to $16,000 \mathrm{ppm}$ ) to about $170,000 \mathrm{ppm}-\min (60$-minute exposure to $2,800 \mathrm{ppm})$. Relevant data involving non-human primate exposures were cited which suggest comparability of the rat and the primate for the purpose of assessing lethal doses of $\mathrm{HCl}$. 


\section{POST.EXPOSURE LETHALITY OF RATS \\ FROM EXPOSURE TO HYDROGEN \\ CHLORIDE}

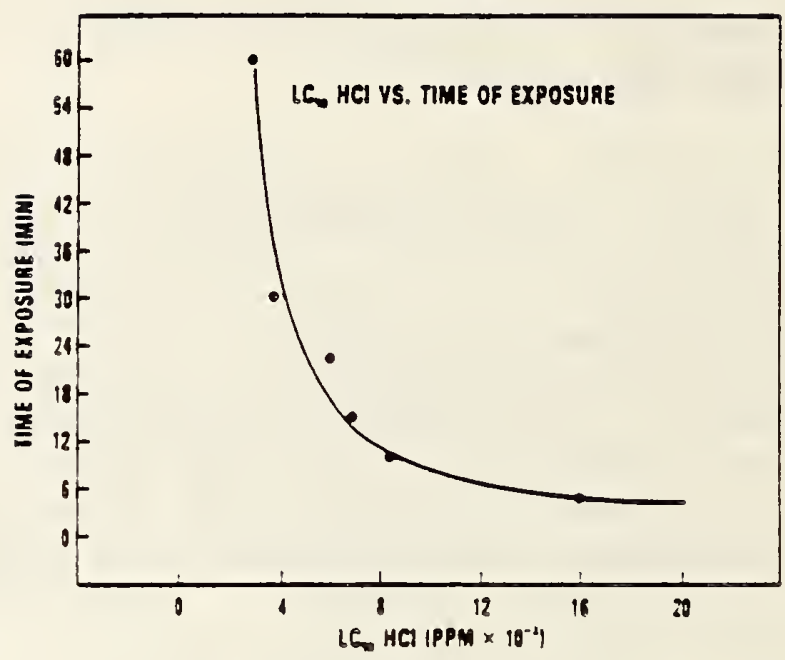

Figure 2

IV. INTOXICATION OF RATS BY CARBON MONOXIDE IN THE PRESENCE OF AN IRRITANT

A mathematical model was developed for the intoxication of rats by carbon monoxide which is a function of carbon monoxide concentration, time of exposure and respiratory minute volume, the latter being dependent upon the concentration of an irritant, hydrogen chloride. Predictions of the model, which were verified experimentally, led to the conclusion that the overall effect of the presence of $\mathrm{HCl}$ on intoxication of rats by $\mathrm{CO}$ is relatively minor and appears to lie in a "window" of about 400 to $1000 \mathrm{ppm} \mathrm{HCl}$ and with CO concentrations up to about $4000 \mathrm{ppm}$. The predominant effect is, therefore, on incapacitating rather than lethal conditions when time frames typical of fire gas exposures are involved.

\section{Reports and Papers:}

1. G. E. Hartzell, A. F. Grand, H. L. Kaplan, D. N. Priest, H. W. Stacy, W. G. Switzer and S. C. Packham, "Analysis of Hazards to Life Safety in Fires: A Comprehensive Multi-Dimensional Research Program -. Year 1," Final Report No. 01-7606, NBS Grant NB83NADA4015, Southwest Research Institute, San Antonio, Texas (May 1985).

2. H. L. Kaplan and G. E. Hartzell, "Modeling of Toxicological Effects of Fire Gases: I. Incapacitating Effects of Narcotic Fire Gases," J. of Fire Sciences, Vol. 2, No. 4, pp. 286-305 (1984). 
3. G. E. Hartze11, D. N. Priest and W. G. Switzter, "Modeling of Toxicological Effects of Fire Gases: II. Mathematical Modeling of Intoxication of Rats by Carbon Monoxide and Hydrogen Cyanide," J. Fire Sciences, Technomic Publishing Company, In Press (1985).

4. G. E. Hartze11, S. C. Packham, A. F. Grand and W. G. Switzer, "Modeling of Toxicological Effects of Fire Gases: III. Quantification of PostExposure Lethality of Rats from Exposure to HCl Atmospheres," J. Fire Sciences, Technomic Publishing Company, In Press (1985).

5. G. E. Hartze11, H. W. Stacy, W. G. Switzer, D. N. Priest and S. C. Packham, "Modeling of Toxicological Effects of Fire Gases: IV. Intoxication of Rats by Carbon Monoxide in the Presence of an Irritant," J. Fire Sciences, Technomic Publishing Company, In Press (1985).

6. G. E. Hartze11, S. C. Packham and W. G. Switzer, "Toxic Hazards of Smoke," Interfiam ' 85 Conference Proceedings, University of Surrey, Guildford, England, pp. 100-105 (March 1985).

7. G. E. Hartze11, D. N. Priest and W. G. Switzer, "Mathematical Modeling of Toxicological Effects of Fire Gases," Eighth U.S.-Japan National Resources Panel on Fire Research and Safety, Tsukuba, Japan (May 1985).

8. G. E. Hartze11, D. N. Priest and W. G. Switzer, "Mathematical Modeling of Toxicological Effects of Fire Gases," First International Symposium on Fire Safety Science, National Bureau of Standards, Gaithersburg, Maryland (October 1985). 


\title{
CENTER FOR FIRE RESEARCH \\ NATIONAL BUREAU OF STANDARDS \\ FY85
}

\author{
Institution: Stanford University \\ Grant No.: $\quad$ NBS Grant NB83NAD4019 \\ Grant Title: The Behavior of Furniture Frames During Fire \\ Principle Investigator: Professor George S. Springer \\ Department of Aeronautics and Astronautics \\ Stanford University \\ Stanford, California 94305 \\ Telephone: (415) 497-4135 \\ Other Professional Personnel: F. K. Chang (Post Doctoral Fellow) \\ J. Burwasser (M.S. student) \\ $\mathrm{Ph}$. Good (M.S. student)
}

NBS Scientific Office: William J. Parker

\section{Technical Abstract:}

The major objective of this investigation was to evaluate the behavior of furniture frames during fire. The problem was attacked along two parallel lines. First, tests were performed measuring the strengths, deflections, and failure times of loaded wooden and plastic structural elements (beams, joints, bends) exposed to elevated temperatures. Second, analytical techniques were developed for calculating the stresses, strains, strength, and failure time of wooden and plastic beams and bends during high temperature exposure.

Tests were performed with bends and joints constructed of southern pine and with beams made of polypropylene and acrylic rods. The southern pine test specimens were fabricated using $3 / 4$ in (nominal) thick wood. Bends were prepared with different grain orientations and different bend angles. Joints were made with different types of fasteners. Each bend and joint was exposed to a constant temperature of 100,160 , or $245^{\circ} \mathrm{C}$ for a predetermined length of time. The deflection of the loaded joint was then measured. These measurements provided the load versus deflection, the deflection at failure, and the failure time.

The "failure times" of plastic rods exposed to elevated temperatures were also measured. In these tests each plastic rod, supported at its two ends, was placed into an oven preheated to $150,200,250,300$, or $350^{\circ} \mathrm{F}$. Load was applied at the center of the rod. The time required to reach a certain deflection (corresponding to a preassigned stress level inside the rod) was measured. 
Three different diameter rods were tested: $3 / 4,5 / 8$, and $1 / 4$ in for polypropylene; and $5 / 8,7 / 16$, and $1 / 4$ in for acrylic. Data were generated at six load levels ranging from 10 to 60 percent of the failure load at room temperature.

In addition to testing, analytical models were developed to simulate the response of bends to elevated temperatures. The models describe the changes in the thermal and mechanical properties of bends, and predict the time of failure. The model is developed in four steps, (a) calculation of the temperature distribution and mass loss inside bends, (b) calculation of the changes in stresses and strains with time, (c) estimation of the changes in strengths and moduli with time, and (d) prediction of the failure time.

In the first part of the model the temperature distribution inside the wood and the mass loss are calculated. This part of the model is formulated on the basis of the law of conservation of energy, with the chemical reactions represented by a single step Arrhenius bulk reaction.

The second part of the model is used to calculate the stresses and strains in bends. This model utilizes a two-dimensional finite element method of solution of the governing equations.

The third part of the model provides a means of estimating the changes in strengths and moduli during exposure to elevated temperatures. This model is based on the hy. pothesis that degradation in mechanical properties is related to the mass loss caused by volatilization of the wood.

The fourth part of the model provides the failure times of bends during high temperature exposure. The model relates the applied stresses to the allowable strength through an appropriate failure criterion.

On the basis of the models, a computer code was developed which provides the stresses and strains in the wood as well as the following parameters, (a) temperature distribution inside the wood, (b) mass loss, (c) strength loss, (d) stiffness loss, and (e) failure time.

Non-dimensional parameters were also established for correlating the data obtained with plastic rods. With the use of these parameters the data can be extended to materials, geometries, and temperatures other than those employed in the present tests.

The data generated and the models developed in this investigation provide information on the behavior of different types of structural elements utilized in the construction of furniture frames. This information can be used to estimate the failure time during exposure to elevated temperatures. Thus, the results of the present study will help in establishing appropriate endurance ratings for furniture, and will lead to more fire resistant furniture design and construction methods.

\section{Reports and Papers:}

1. Springer, G. S. “The Behavior of Furniture Frames During Fire," Report to the Center for Fire Research, National Bureau of Standards, October 1985.

2. Chang, F. K. "Thermal-Mechanical Loading Effect on Strength and Failure Time of Wooden Structures Exposed to Elevated Temperatures," Journal of Reinforced 
Plastics and Composites (in print).

3. Chang, F. K. "Strength of Wooden Bends," Journal of Reinforced Plastics and Com. posites (in print).

4. Chang, F. K. "Stress Analysis of Wooden Bends," Journal of Reinforced Plastics and Composites (in print).

5. Burwasser, J., P. Homer, and F. K. Chang. "Behavior of Wooden Joints and Bends Exposed to Elevated Temperature," Journal of Reinforced Plastics and Composites (in print).

6. Burwasser, J. and Ph. Good. "Deflection of Loaded Plastic Rods at Elevated Temperatures," Journal of Reinforced Plastics and Composites (in print). 
CENTER FOR FIRE RESEARCH

NATIONAL BUREAU OF STANDARDS

FY 85

\section{Institution: University of California, Berkeley}

Grant No.: $\quad$ 60NANB5D0552

Grant Title: Fire Modeling

Principal Investigator: Professor Patrick J. Pagni

Department of Mechanical Engineering

University of California

Berkeley, CA 94720

Telephone: (415) 642-0729

Other Professional Personnel: James Ang (Ph.D. Candidate)

Valerie Lyons (Ph.D. Candidate)

Corey Dunsky (M.S. Candidate)

Thomas Mataga (M.S. Candidate)

NBS Scientific Officer: Dr. Howard Baum

Technical. Abstract:

The overall goal of this project is to develop physical and mathematical models of the detailed combustion phenomena which control a fire's growth within a compartment and its subsequent propagation throughout a structure. Our effort this grant period was directed primarily at the first area listed below with some progress also in the second:

Fire Radiation:

In flame radiation, the most important and least known parameter is $f_{V}$, the soot volume fraction, defined as the volume occupied by soot per unit of flame volume. Previous reports have described a multi-wavelength laser extinction technique for in situ measurement of the local flame $f_{V}$ in free and forced boundary layers $(2,3,6)$ as well as in pool fires (8). The full Mie theory, Lee and Tien optical properties and a two-parameter size distribution are assumed. Alternative simplifying assumptions have been shown to overestimate $f_{V}$.

Since we have experimental $f_{V}$ profiles, along with both experimental and theoretical velocity and temperature profiles, it is possible to calculate the local radiation from each sooty volume element within the flame. Applying the emission only approximation permits incorporating radiation as a simple sink term in the energy equation of strength:

$$
\dot{q}^{\prime \prime \prime}=4 k \sigma T^{4}=A F{ }_{a} f^{T} T^{5},
$$

where $A=6.4 \times 10^{-3} \mathrm{~W} / \mathrm{m}^{3} \mathrm{~K}$ and $\mathrm{F}_{\mathrm{Q}} \sim 0.05$ are constants and $\mathrm{T}$ is the locaI ter- 
perature. The fifth power comes from the additional linear temperature defendence of the absorption coefficient $k=36 \pi \mathrm{Fafv}_{\mathrm{v}} / 0.4, \mathrm{~cm}^{-1}(2,3)$. The significance of this approximation is that it allows treating the radiation as a perturbation on the Emmons problem. We are adding normal and streamise buoyancy also as perturbations to that problem. The solutions obtained will permit us to interpret our existing $f_{v}$ data in mixed boundary layers with the goal of modeling the soot formation there, as we did last grant period for our free flow $f_{v}$ data $(2,3)$. In the future, we will use large activation energy asymptotics to include finite kinetics, possibly with multiple reactions, in these diffusion flame analyses.

Concurrently, a student on this project working at NASA Lew is Research Center, will be comparing scattering and multi-wavelength extinction techniques for measuring $f_{\mathrm{V}}$ in the same sooting flame to determine the advantages of each method and to explore the possibility of a more useful hybrid experimental system. Shown in the figure below are experimental velocity profiles she obtained using LDV on free vertical diffusion flames for corrparison (6) with the previously published theoretical profiles $(2,3)$

$$
\text { EXPER!MENTAL VELOCITY PROFILES }
$$

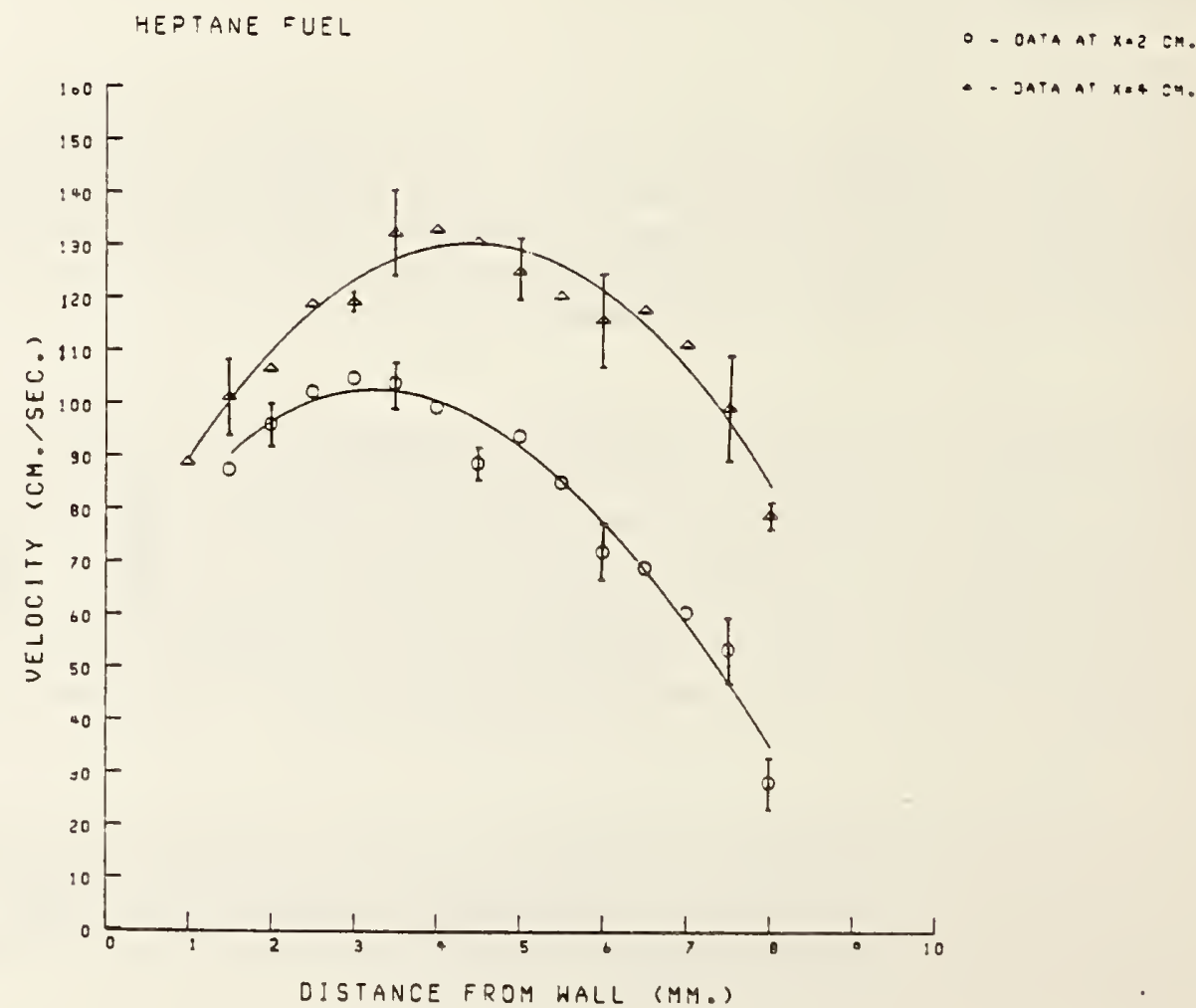

Temperature Correlations:

Spurred by the success of the hot layer temperature correlation published by McCaffrey, Quintiere and Harkleroad for naturally ventilated fires, we have attempted to uncover similar results for force ventilated corpartment fires based on experiments at the Lawrence Livermore Nationa? Laboratory $(1,7)$. Two correlations emerged; one following McCaffrey et al.: 


$$
\frac{\Delta T}{T_{\infty}}=0.63\left(\frac{\dot{Q}}{m_{c_{p} T_{\infty}}}\right)^{0.72}\left(\frac{h A}{\dot{m c}_{p}}\right)^{-0.36} \text {, }
$$

where $\Delta T=T_{l}-T_{\infty}, \dot{Q}$ is the fire strength, $\dot{m}$ is the forced mass flow rate, $A$ is the surface area of the hot layer and $h$ is a time dependent coefficient representing the heat loss as a thermal resistance to $\Delta T$ across the compartment walls. The two parameters on the right, the fire strength and the compartment heat loss, may not be independent. Nondimensionalization suggests $\dot{Q} / \mathrm{mc}_{p}$ as a characteristic temperature. An example of such a correla-
tion is

$$
\frac{\Delta T}{\left(\dot{Q} / \dot{m c_{p}}\right)}=\exp \left[-\left(\frac{h A}{\dot{m c}_{p}}\right)^{0.23}\right]
$$

Two parameters were originally introduced as $\exp \left[-\mathrm{C}\left(\mathrm{hA} / \dot{\mathrm{mc}}_{\mathrm{p}}\right)^{\mathrm{n}}\right]$, but $\mathrm{C}=0.99$ in

the fit so $\mathrm{C}$ was set equal to unity. This correlation goes to the right limits as $h$ approaches 0 or $\infty$. The implications of the $\Delta T>500^{\circ} \mathrm{C}$ criteria for flashover are currently being compared with more detailed analyses.

\section{Reports and Papers:}

1. N.J. Alvares, K.L. Foote and P.J. Pagni, "Forced Ventilation Enclosure Fires," Combustion Science and Technology, 39, 55-82, 1984.

2. R.A. Beier, P.J. Pagni and C.I. Okoh, "Soot and Radiation in Combusting Boundary Layers," Combustion Science and Technology, 39, 235-262, 1984.

3. P.J. Pagni and C.I. Okoh, "Soot Generation within Radiating Diffusion Flames," presented at the Twentieth Symposium (International) on Combustion, Ann Arbor, MI, August 12-17, 1984.

4. R.S. Levine and P.J. Pagni, Editors, Fire Science for Fire Safety, Gordon and Breach Science Publishers, New York, NY, 1985.

5. P.J. Pagni, "Materials Fire Properties and Test Methods," presented at the Eighth Joint Meeting, United States-Japan Natural Resources Panel on Fire Research and Safety, May 13-21, Tsukuba, Japan.

6. J.A. Ang, P.J. Pagni, V.J. Lyons, J.M. Margle and T.G. Mataga, "Free, Sooting, Boundary Layer, Diffusion Flame Profiles" to be presented at the AIAA Annual Meeting, January 6, 1986, Reno, NV.

7. K.L. Foote, P.J. Pagni and N.J. Alvares, "Temperature Correlations for Force-Ventilated Compartment Fires", presented at the First

International Symposium on Fire Safety Science, Oct. 7-11, 1985, MBS, Gaithersburg, MD.

8. S. Bard and P.J. Pagni, "Soot Volume Fractions in Pool Fire Diffusion Flames" presented at the First International Symposium on Fire Safety Science, Oct. 7-11, 1985, NBS, Gaithersburg, MD. 
CENTER FOR FIRE RESEARCH

NATIONAL BUREAU OF STANDARDS

FY 85

Institution: University of California, Berkeley

Grant No.: $\quad$ NB83NADA4020

Grant Title: Fire Propagation in Concurrent Flows

Principal Investigator: Professor A.C. Fernandez-Pello

Department of Mechanical Engineering

University of California

Berkeley, CA 94720

Other Professional Personnel: H-T. Loh, Research Assistant

H. Kodama, Research Assistant

NBS Scientific Officer: Dr. H. R. Baum

Technical Abstract:

A study is currently underway of the spread of flames over the surface of a solid combustible in a mixed, forced and free, convective flow. Research efforts have concentrated primarily on an experimental study of the flow-assisted spread of flames over thermally thin fuels, and a numerical analysis of the extinction of flames established over a flat combustible surface. During this reporting period, a series of experiments of the dependence on the velocity and oxygen concentration of the concurrent forced flow of the rate of flame spread over thin Cellulose sheets have been completed. The results indicate that this form of fire spread is primarily controlled by heat transfer from the flame to the unburnt combustible. The flame spread rate data can be correlated with an expression obtained from a heat transfer analysis of the flame spread process. The experiments also showed that extinction of the flames, due to vitiated (low oxygen concentration) or high velocity conditions, occurs at the upstream leading edge of the flame. A numerical analysis of the flame extinction process has also been completed. The steady state elliptic conservation equations, including finite rate Arrhenius Kinetics describing the reacting flow over a flat plate, are solved in the analysis. It is predicted that the flame positions itself along the viscous layer such that the chemical and residence times are of the same order of magnitude, and that total extinction occurs at oxygen concentrations of approximately 0.18 , in agreement with previous experiments of the limiting oxygen index for PMMA.

\section{Experimental Study of Flow Assisted Flame Seread Over Thin Paper}

Sheets. Measurements have been performed of the flow assisted spread of flames over the surface of thin paper sheets. The objective of the experiments is to obtain information about the spread of flames over thermally thin materials. The experiments are carried out in a small scale combustion tunnel. The paper sheets are positioned in the middle of the tunnel test section to generate a flat plate flow over both surfaces of the fuel sheet. 


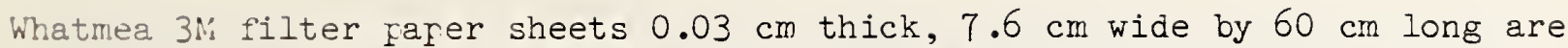
used in the experiments. The gas flow in the tunnel consists of mixtures of oxygen and nitrogen of varied concentrations and velocities.

The measured progress of the pyrolysis $\left(x_{p}\right)$, burnout $\left(x_{f}\right)$ fronts, and of the flame tip $\left(x_{f}\right)$ are presented in Fig. 1 for several air flow velocities. The spread rate of each front can be deduced from these results by differentiating the corresponding distances with time. From the results presented in Fig. 1, it is seen that for air the flame spreading process is accelerative from ignition to approximately $15 \mathrm{~cm}$ downstream, becoming constant afterwards. This result follows the variation of the pyrolysis length $\ell_{p}=x_{p}-$ $X_{b}$ and of the flame length $\ell_{f}=X_{f}-X_{p}$ with the distance from ignition. From Fig. 1 it is seen that both the pyrolysis and flame lengths increase rapidly during the initial period of the flame spread process until burnout of the fuel starts. After that, the rate of increase of these lengths decrease as the burnout front progresses until finally they become practically constant at approximately $15 \mathrm{~cm}$ from ignition. The results of Fig. I also show that, for low flow velocity (mixed convection), t he pyrolysis and flame lengths decrease as the flow velocity increases. Both lengths approximately become constant for forced flow conditions $\left(u_{\infty}>1 \mathrm{~m} / \mathrm{s}\right)$. The flame spread rate follows the variations of these lengths, increasing with the flow velocity for mixed flow conditions and becoming practically constant for forced flow.

In order to explain the experimental results, a simplified model of the flame spread process over thermally thin fuels was developed. Assuming: that the primary controlling mechanism of flame spread is heat transfer from the flame to the non-burning material downstream from the pyrolysis front; that the heat flux from the flame is constant over the flame length and zero afterward; that the temperature of the fuel is uniform along its thickness (thermally thin); and that the combustible does not vaporize until its temperature reaches a given value; an energy balance for a control volume in the solid downstream from the pyrolysis front gives an approximate expression for the rate of spread of the pyrolysis front of the form.

$$
V_{F}=\lambda g\left(T_{f}-T_{V}\right)\left(\ell_{f} / \delta\right) /\left[\rho c \tau\left(T_{V}-T_{\infty}\right)\right]
$$

The experimental results for the flame spread rate can be explained phenomenologically with the help of the above equation and some additional related measurements

- A correlation, using the above equation, of the spread rate data obtained in this work is presented in Fig. 2 . It is seen that the above equation correlates very closely the flame spread data obtained for different flow velocities and oxygen concentrations.

Numerical Modeling of the Extinction of a Diffusion Flame. This work is an analysis of the extinction characteristics of a diffusion flame above a vertical combustible surface burning steadily in a mixed convective flow. In the analysis, which includes longitudinal diffusion, the two-dimensional, elliptic, gas-phase conservation equations are solved nurrerically using a finite difference scheme. The primary result of the analysis is the rediction of the distance from the upstream edge of the fuel surface to the foint where the flame leading edge is stabilized (extinction distance) as a function of the velocity and oxygen concentration of the flow. The results of 
this work not only are relevant for the description of extinction processes but also for the study of the spread of flames in an opposed flow. This is because in opposed flame spread the flame leading edge is at near extinction conditions.

In Fig. 3 the results are presented for the predicted distance from the upstream edge of the combustible surface to the flame leading edge (extinction distance) as a function of the flow velocity for several values of the oxygen mass fraction of the flow. In Fig. 4 the extinction distance is shown as a function of the oxygen mass fraction for several flow velocities. From these figures it is seen that the extinction distance increases as the flow velocity increases or oxygen concentration decreases. These results are in agreement with a phenomenological view of the extinction process in terms of the existence of a critical Damkohler number for extinction, i.e., the critical ratio of the flow (residence) time to the chemical time of the reaction. For a fixed oxygen concentration (fixed chemical time) as the flow velocity increases, the flow time (which is determined by the ratio of the characteristic length of upstream heat conduction to the flow velocity) decreases. Consequently the Damkohler number also decreases with the flow velocity. In order to maintain the value of the Damkholer number the reaction zone must move downstream where the velocity gradients and heat losses are smaller because of the thickening of the boundary layer and consequently where the flow time is larger. Similarly, for a fixed flow velocity (fixed residence time), as the oxygen concentration decreases the chemical time increases which results in a decrease of the Damkholer number. Therefore, in this case also, the reaction zone must move downstream to regions of larger flow time in order to increase the value of the Damkohler number of its critical value. Finally, from the results of Fig. 4, it is also seen that the predicted limiting oxygen mass fraction for extinction is about $Y_{\infty}=0.18$, which is in agreement with the experimental measurements of Sibulkin, et al. (Combustion and Flame, 44, 187, 1982), obtained with vertical PMMA cylinders burning in a flow of $\mathrm{O}_{2} / \mathrm{N}_{2}$ at low velocity.

\section{Reports and Papers:}

1. H.T. Loh and A.C. Fernardez-Pello, "Flow Assisted Flame Spread Over Thermally Thin Fuels," Accepted for presentation at the First International Symposium on Fire Safety Science, National Bureau of Standards, Gaithersburg, MD, October 9-11, 1985.

2. M. Kodama and A.C. Fernandez-Pello, "Extinction of a Diffusion Flame Established Over a Flat Combustible Surface," Presented at the 1984 Fall Technical Meeting, Eastern Section of The Combustion Institute, Clearwater Beach, Florida, December 3-5, 1984. 
CENTER FOR FIRE RESEARCH

NATIONAL BUREAU OF STANDARDS

FY 1985

$\begin{array}{ll}\text { Institution: } & \text { University of California - Berkeley } \\ \text { Grant No.: } & \text { 60NANB4D0018 } \\ \text { Grant Title: } \quad \text { Flame Radiation } & \\ \text { Principal Investigator: } & \begin{array}{l}\text { Professor Chang-Lin Tien } \\ \text { Mechanical Engineering Department } \\ \text { University of California } \\ \text { Berkeley, California } 94720 \\ \text { Telephone: (415) 642-0877 }\end{array}\end{array}$

Other Professional Personnel: K. Y. Lee (Ph.D. student)

M. A. Brosmer (Ph.D. student)

A. J. Stretton (Ph.D. student)

NBS Scientific Officer: Dr. Takashi Kashiwagi

Technical Abstract:

The objective of this project is to establish a simple physical framework for the calculation of radiation from complex fire phenomena. The research approach aims at developing approximate formulations by systematic experimentation and analysis of the fundamental aspects of the problem. During the past year, the thrust of the research was focused on two primary topics: 1) Experimental and theoretical determination of radiative properties of gases evolved from burning condensed fuels, principally PMMA, and 2) Development of simple calculation schemes for the determination of radiation absorption in a thin non-isothermal layer composed of these gases including the effects of soot.

Radiation Properties of Gases Evolved from Condensed Fuels. The ignition and continuous combustion of condensed fuels requires a significant energy input. For moderate to large scale fires, which are of practical interest, this energy is supplied by radiant transport from the flame zone to the fuel surface. The radiant energy is attenuated by a thin gas layer composed of species evolved from the fuel surface. These species are primarily hydrocarbons which are strong absorbers of infrared energy and thus greatly influence the ignition and combustion processes. At present, knowledge of the radiant properties of the hydrocarbon species is quite $1 \mathrm{im}-$ ited. A combined analytic and experimental research effort has therefore been directed at the determination of the radiative characteristics of several gas species common to combustion systems. The experimental phase consists of the determination of the spectral and total radiation absorption properties of several hydrocarbons commonly evolved from petroleum-based fuels. These gases include methyl methacrylate $\left(\mathrm{C}_{5} \mathrm{H}_{8} \mathrm{O}_{2}\right)$, propane $\left(\mathrm{C}_{3} \mathrm{H}_{8}\right)$, propylene $\left(\mathrm{C}_{3} \mathrm{H}_{6}\right)$, ethane $\left(\mathrm{C}_{2} \mathrm{H}_{6}\right)$, ethylene $\left(\mathrm{C}_{2} \mathrm{H}_{4}\right)$, acetylene $\left(\mathrm{C}_{2} \mathrm{H}_{2}\right)$, and methane $\left(\mathrm{CH}_{4}\right)$. Infrared absorption data are obtained for a temperature range of 300 to $900 \mathrm{~K}$ and partial gas pressures of 0.05 to $2.0 \mathrm{~atm}$. The 
spectral absorption data are used to evaluate the spectral mean and total radiative properties of the various absorption bands of the gases. The total band properties are used to specify the total gray gas radiative properties, including the gas emissivity, absorptivity and Planck mean absorption coefficients. Thus far, the various radiative properties have been determined for acetylene, methane and propylene $[1,2,3]$, and the Planck mean absorption (emission) coefficients for these gas species are presented in Fig. 1. The analytic portion of this project has been directed at the development of a simple model which will accurately specify the total absorption characteristics of a gas without characterizing the absorption of the individual bands. A combined-band model, which is particularly convenient for correlating radiation properties of gases and gaseous mixtures with complex band structures, has been developed and shown to accurately predict the radiant behavior of $\mathrm{H}_{2} \mathrm{O}, \mathrm{CO}_{2}, \mathrm{CO}, \mathrm{CH}_{4}$ and $\mathrm{SO}_{2}$ [4]. The model is based on the exponential wide-band model which has been shown to accurately predict the total radiant absorption of the individual absorption bands. It therefore retains the fundamental basis of gas band radiation yet simplifies the prediction of total gas radiation properties, particularly for complex hydrocarbon gases and mixtures.

Blockage of Thermal Radiation and Radiation Quenching. For moderate and large scale fires, one of the most important elements in determining the energy feedback from a flame to the fuel surface is the radiative blockage by pyrolyzed gaseous and particulate components. Calculations of the fuel pyrolysis rate have consistently overpredicted the experimental data, which are believed to be due to both the underestimation of radiation blockage and the quenching effect of a relatively cold fuel surface. It has been found that the blockage effect may be significant even in small scale fires for a sooty polymer fuel such as polystyrene [5]. The information on radiation blockage was utilized in an investigation of radiation heat attenuation in ignition models of various condensed fuels [6]. The predicted ignition delay time and surface temperature history are in much better agreement with experimental data compared to previous analyses. The blockage effect on ignition is more pronounced as the heat flux and soot content of the system increase. The investigation into cold wall flame-quenching used the singular perturbation technique to determine the quenching distance as a function of various physical parameters [7]. A new dimensionless group, a modified Damkohler number, emerges from the analysis and characterizes the relative strength of chemical heat generation to conduction-radiation heat transfer. It was found that the quenching distance tends to increase as the heat source intensity and optical thickness of the system decrease, which may be seen in Fig. 2. Furthermore, it was determined that the fuel surface emissivity is not a major influence in the calculation. The analysis also suggests a potential scheme for the experimental measurement of extinction temperatures in several combustion configurations. These studies have concentrated on the contribution of particulates to the radiant transfer, while neglecting the effects of gaseous absorption/emission. For moderately sooty fuels, such as PMMA, the contribution of the gases in the quenching layer is as significant as the soot contribution to the radiant transfer. The gaseous effects are presently being considered for pool fires, where the combustion zone surrounds a fuel-rich core. This core region strongly attenuates the radiant feedback to the fuel, and limits the combustion rate. 


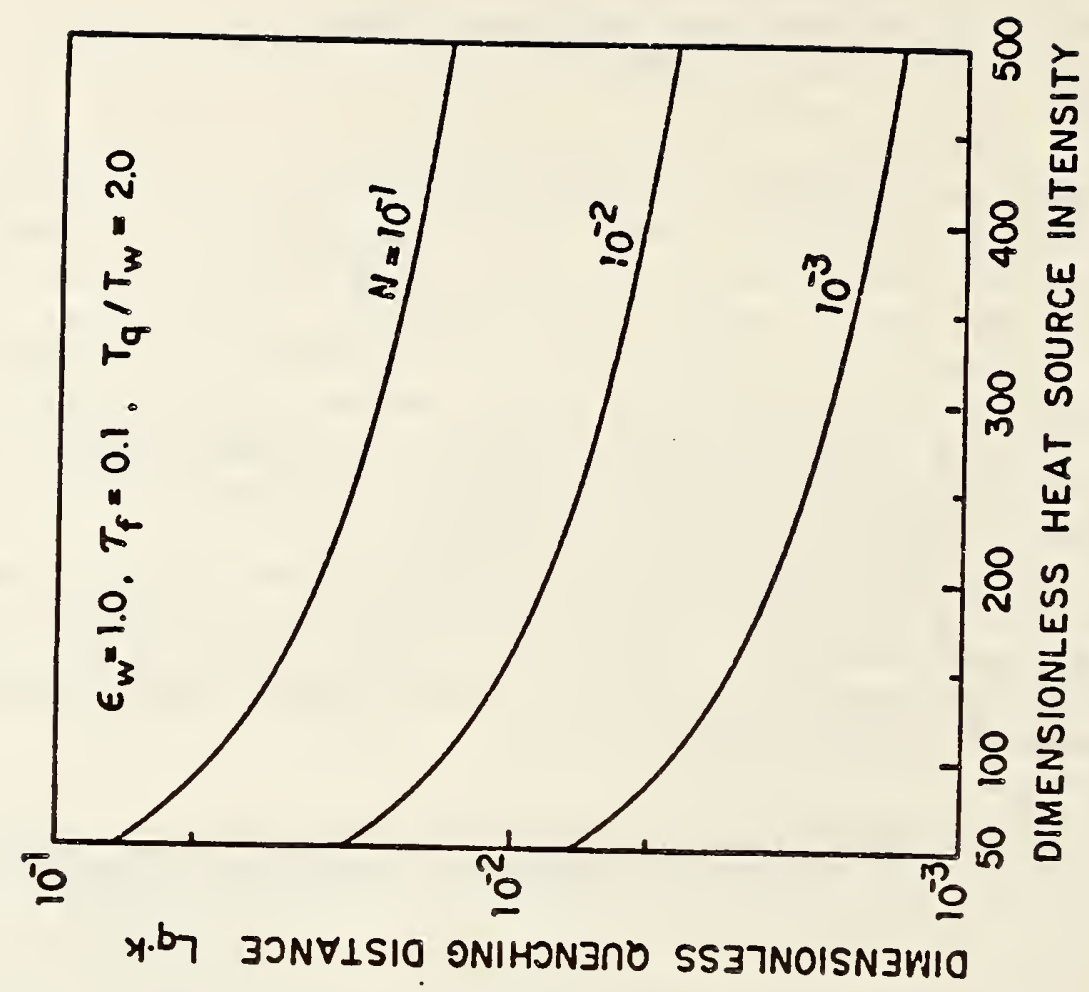

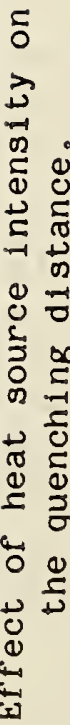

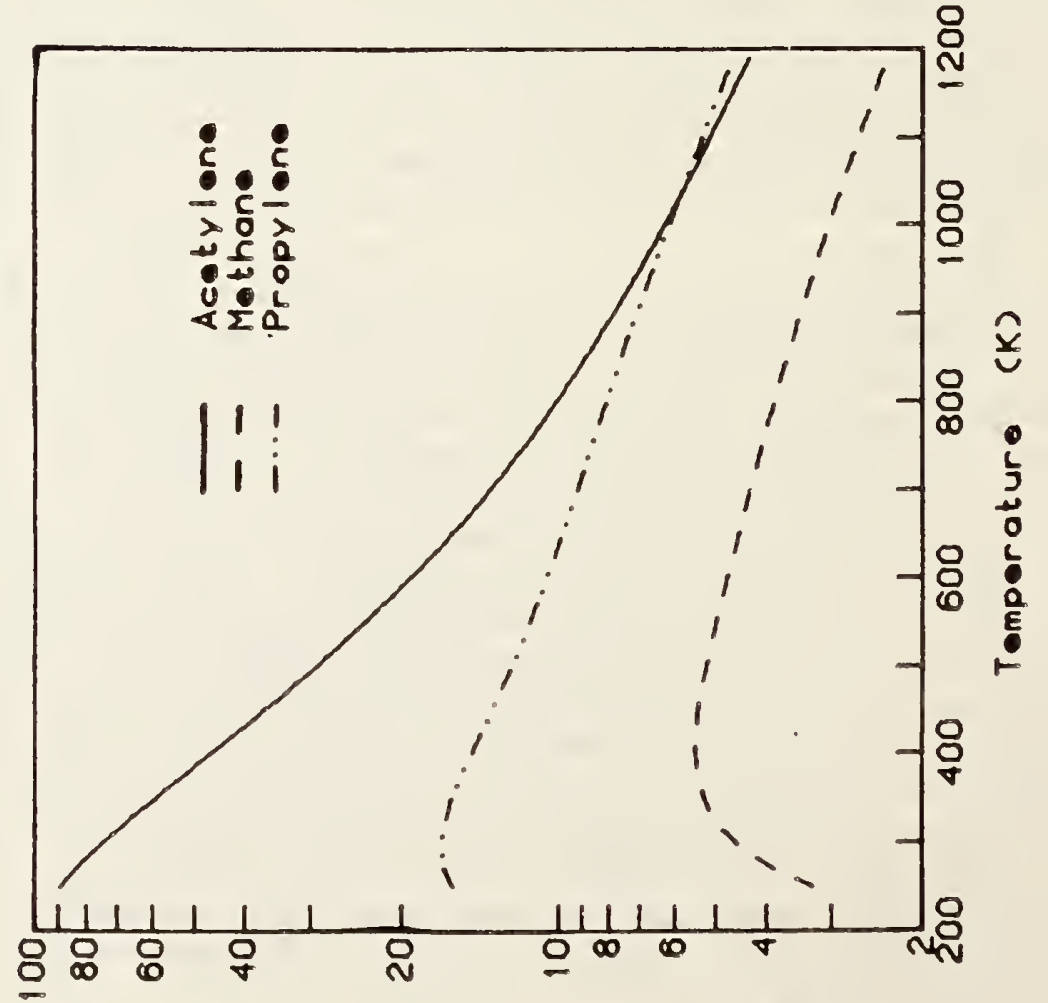

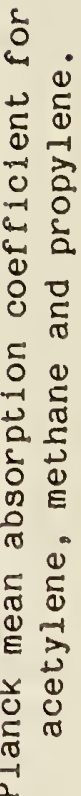

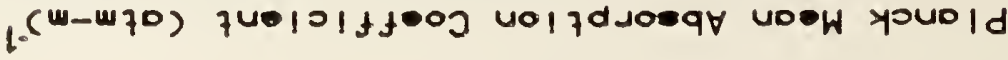




\section{Reports and Papers:}

1. M. A. Brosmer and C. L. Tien, "Infrared Radiation Properties of Methane at Elevated Temperatures," J. Quantitative Spectroscopy and Radiative Transfer, $\underline{33}, 521-532(1985)$.

2. M. A. Brosmer and C. L. Tien, "Thermal Radiation Properties of Acetylene," ASME J. of Heat Transfer (to appear).

3. C. L. Tien and M. A. Brosmer, "Infrared Radiation Properties of Propylene," (submitted for publication).

4. Q. Z. Yu, M. A. Brosmer and C. L. Tien, "A Simple Combined-Band Model to Calculate Total Gas Radiative Properties," submitted for presentation at the 1985 International Symposium on Heat Transfer, Beijing, China.

5. K. Y. Lee, Z. Y. Zhong and C. L. Tien, "Blockage of Thermal Radiation by the Soot Layer in Combustion of Condensed Fuels," Twentieth Symposium (International) on Combustion, the Combustion Institute, Aug. $(1984)$.

6. K. Y. Lee and C. L. Tien, "Radiation Induced Ignition of Condensed Fuels Including Effects of Radiation Blockage," submitted for journal publication.

7. K. Y. Lee and C. L. Tien, "Flame Wall-Quenching by Radiation and Conduction of Condensed Fuels," Combustion Science and Technology, 43 , $167-182(1985)$. 
CENTER FUR FIRE RESEARCH

NATIONAL BUREAU DF STANDARDS

FY 85

Insititution: University of Dayton Research Institute, Dayton, Ohio

Grant No.: $\quad$ NB83NADA4056

Grant Title: Mathematical Modeling of Furniture Fires

Principal Investigator: Mark A. Dietenberger

Research Physicist

University of Dayton Research Institute

300 College Park - JPC/201

Dayton, Ohio 45469

(513) 229-3921

NBS Scientific Officer: Dr. Vytenis Babrauskas

Technical Abstract:

The objective of this work is to develop a working computer model of a furniture fire which utilizes the bench scale measurements on furniture samples of burning rate history, flame spread rate, time to ignition, and the fraction of fuel converted to soot. The primary prediction of the model is the burning rate of a furniture fire as a function of time. The approach is to design modular submodels that are simple, accurate, and highly coupled. This research has concentrated in three areas: (1) Crucial to allowing a full modularity of submodels was the development of a practical threedimensional graybody radiation model of the flames and the furniture. The analytical models of the time to ignition and of the flame spread rate were developed to adequately describe the corresponding bench scale measurements and also to be suitable for use in the furniture fire model. (3) A furniture fire demonstrator model was developed to combine various submodels to compute the burning rate of a furniture fire as a function of time. The main purpose of the demonstrator model is to verify the numerical schemes utilized.

\section{3-D Gray Radiation From Fire to Furniture Surface}

It was realized early that in order to properly model the growth of a small fire to a fire engulfing the furniture, the geometric representations of the furniture and the flame needed to consist of small surface elements. Each surface element will have its unique history of surface temperature, of flame front arrival, and of the burning rate. To accommodate these surface elements in a radiation model a very efficient computer program was used to calculate the view factors between all the surface elements. The Hottel's zoning approach with appropriate mean beam length approximations was applied to the flame volume so that the flame can be treated as a semi-transparent solid with surface elements. That is, instead of many small radiating gray gas volumes, the flame is treated as one large radiating iso-thermal volume. This implied a new approach to calculating the surface to surface and the gas to surface exchange areas in the Hottel's zone model. Another dramatic reduction in the 
size of the matrix radiation equations was in the use of the energy conservation equations to derive the exchange areas with respect to the room walls. This avoided dividing the room walls into small surface elements and calculating their view factors. The energy conservation equations also showed the resulting matrix equations is diagonally dominant, leading to a Gauss-Seidel matrix solution method that is absolutely convergent. This approach to the Hottel's zoning method allows us to focus on critical radiation regions through utilization of surface elements and yet maintain a high computational efficiency.

We have developed a computer program that will generate a variety of couch or chair shapes constructed of quadralateral planes consisting of surface elemental areas. Also in the program is a feature to generate a conical frustrum complete with surface elemental areas of any size and place it anywhere on the furniture at any orientation. With minor changes in the program a wedge-shaped flame for wall fires or a quarter cylinder for corner fires can be generated.

We have done a sample run of a generic chair and flame shape and computed the surface radiative flux distribution. A cylindrical flame volume $0.2 \mathrm{~m}$ high and $0.1 \mathrm{~m}$ in diameter was set on the center of a seat, $0.4 \mathrm{~m}$ by $0.4 \mathrm{~m}$, of the chair with the back rest of the same size and arms of $0.2 \mathrm{~m}$ height. The cylindrical flame volume had 57 surface elements and the chair had 48 surface elements. The properties of the flame had a temperature of $1400^{\circ} \mathrm{K}$, air extinction coefficient of $2.0 \mathrm{~m}^{-1}$, and no scattering. The properties of the chair had a temperature of $300^{\circ} \mathrm{K}$ and surface emissivity of 0.8 . The Gauss-Seidel matrix solution method only took four iterations to converge with a relative error tolerance of 0.001 . On our VAX 11/780 computer the generation of chair and flame shapes took about $10 \mathrm{cpu}$ seconds and the rest of the calculations took about $10 \mathrm{cpu}$ seconds. The sum of the radiative power absorbed by the chair and by the room agrees with the power emitted from the cylindrical flame to within $4 \%$.

\section{Models of Time to Ignition' and of the Flame Spread Rate}

Because the radiative heat flux calculations will need to be updated every time the flame grows larger, thus leading to greater computation time, it would be imperative to seek simple analytical forms for the time to ignition and for the consequential flame spread. In the bench scale experiments for ignition and flame spread, external irradiances constant over time were used. Whereas a furniture surface element would experience an exponentially increasing irradiance over time due to a growing fire. Furthermore it was not known whether the fabric/foam furniture samples used in the tests were thermally thick or thin. Consequently, a heat conduction analysis was done for a semi-transparent thermally thick sample with a thermally thin top layer as subjected to external irradiance, reradiation, and convective cooling. The analytical solution was curve fitted to the data of time to ignition versus irradiance in order to derive values of effective thermal thickness, the thermal inertia, and the ignition temperature of the sample. Many samples, including particle board, carpet, PMMA, polyurethane foams, aircraft panels, and all the furniture fabric/foam materials, were successfully fitted in this way. After the sample is ignited, the flame will provide an additional radiative and convective heat flux to the sample. Assuming a step function or 
a exponential function surface distribution for both flame radiative and convective heat flux ahead of the flame front, an analytical form of the flame spread rate was derived. The important conclusions of this investigation was that all of the materials mentioned above, except for PMMA, could no longer be described as thermally thick when subjected to high irradiances. To put it another way, the effective thermal thickness, consisting of in-depth radiation absorption, of the radiation induced surface pyrolysis, and of thermally thin layer, is an important term. It is the dominate term in the case of furniture fabric/foam material, such that these samples are described as thermally thin, at least during the time it takes for the samples to ignite. This result provides a convenient application to computing the time to ignition and the flame spread in the furniture fire model.

\section{Furniture Fire Demonstrator Model}

The main purpose of the demonstrator model is to verify the numerical schemes utilized to couple the various submodels together and to check for stability and reasonableness as the program steps through time. In the future, some submodels will be replaced or improved to obtain model validation with the NBS furniture fire experiments. Thus the pool fire was modeled in the shape of a conical frustrum whose dimensions were correlated with the total burning rate of the surface elements minus the flame radiative power and with the hydraulic diameter of the pool fire base. The flame temperature was related to the total burning rate minus the radiative power assuming stoichimetric conditions. The soot volume fractions was related to the burning rate and the fraction of fuel converted to soot. The soot volume fraction and the flame temperature were used to compute the extinction coefficient. The burning rate history of each burning surface element was taken directly from the bench scale burn testing of a furniture sample. The computer program is being verified and debugged. In the future we expect to validate the furniture fire model and incorporate it into a room fire model being used by NBS. The resulting model can aid in resolving some fire safety issues and aid in fire engineering a room. With further small improvements it can lead to a prediction of time to flashover.

\section{Publications}

"Furniture Fire Mode1," NBS-GCR-84-480, Interim Report prepared for the National Bureau of Standards, Gaithersburg, MD, November 1984.

"Practical Thermal Radiation Model for 3-D Gray Flames and Objects." Presented at Annual Conference of Fire Research at NBS, Gaithersburg, MD, Uctober 1984.

"Utilization of Bench Scale Ignition and Flame Spread Measurements for a Furniture Fire Model." Prepared for UJNR Panel on Fire Research and Safety, Tsukuba, Japan, May.1985. 


\section{Institution}

Grant No.

Grant Title

Principle Investigator
University of Maryland

7ONANB4H0O2O

Transient Heat Transfer in Ceiling Jets

Professor Colin H. Marks

Mechanical Engineering Department

University of ilaryland

College Park, MD 207842

Telephone: (301)454-4216

Other Professional Personnel Anne Hoodhouse (iS Student)

NBS Scientific Officer Dr. Leonard Y. Cooper

\section{Technical Abstract}

The work described herein represents joint research being carried out by L. Y. Cooper of CFR/NBS, and A. Woodhouse and C. Marks of the University of Maryland. The overall purpose of this research is to develop a raliable predictive model for the transient response of unconfined ceilings to a fire. This phase of the research consists of two concurrent efforts: (1) the development of a data base which can be used to check the results of predictive modeling, and (2) the modification of a predictive model. The prediction of the transient response of ceilings is an important part of the modeling of compartment fires.

The data obtained in this part of the research consists of the ceiling temperature as a function of time and position froin the fire plume stagnation point for unconfined ceilings exposed to the plume from a small (up to $2 \mathrm{KW}$ ) fire. Three ceiling materials have been used: Marinite, steel and fiberboard. The Marinite and steel cailings had diameters of $1.22 \mathrm{~m}(4 \mathrm{ft})$ and the fiberboard ceiling had a diameter of $2.13 \mathrm{~m}(7 \mathrm{ft})$. All ceilings were insulated with $3^{\prime \prime}$ of insulation, $\mathrm{R}-24$. The fires were provided by burning stoichimetric portions of methane premixed with air. For such flames, thermal radiation is very small. 
Two burner-to-ceiling heights were used: $0.5 \mathrm{~m}$ and $1 \mathrm{~m}$. The combinations of flame strength and burner-to-ceiling heights yielded nondimensional fire strengths, $Q^{\star}$, of from 0.00079 to 0.0099 .

The temperatures on the lower surface of the Marinite and the fiberboard ceilings were measured by thermocouples mounted flush with the surface. Other thermocouples were mounted on the top of these ceilings to obtain the temperatures there and to enable an estimation of heat losses to be made. For the steel ceiling, thermocouples were only mounted in holes drilled half way through the ceiling from the back side, since the temperature gradient through the steel was very small. The lower surface of the ceilings were sprayed with high emmissivity paint, $(\varepsilon \approx 0.9)$. In addition the steel plate was tested with a polished surface $(\varepsilon=0.1)$.

For the range of radii to burner-to-ceiling heights utilized, most of the data were for the region of the ceiling jet for which buoyancy forces were negligible, and the jet was driven primarily by the momentum of the fire plume just before it impinged on the ceiling

The predictive model is a finite-difference solution to the heat transfer equation using an expression for the radial convective heat transfer coefficient based on data from forced-jet measurements. The model does not include radial heat conduction.

Examples of test results and predicted values of temperature for Marinite and black steel are presented in Figures 1 and 2. For the steel the model predicts higher than measured temperatures near the impingment point and lower than measured temperatures at large radii. However, for Marinite the experimental data and predicted values correlate quite well near the impingment point and are slightly off at larger radii. One reason for the discrepancy with the steel ceiling is the importance of radial conduction which is not accounted for in the model. This term would help to lower the stagnation zone temperatures and raise the temperature at large radif. We are currently examining other reasons for the inconsistancies.

\section{Reports and Papers}

Cooper, L.Y. and Woodhouse, A., "The Transient Prume-Driven Adiabatic Ceiling Temperature Revisited", NSIR 85-3134. 


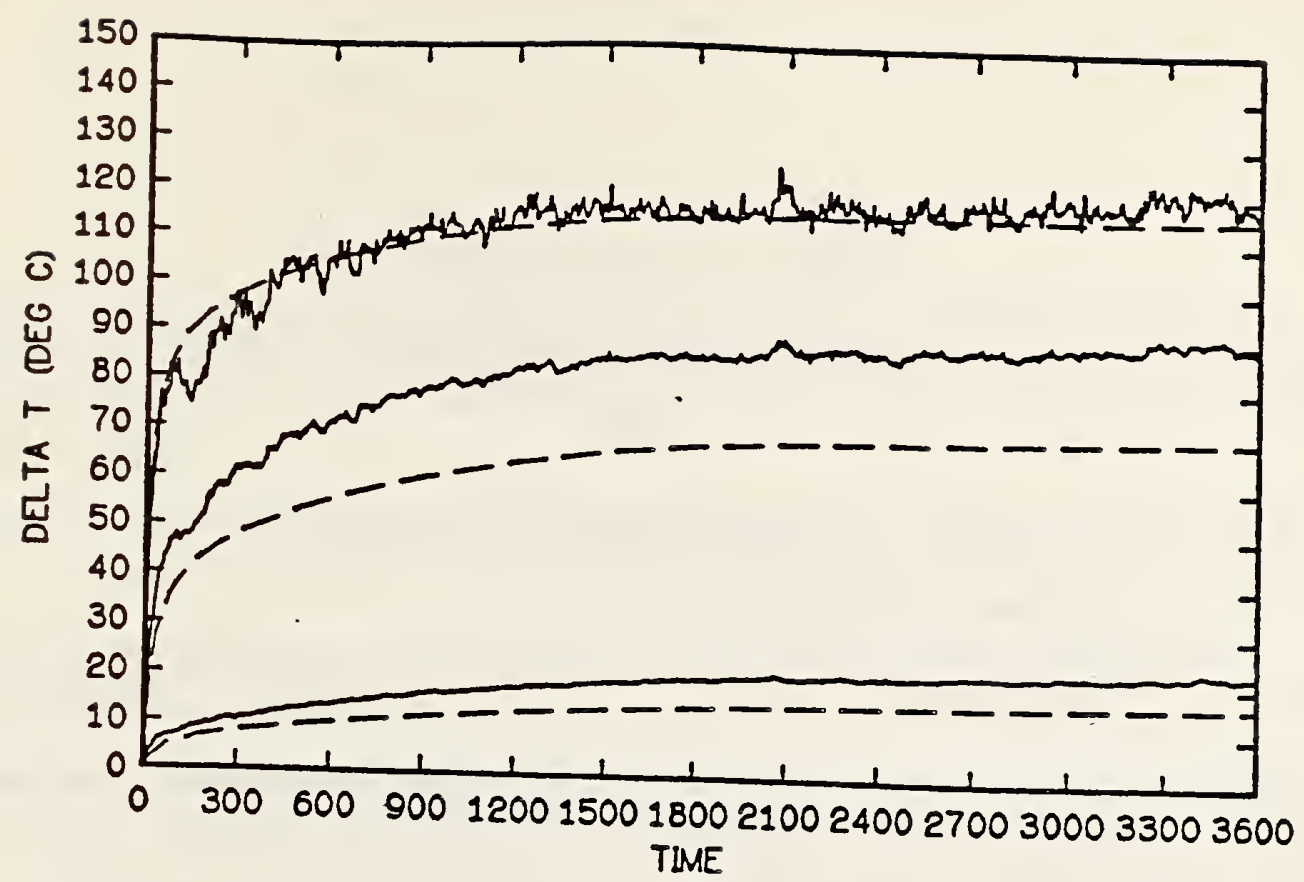

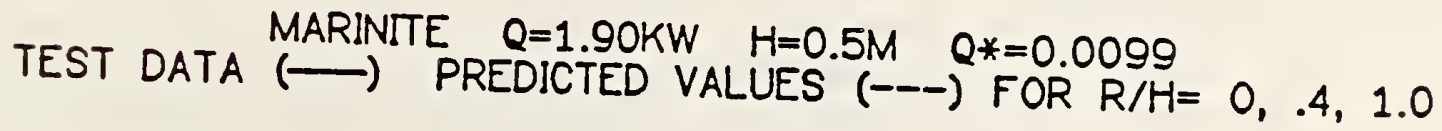

FIGURE 1

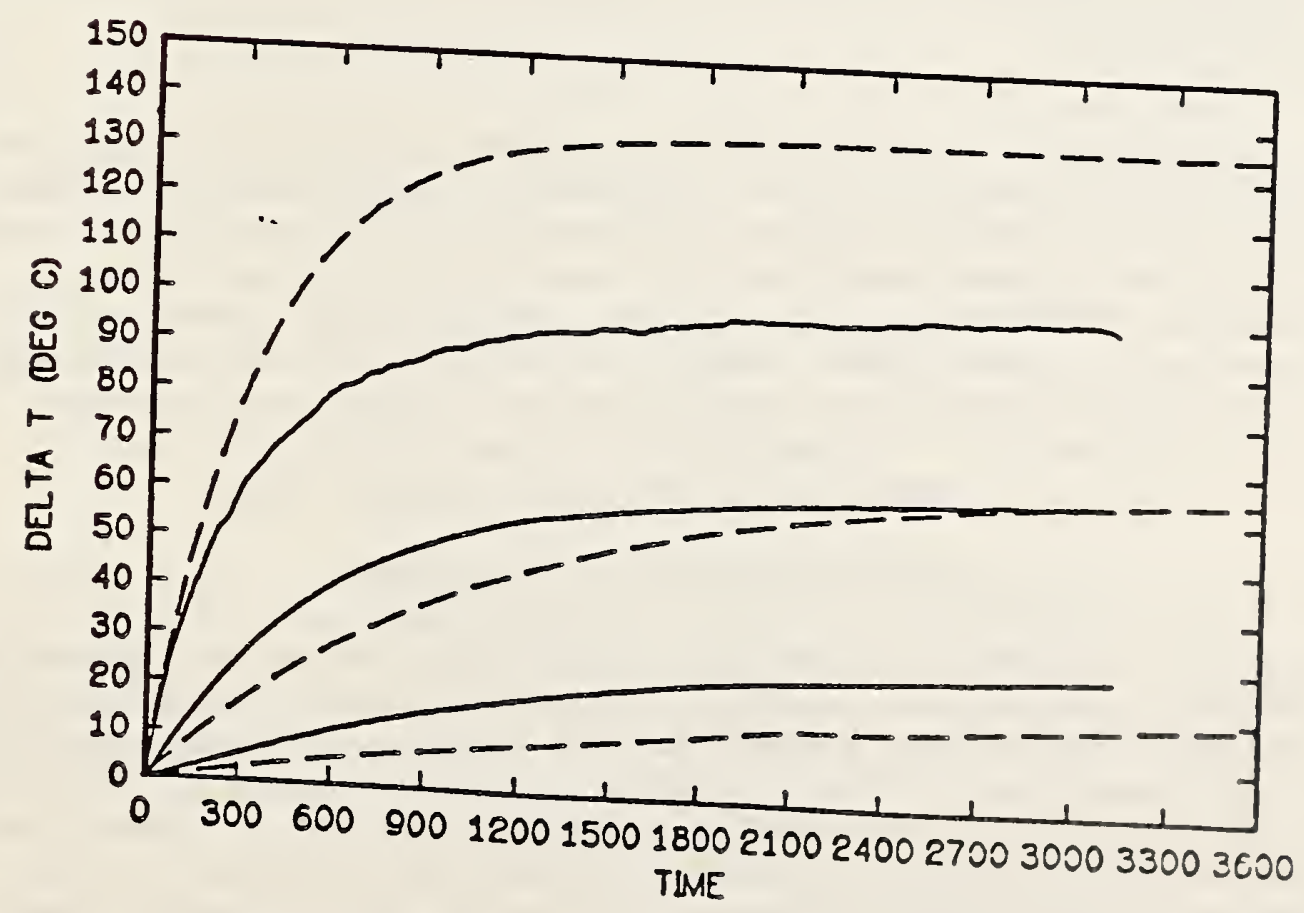

BLACK STEEL $Q=1.90 \mathrm{KW} H=0.5 \mathrm{M} \quad Q^{*}=0.0099$
TEST DATA $(-)$, PREDICTED VALUES $(--)$ R/H=0, .4, 1.1 
Institution: Department of Pharmacology and Toxicology University of Mississippi Medical Jackson, Mississippi

Grant No.: $\quad$ 60NANB4D0028

Grant Title: Study of Some Aspects of the Toxicology of the Inhalation of Carbon Monoxide and Cyanide in Fire Victims

Principle Investigator: Dr. Arthur S. Hume

Associate Professor

Department of Pharmacology and Toxicology

University of Mississippi Medical Center

Jackson, Mississippi 39216

Telephone (601) 987-5520

Other Professional Dersonnel: Dr. James Norris Research Associate

Dr. Steven Moore (Ph.D. student)

NBS Scientific Officer: Dr. Barbara Levin/Dr. Joseph Rukowski

Technical Abstract:

The objective of this project is to study the efficacy of presently used antidotal regimens for carbon monoxide and hydrogen cyanide when exposures to the noxious gases are simultaneous as occurs in fire victims. The research accomplished thus far has been focused in two areas:

1) Experimental determination of efficacy of oxygen, (antidote on CO) nitrite, and sodium thiosulfate (antidotes for cyanide) in increasing the survival of mice exposed to lethal doses of carbon monoxide and cyanide. 2) Studies into the mechanism of counteraction of toxic effects of carbon monoxide/cyanide by these antidotal agents.

\section{$\mathrm{LD}_{50}$ Studies of Combined $\mathrm{CO}$ and $\mathrm{CN}$}

Initially, LD 50 data for both potassium cyanide and carbon monoxide were collected. An LD50 of potassium cyanide intraperitoneally of 7.0 $\mathrm{Mg} / \mathrm{kg}$ was determined. From these LD50 data studies a concentration of $.35 \%$ of carbon monoxide in the inhalation apparatus used a carboxyhemoglobin blood level of $40-50 \%$. It would appear that, at the lower concentration of $\mathrm{CO},(0.100 \%)$ the combined effects of $\mathrm{CO}$ and $\mathrm{CN}$ are not additive, but at the higher concentrations of $\mathrm{CO},(0.30 \%$ and greater) a synergistic effect does appear. 
Adequate methods of analysis for $\mathrm{CO}$, and $\mathrm{CN}$ in chamber air and blood have been established. In order to provide information necessary for the administration of antidotal agents, half life studies of cyanide in mice were made.

As noted, cyanide has a biological half life of 16.2 minutes. Therefore, the antidotal agents were administered within this time period.

\section{Efficacy of Antidotes for Combined Toxicity of Carbon Monoxide and Potassium Cyanide}

Comparisons were made between the mortality observed among those animals treated with specific cyanide antidotes, and those animals which were not treated. Mice which were to be treated were predetermined before challenge in order to prevent any introduction of bias. Antidotes were administered immediately upon rescue in the following doses: sodium thiosulfate $1.0 \mathrm{~g} / \mathrm{kg}$, i.p., sodium nitrite $80 \mathrm{mg} / \mathrm{kg}$, i.p., oxygen $100 \%$, a-ketoglutaric acid $2 \mathrm{~g} / \mathrm{kg}$, i.p., sodium nitrite $80 \mathrm{mg} / \mathrm{kg}$, i.p., and amyl nitrite $12 \mathrm{mg} / \mathrm{liter}$ air. The dose of sodium nitrite utilized was arrived at experimentally, such that a maximum methemoglobin concentration of approximately $40 \%$ was attained (this concentration is induced in severe cases of cyanide poisoning. It took approximately 25-40 minutes for maximal methemoglobin concentrations to occur. The dose of amyl nitrite used was determined to result in a methemoglobin concentration no greater than $15 \%$ in 1 minute, and a methemoglobin concentration no greater than $35 \%$ in 2 minutes (figure 4 ). Amyl nitrite inhalation was found to be quite detrimental. Whereas 2 out of 7 non-treated mice died, 8 out of 9 mice treated with amyl nitrite for 2 minutes died. Amyl nitrite inhalation for 1 minute was also found to be detrimental. Sodium nitrite treatment resulted in about $30 \%$ more deaths than if the mice were not treated at all. Pure oxygen for 5 minutes was found to be the most effective mode of treatment at the challenge doses utilized. All animals survived after treatment (and for 1 month beyond). None of the other cyanide antidotes resulted in a significant increase or decrease of mortality as compared to the non-treated control group.

\section{Cytochrome Oxidase Studies in Mice}

Studies into the inhibition of cytochrome oxidase by cyanide and/or carbon monoxide and its prevention or reversal by antidotal agents have been established. Our work would show a definite correlation between concentration of cyanide and inhibition of cytochrome oxidase. Inhibition of cytochrome oxidase by cyanide is inhibited by a-ketoglutaric acid.

\section{Antidotal Studied in Mice}

Oxygen treatment alone did not statistically ( $\left.\mathrm{X}^{2}\right)$ affect survivability, neither did sodium thiosulfate, sodium pyruvate, methylene blue, cobalt edetate, a-ketoglutarate, sodium thiosulfate + sodium nitrite, sodium thiosulfate + oxygen, sodium pyruvate + oxygen, methylene blue + oxygen, cobalt edetate + oxygen, nor sodium thiosulfate + nitrite + oxygen. Amy 1 nitrite inhalation was shown to statistically increase mortality. Sod lum nitrite i.p. increased mortality, however, when it was combined with oxygen 
it significantly enhanced survivability of those animals simultaneously exposed to both of these toxins. Sodium pyruvate + oxygen statistically improved survivability, albeit only about $17 \%$ over control. It is of significant interest that sodium thiosulfate is not beneficial to the fire victim.

Investigations into the mechanism of interaction between these agents is ongoing. Mice treated with cyanide before exposure to carbon monoxide did not accumulate carbon monoxide as rapidly, nor form carboxyhemoglobin more expeditiously, than those animals exposed to carbon monoxide alone. Carbon monoxide did not statistically change the elimination of cyanide from whole blood over time. Carbon monoxide does affect the distribution of cyanide to the brain stem, heart, liver, diaphragm, or plasma after intraperitoneal injection of $\mathrm{KCN}$.

It appears that there is a concentrating effect of cyanide in the brain stem and diaphragm.

At this point, the presently used antidotal regimen for cyanide is not beneficial to fire victims and can be detrimental if not used properly.

Research is planned to continue to study the mechanism of action of antidotal agents in higher animals and to the toxic effects of $\mathrm{CO} / \mathrm{CN}$ to optimize the dosages and mode of administration and time intervals of antidotal agents, i.e., oxygen and nitrite, sodium pyruvate, hychorycobalamin and a-ketoglutarate.

\section{Reports and Papers}

1. J.C. Norris, S.J. Moore, and A.S. Hume. "Interaction of Carbon Monoxide and Cyanide". Manuscript in progress (rough draft).

2. S.J. Moore, J.C. Norris, T.G. Smith, and A.S. Hume. "Antagonism of Concurrent Carbon Monoxide (CO) and Cyanide (CN) Poisoning". To be presented ASPET, August 1985. 
Institution: Graduate School of Public Health, University of Pittsburgh, Pittsburgh, PA 15261

Grant No.: $\quad$ 60NANB4D001

Grant Title: Toxicity of Plastic Combustion Products

Principle Investigator: Yves Alarie, Ph.D.

University of Pittsburgh

Pittsburgh, PA 15261

Telephone: (412) 624-3047

Other Professional Personnel: K. L. Wong, Ph.D.

M. Schaper, Ph.D.

D. Malek (Ph.D. student)

NBS Scientific Officer: Dr. B. C. Levin

Technical Abstract:

The current objective of this project is to establish animal models of escape performance which can be used to provide a data base suitable for inclusion in hazard analysis of fire situations. Also we have completed the development of a nephelometer which permitted us to measure visibility on a continuous basis as samples were decomposed in a furnace for investigation of acute lethality of the smoke produced. The animal model consists of a glass tube, 150 feet in length, into which a mouse is introduced. A mouse, after two trials, will move forward consistently and will travel the entire distance when this tube (referred to as a "mouse track") is ventilated with air. Various toxic situations have been created in the track by lowering the amount of $\mathrm{O}_{2}$, or by adding different concentrations of $\mathrm{CO}$ or $\mathrm{HCl}$. Under these situations the traveling speed and distance traveled are markedly reduced and concentration-response relationships were developed. These can be used to determine available time of performance under different concentrations of toxic gases and maximum distance which can be traveled. Thus both distance and time, which are basic parameters to consider in hazard analysis, are available and both are available over a wide range of toxicant concentrations which are present in fire situations.

\section{Reports and Papers:}

Alarie, $Y$. The toxicity of smoke from polymeric materials during thermal decomposition. Ann. Rev. Pharmacol. Toxicol. 25, 325-347, 1985.

Wong, K. L., Stock, M. F., Malek, D. E. and Alarie, Y. Evaluation of the pulmonary effects of wood smoke in guinea pigs by repeated $\mathrm{CO}_{2}$ challenges. Toxicol. App 1. Pharmaco1. 75, 69-80, 1984. 
Kennah, H. E. Toxicity of thermal decomposition products from commonly used synthetic and natural polymers. Master of Science degree Thesis, University of Pittsburgh, 1985. Being prepared as an NBS-1R report and for publication.

Burleigh-Flayer, H., Wong, K. L. and Alarie, Y. Evaluation of the pulmonary effects of $\mathrm{HCl}$ using $\mathrm{CO}_{2}$ challenges in guinea pigs. Fund. Appl. Toxicol., in press.

Durr, D. E. The design, evaluation and application of a smoke nephelometer. Master of Science degree Thesis, University of Pittsburgh, 1984. Being prepared as an NBS-IR report and for publication after revision suggested by V. Barbrauskas of NBS. 


\section{CENTER FOR FIRE RESEARCH \\ NATIONAL BUREAU OF STANDARDS \\ FISCAL YEAR 1985}

Institutien: University of Virginia

Grant Ne:

NBS6 ONAN1 3 4D0034

Grant Iitle: Methods for Enhancement and Evaluation of Fire Risk Assessments

Principle Investigator:

Professor Carl M. Harris

Department of Systems Engineering

University of Virginia

Charlottesville, VA. 22901

Telephone: (804) 924-3803

N3s Scientific efficers: Bernarä M. Levin and S. Wayne Stiefel

\section{Technical abstract:}

This research effort has focused on assessing and enhancing methodologies used for fire risk assessments, together with the establishment of generic procedures for the validation of fire modeling and evaluation systems. Our work to date has incluced an examination of the latest developments in the incorporation of both subjective elements and mathematical, computer-basec mooels into fire-risk analyses. A special emphasis has been placed on the development of definitive strategies for improving tie credibility and usefulness of fire risk models by quantifying anticipated levels of prediction uncertainty.

In parallel to the above, we have begun to examine gereric methods for evaluating databases used for fire risk moceling systems. We have also begun to explore methods for assessing the technical valiaity of major types of fire modeling systems. In this element, the underlying assumptions, theoretical cerivations, parameter estimation techniques, functional relationships, and logical properties of the systems have been examined and preitminary criteria developed for evaluation. This has been followed by the tentative establishment of procedures for evaluating operational validity, and has includeó tess for robustness, sensitivity and performance.

\section{Reports:}

Quarterly Report Number 1: Some Thoughts on Critical Issues in Fire Risk Assessment \#UVA/529440/SE85/101 February 1985

Quarterly Report Number 2: Model Uncertainty, Sensitivity Analysis, anascenatic Evazuation $\neq U V R / 5294 \div 0 / S \equiv 85 / 2 C 2$ Nay 1985 

NBS.11 $\triangle A$ AEV. $2.0 C$

\begin{tabular}{|c|c|c|}
\hline \begin{tabular}{c|c} 
U.3. DEPT. OF COMM. & 1. PUBLICATION OR \\
RIBLIOGRAPHIC DATA & NEPORT NO. \\
SHEET (see instructions) & NBSIR-85/3258
\end{tabular} & 2. Performing Organ. Report & $\begin{array}{l}\text { Vof. Publication Date } \\
\text { Irovember } 1985\end{array}$ \\
\hline \multicolumn{3}{|l|}{$\begin{array}{l}\text { Summaries of Center for Fire } \\
\text { Programs - } 1985\end{array}$} \\
\hline \multicolumn{3}{|l|}{$\begin{array}{l}\text { S. AUTHOR(S) } \\
\text { Sonya M. Cherry }\end{array}$} \\
\hline 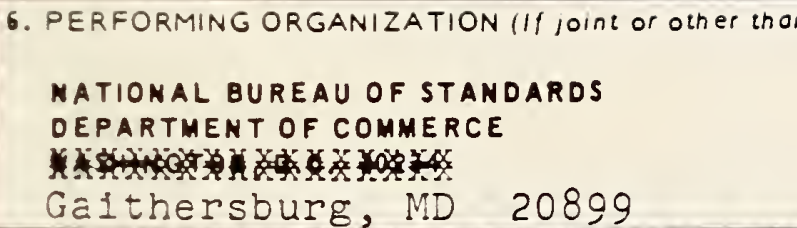 & NES, see instructions) & 8. Type of Report \& Period Covered \\
\hline
\end{tabular}

9. SPONSORING ORGANIZATION NAME AND COMPLETE ADORESS (STTET, CITY. STOTE, ZIF)

10. SUPPLEMENTARY NOTES

Document describes a computer program; SF-185. FIPS Software Summary, is attached.

1. ABSTRACT (A 200-word or less foctual summory of most significont informotion. If document includes o significon:

bibliogrophy or literoture survey. mention it here)

This report contains extended abstracts of grants and contracts for

fire research sponsored by the Center for Fire Research, laticre?

Eureau of Standards, as well as descriptions of the Internal preframs

of the Center for Fire Research.

12. KEY WORDS/Six to twelve entries; olphobetical order; copitalize only proper names: and seporate key words ty semicolors combustion; fire extinguishment; fire models; flame spread; 1 inttior.; polymers; smoke; soot; toxicity; water sprays

13. AVAILABILITY

X Unlimited

For Officlal Distribution. Do Not Release to NTIS

Order From Superintendent of Documents, U.S. Government Printing Office, Washington, O.C. 20402.

- X Order From National Technical Information Service (NTIS). Soringfield, VA. 2216I

14. NO. OF

PRINTED PAGES

160

15. Pice

$\$: 6.95$ 



(1)


